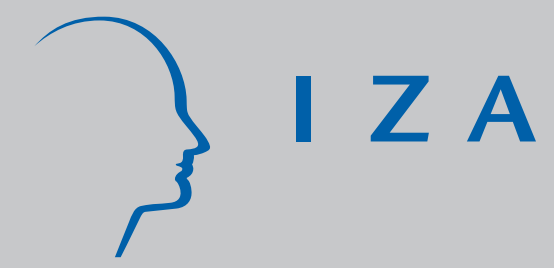

IZA DP No. 535

Wage Determination and the Sources of Bargaining Power

Paola Manzini

Dennis Snower

J uly 2002 


\title{
Wage Determination and the Sources of Bargaining Power
}

\author{
Paola Manzini \\ Queen Mary, University of London and IZA Bonn \\ Dennis Snower \\ Birkbeck College, University of London, \\ CEPR and IZA Bonn
}

\author{
Discussion Paper No. 535 \\ July 2002
}

\author{
IZA \\ P.O. Box 7240 \\ D-53072 Bonn \\ Germany \\ Tel.: +49-228-3894-0 \\ Fax: +49-228-3894-210 \\ Email: iza@iza.org
}

This Discussion Paper is issued within the framework of IZA's research area Welfare State and Labor Market. Any opinions expressed here are those of the author(s) and not those of the institute. Research disseminated by IZA may include views on policy, but the institute itself takes no institutional policy positions.

The Institute for the Study of Labor (IZA) in Bonn is a local and virtual international research center and a place of communication between science, politics and business. IZA is an independent, nonprofit limited liability company (Gesellschaft mit beschränkter Haftung) supported by the Deutsche Post AG. The center is associated with the University of Bonn and offers a stimulating research environment through its research networks, research support, and visitors and doctoral programs. IZA engages in (i) original and internationally competitive research in all fields of labor economics, (ii) development of policy concepts, and (iii) dissemination of research results and concepts to the interested public. The current research program deals with (1) mobility and flexibility of labor, (2) internationalization of labor markets, (3) welfare state and labor market, (4) labor markets in transition countries, (5) the future of labor, (6) evaluation of labor market policies and projects and (7) general labor economics.

IZA Discussion Papers often represent preliminary work and are circulated to encourage discussion. Citation of such a paper should account for its provisional character. A revised version may be available on the IZA website (www.iza.org) or directly from the author. 


\title{
ABSTRACT
}

\section{Wage Determination and the Sources of Bargaining Power}

This paper explores the sources of bargaining power in wage negotiations. In the standard analyses of wage bargaining, the negotiation partners are specified a priori, and thus it is impossible to address the question of how they achieve and retain their negotiating positions, on which their bargaining power is based. In our analysis, by contrast, the firm can choose between two sets of wage negotiations: those it can conduct with its incumbent employees and those with new job seekers. These negotiations are imperfectly substitutable, and the degree of substitutability is determined by the firm's labor turnover costs (e.g. costs of hiring, training, and firing). In this context, labor turnover costs not only influence the negotiators' alternative to bargaining (i.e. their fall-back positions and outside options); they affect the nature of the bargaining process itself. This approach leads to a new theory of wage determination.

JEL Classification: $\quad$ C76, J31, J32

Keywords: bargaining, wage determination, labor turnover costs, credibility, bonding, churning

\author{
Dennis Snower \\ Department of Economics \\ Birkbeck College \\ University of London \\ 7 Gresse Street \\ London W1P 1LL \\ UK \\ Tel.: +44 (207) 6316408 \\ Fax: +44 (207) 6316416 \\ Email: dsnower@economics.bbk.ac.uk
}

\footnotetext{
* The financial support of IZA, Bonn, for the Unemployment Project and the Leverhulme Trust for the CEPR project on "Unemployment Dynamics and Matching Workers with Jobs" (grant No. F/558/D) is gratefully acknowledged. We wish to thank, with the usual disclaimers, seminar participants at the Labor Market Imperfections Group and the Universities of Bristol, Exeter and Manchester. We are particularly grateful to Christopher Bliss, Roberto Burguet, Giulio Fella, Steinar Holden, Marco Mariotti, Abhinay Muthoo and John Muellbauer for helpful discussions and comments.
} 


\section{Introduction}

In the standard analyses of wage bargaining, firms and employees bargain without interference from other job searchers. The negotiating parties are specified a priori. Thus it is impossible to address the question of how they achieve and retain their bargaining position, on which their bargaining power is based. In the conventional wage bargaining models, the bargaining power of the negotiators is portrayed either as exogenously given (Nash bargaining, where the negotiators' bargaining power is depicted by a constant exponent of the Nash product) or by the preferences of the specified negotiators (strategic bargaining, where bargaining power depends on the negotiators' relative rates of time preference or risk aversion). Job searchers who are not party to the negotiations affect these wage bargains only through their influence on the outside options and fall-back positions of the negotiators.

But what gives the negotiators their privileged negotiating position? Why do firms often choose to negotiate with their incumbent employees before turning to new recruits? Unless these questions are tackled, we can gain little insight into the sources of bargaining power, and thus little understanding of the ultimate determinants of negotiated wages. This paper addresses these questions straightforwardly in a simple analytical context, where a firm is free to negotiate either with its incumbent employees or with unemployed job seekers.

Our analysis indicates that, in the presence of unemployment, the ultimate sources of employees' bargaining power are labor turnover costs (which, in our analysis, are firing costs and a productivity differential between incumbent employees and new recruits). The reason is that, in the absence of such costs, employees could not have any market power; for if they would claim any wage in excess of their reservation wage, their employers could costlessly replace them by unemployed job seekers. On this account, labor turnover costs must play a critical role in the wage bargaining process.

What is the mechanism whereby these costs generate employees' bargaining power? Our analysis shows that labor turnover costs determine the firm's degree of substitutability between two alternative sets of wage negotiations: (i) those the firm conducts with its incumbent employees ("insiders") and (ii) those it could conduct with other job seekers ("outsiders"). In other words, the turnover costs determine the degree of interdependence between the firm-insider bargains and the firm-outsider bargains. It is only when these bargains are imperfect substitutes that incumbents may be able to negotiate wages in excess of their reservation wage.

Specifically, consider a firm facing unemployed job seekers who behave atomistically, and suppose that the firm makes its employment decisions unilaterally. The greater are a firm's labor turnover costs, ceteris paribus, the more profitable the firm finds negotiations 
with an insider relative to those with an outsider, and consequently the less dependent is an insider on the bargain the employer could have made with an outsider. There are only two circumstances in which labor turnover costs do not affect the negotiated wages: (i) when these costs are zero, so that the two sets of negotiations are perfect substitutes for the firm and consequently insiders and outsiders become perfect competitors, and (ii) when the costs are prohibitively high, so that the firm-insider negotiations are independent of the firm-outsider negotiations, thereby creating a bilateral monopoly between the firm and its insiders.

Between these extremes, the negotiations between the firm and an insider are conducted with a view to the negotiations that could take place between the firm and an outsider; and the firm-outsider negotiations, in turn, proceed with a view to the negotiations that occur if the outsider eventually turns into an insider. In this interaction between the two sets of negotiations, labor turnover costs may be interpreted as a fee for switching the employer's negotiating partners. It is here, we argue, that the central role of labor turnover costs in wage bargaining is to be found.

The aim of this paper is to provide game-theoretic foundations for this insight. It turns out that this means taking leave of the well-known wage setting equations in the wage bargaining literature. ${ }^{1}$ Our analysis suggests that the prevailing Nash bargaining paradigm obscures the role played by labor turnover costs in wage negotiations, and therefore needs to be relinquished in favor of a new wage determination mechanism, which we examine here. Our analysis indicates that labor turnover costs do not just influence the external environment of the wage bargaining process - viz., the negotiators fall-back positions and outside options - but affect the very nature of the bargaining process by determining the way in which the negotiators interact.

In addition to providing an account of where employees' market power comes from and examining the role of labor turnover costs in the bargaining process, this paper provides a game-theoretic foundation for the analysis of two further phenomena: (i) why some firms "bond" with their employees (i.e. enter into long-term relationships with them) whereas other firms "churn" their employees (characterized by short-term relationships), and (ii) why, under some bonding conditions (specified below), all the employees of a firm may receive wages in excess of their reservation wages.

Our analysis sheds new light on how the wages of insiders and entrants are affected by firing costs, insider-entrant productivity differentials, unemployment benefits, productivity growth, on-the-job training and quits.

The paper is organized as follows. Section 2 relates our analysis to the existing literature. Section 3 presents our basic model and derives the bargaining outcome. Section

\footnotetext{
${ }^{1}$ McDonald and Solow (1981) and Layard et al. (1991, ch. 2) are two examples from a very large literature.
} 
4 looks at the comparative static effects produced by changes in different turnover costs on equilibrium wages. Section 5 extends our results in several important directions, and section 6 concludes.

\section{Relation to the Literature}

To see how our approach differs from axiomatic theories of bargaining as conventionally applied to wage negotiations, consider the following standard variant of the Nash bargaining model. Suppose that the wage is the outcome of negotiations between an employee-employer pair. Let the wage $w$ and $w^{-}$be the employee's payoff in the presence and absence of agreement, respectively; let profits $\pi(w)$ and $\pi^{-}$be the employer's payoff under these contingencies; and let $w^{O}$ and $\pi^{O}$ be the employee's and employer's outside options $^{2}$, respectively. Then the negotiated wage can be found as the solution to the following maximization problem: $\max _{w}\left(w-w^{-}\right)^{\mu}\left(\pi(w)-\pi^{-}\right)^{1-\mu}$ subject to $w \geq w^{O}, \pi \geq \pi^{O}$, where $\mu(0<\mu<1)$ is a constant describing the employee's bargaining strength relative to that of the employer, and $w^{-}, \pi^{-}, w^{O}$, and $\pi^{O}$ are constants. When there is an interior solution to this problem, the available economic rent is divided among the employee and employer in the proportions $\mu$ and $(1-\mu)$; otherwise, either the employee or the employer exploit their respective outside options, so that $w=w^{O}$ or $^{3} \pi=\pi^{O}$. In most wage bargaining models of this type in the literature (e.g. Layard et al. (1991, ch.2)), labor turnover costs play no role at all. More importantly, even when such models are extended to include these costs as determinants of the negotiators' fall-back positions $\left(w^{-}\right.$and $\left.\pi^{-}\right)$ or the outside options $\left(w^{O} \text { and } \pi^{O}\right)^{4}$, they still fail to capture the phenomenon discussed in the previous section, namely, that of labor turnover costs determining the nature of the bargaining process rather than merely constraining it.

\footnotetext{
${ }^{2}$ See Binmore, Shaked and Sutton (1989).

${ }^{3}$ If both outside option constraints were binding, then there would be no gains from bargaining in the first place.

${ }^{4}$ For example, when the employers' alternative to wage negotiations with the insiders is replacing the insiders by outsiders, then the employers' outside option is the outsiders' wage plus the relevant labor turnover costs. Furthermore, labor turnover costs affect the probabilities of locating vacancies and jobs and thereby influence the fall-back positions of the employers and employees. In Osborne (1988) the firm's fall-back position is endogenous, and its value is given by the outcome of a bargain with a varying number of members of a union. More recent contributions along these lines are Stole \& Zwiebel (1996b), Stole \& Zwiebel (1996a), and de Fontanay \& Gans (2000), which modifies the setup by allowing for a pool of replacement workers. These models have a different perspective from ours, since they consider bargains between a firm and a "composite opponent" (typically a union), focusing on the size of its membership. Burguet, Caminal \& Matutes (2002) consider an incomplete information contracting framework, and, for given types of contracts, derive the equilibrium renegotiated labor contract in a Nash Bargaining setup with interconnected negotiations. In contrast to our analysis, their firms compete for jobless workers.
} 
Turning to strategic models of wage bargaining, the basic Rubinstein (1982) model, interpreted in terms of a negotiation between a worker and a firm over a given amount of revenue, describes a bilateral monopoly problem, and thus does not deal with the issue of substitutability between alternative wage bargains. The first attempt to consider this issue was made by Shaked \& Sutton (1984). In their model, labor turnover costs take the form of a fixed number of time periods over which the employer and the insider are obliged to bargain with one another. Here the substitutability between the employer's negotiations with an insider and those with an outsider depends on the length of this negotiation period ${ }^{5}$. While this is an important insight, it is clear that, in practice, labor turnover costs commonly take other forms, especially monetary costs of replacing insiders by entrants and insider-entrant productivity differentials. Our analysis focuses on these labor turnover costs. ${ }^{6}$

Furthermore, Shaked \& Sutton (1984) do not distinguish between negotiations with insiders and those with outsiders: they assume that when the firm switches to an outsider, that outsider instantaneously turns into an insider, entitled to the same negotiation period as the previous insider. In practice, labor turnover costs associated with insiders generally exceed those of the entrants (e.g. insiders generally have greater job security than entrants). Our analysis takes this asymmetry into account.

In our model, we assume it takes time for an entrant to turn into an insider. Thereby the firm's negotiations with its insiders become distinguishable from those with its entrants, and thus the issue of substitutability between the two sets of negotiations can be addressed explicitly.

Both the Rubinstein and Shaked-Sutton models are concerned with the division of an existing pie (revenue) between two parties, but not with a temporal production process in which revenue can be generated during each time period. In their models, the only cost of delaying agreement is a temporal discounting cost (i.e. the pie shrinks with the passage of time). In our paper, by contrast, there is a temporal production process running alongside the temporal bargaining process, so that delaying agreement generates an additional cost in the form of foregone output. This is generally the case in practice, since production usually yields a flow of output through time, rather than being a oneshot event. Implications of this latter approach has been explored by Fernandez \& Glazer (1991), Haller \& Holden (1991), Holden (1994), who however do not take account of the

\footnotetext{
${ }^{5}$ In their model the insider has a priviledged position vis a vis the outsider because the former has the right to bargain with the firm for the duration of the negotiation span, but the insider does not become an employee - entitled to a wage and producing output - until the negotiations are over.

${ }^{6}$ See also Fella (1999), who in an alternating offers bargaining model of wage negotiations focusses on the relationship between firing costs and voluntary separation.
} 
possibility that an employer may have several alternative bargaining partners. ${ }^{7,} 8$

Finally, it is worth emphasizing that our contribution focuses on the sources of employees' wage bargaining power; it is not concerned with other possible rationales for setting wages above their competitive levels, such as the efficiency wage rationales.

\section{The Basic Model}

Our basic model provides a simple analytical framework for examining the sources of bargaining power. We let labor turnover costs take the form of a firing cost (constant per insider) and an insider-entrant productivity differential. We focus on these two turnover costs because, as shown below, they have different influences on wage bargaining ${ }^{9}$.

The labor turnover costs allow us to distinguish among three types of workers: ${ }^{10}$

1. an insider: an incumbent employee whose position is associated with a firing cost $\varphi$ (a positive constant), and who produces an output of 1 per period when there is bargaining agreement;

2. an entrant: a previously jobless worker who has just been hired, whose position is not associated with a firing cost, and who produces an output of $\alpha$ under bargaining agreement (where $\alpha$ is a constant, $0 \leq \alpha \leq 1$ ); and

3. an outsider: an unemployed worker, willing to work for any wage at or above his reservation wage.

When an outsider is hired, he turns into an entrant, with a temporary employment contract spanning an "initiation period," at the end of which the firm decides whether

\footnotetext{
${ }^{7}$ In these papers the flows depend not only on acceptance or rejection of a wage offer, but also on the union's decision on whether to strike or work at an old wage, in the process of being renegotiated. Our model does not contain the latter feature, since we focus on the influence of labor turnover costs on wages. Thus bargaining over flows can, at a technical level, be renormalized into bargaining over a stock (viz, the present value of the revenue flows).

${ }^{8}$ There is a potentially interesting connection between our contribution and the hold-up literature (as surveyed, for example, by Malcomson (1997)), since this paper examines the origins of employees' bargaining power whereas the hold-up literature (in this context) focuses on the implications of this bargaining power for investment undertaken by the firm. This paper however does not focus on this investment aspect. The joint endogenization of employees' bargaining power and employers' investment remains a topic for future research.

${ }^{9}$ It can be shown that hiring and training costs exert an influence analogous to that of the insiderentrant productivity differential, and thus they add nothing of substance to our analysis. Details are available from the authors upon request.

${ }^{10}$ These distinctions underlie the insider-outsider theory of labor market behavior. See, for example, Lindbeck \& Snower (1989). For a game theoretic interpretation, see Sabourian (1988).
} 
to retain him or replace him by another entrant. If he is retained, he turns into an insider, which means that (i) his productivity rises from $\alpha$ to 1, (ii) his position becomes associated with the firing cost $\varphi$, to be paid by the firm upon dismissal, and (iii) his wage is renegotiated on this basis. All workers are infinitely lived. The insider is employed on a permanent contract, i.e. once the insider's wage has been agreed, it is not renegotiated, for neither the firing cost nor the insider's productivity changes thereafter.

\section{3.a Structure of the Game}

The object of negotiations is the stream of revenues that a worker produces if employed. The agents' payoff are their shares of the revenue, and future payoffs are discounted by a factor $\delta \in(0,1)$.

The structure of the game is depicted in Figure 1a. It comprises three types of subgames. The first is an outsider subgame $G^{O}$, in which the firm bargains with an outsider $(O)$. After agreement is reached, the outsider turns into an entrant $(E)$. The second is an entrant subgame $G^{E}$, in which the firm decides whether to retain or replace the entrant. If the firm fires the entrant, it moves to another outsider subgame. But if the firm retains the entrant, it moves to an insider subgame $G^{I}$, in which the firm bargains with an insider $(I)$. If the firm fires the insider, it moves to another outsider subgame $G^{O}$, and so on.

[Figure 1a here]

The structure of each of these subgames is pictured in Figure 1b. In each set of negotiations the firm and the worker alternate in proposing a wage settlement, and the firm has the option to terminate the relationship with the incumbent worker and turn to another prospective employee. Failure to reach agreement entails that no revenue is generated for that period.

[Figure 1b here]

In the subgame $G^{0}$, the firm proposes an entrant wage at time $t$. If the proposal is accepted $(a)$, negotiations proceed to subgame $G^{E}$ (in which the firm decides whether to retain or replace the entrant); if the proposal is rejected $(r)$, then the outsider makes a counter-proposal at time $t+1$; and so on. In subgame $G^{I}$, the firm proposes an insider wage. If the proposal is accepted $(a)$, the insider wage is established; if the proposal is rejected $(r)$, the insider makes a counter-proposal in the following period, and so on. If the firm then decides to fire the insider, it has to pay the firing $\operatorname{cost} \varphi$. 


\section{3.b Overview of the Outcomes}

We now summarize our results and provide underlying intuitions; the formal analysis comes later.

Our two labor turnover costs - the firing cost and the insider-entrant productivity differential - have different effects on wage negotiations. In particular, it can be shown that the relative magnitude of the productivity differential and the firing cost determine whether the firm bonds or churns, whereas the combined magnitude of these turnover costs determine whether entry is blockaded or restricted. The intuition is straightforward. First, when deciding whether to retain or replace an entrant, the firm faces a trade-off between sacrificing either bargaining power or sacrificing productivity, as shown in Fig. 2. If the entrant is retained and subsequently turns into an insider - the case of bonding - the firm gains a more productive employee ${ }^{11}$ but loses bargaining power to the insider in wage negotiations (since the insider's position is protected by the firing cost whereas the entrant's position is not). On the other hand, if the entrant is replaced by another entrant - the case of churning - the firm sacrifices productivity (since an entrant is less productive than an insider), but loses no market power. The loss of bargaining power depends on the magnitude of the firing cost whereas the productivity gain depends on the magnitude of the insider-entrant productivity differential. If the size of the productivity differential is large relative to the firing cost, then the firm gains much from retaining the entrant and loses little in bargaining power. In that case, the firm will prefer bonding. Otherwise, it chooses churning.

[Figure 2 here]

Second, labor turnover costs also influence how much competition an insider faces from an entrant. If the firm chooses bonding and the combined labor turnover costs (the firing cost and the insider-entrant productivity differential) are sufficiently high, then entry into the firm is blockaded, so that the firm's negotiations with an insider become a bilateral monopoly problem. On the other hand, if the combined turnover costs are sufficiently low, the firm has an incentive to fire its insider unless the latter accepts a wage below the bilateral monopoly outcome. The insider, knowing this, sets his wage as high as possible without inducing firing. Here entry to the firm is restricted (as summarized in Figure 2).

The wage bargaining outcomes are given in Table 1 , where $W^{E}$ and $W^{I}$ denote the equilibrium entrant wage and insider wage, respectively. In the Churning Scenario $(\mathrm{CH})$, the firm hires an entrant and fires him before he turns into an insider. If an outsider claimed a wage in excess of the reservation during the negotiations preceding employment,

\footnotetext{
${ }^{11}$ Recall that the insider produces an output of 1 per period, whereas the entrant produces an output of $\alpha \leq 1$.
} 
the firm would switch costlessly to another outsider, willing to work at the reservation wage. Consequently, entrants receive the reservation wage, denoted by $R_{C H}$, which is zero in our simple model: $W^{E}=R_{C H}=0$. As result, the firm is left with a profit of $\Pi^{E}=\alpha$ per entrant.

\section{[Table 1 here]}

By contrast, when the firm chooses bonding, there are two possibilities:

- Suppose that, for any given firing cost $\varphi$, the insider-entrant productivity differential is sufficiently large, so that an entrant is never more profitable than an insider - even if the insider fully exploits his bargaining power and obtains his bilateral monopoly wage. Then, clearly, the firm has an incentive to bond (retaining the entrant, who then turns into an insider). Once again, the entrant receives the reservation wage, because if an outsider were to claim more, the firm would incur no costs in commencing negotiations with another outsider. But this reservation wage, $R_{C B}$, is less than the churning reservation wage $R_{C H}$. After all, in the Churning Scenario the entrant anticipates only one period of entrant employment, followed by unemployment (or more entrant employment at another firm); whereas now the entrant anticipates one period of entrant employment followed by insider employment, at a higher wage in perpetuity. This is called the Competitive Bonding Scenario $(C B)$ in Table 1, since the entrant's remuneration is at the competitive level under bonding.

- Alternatively suppose that, for any given firing cost $\varphi$, the insider-entrant productivity differential is sufficiently small, so that an insider is no longer assured of being more profitable than an entrant. If there were bonding and the entrant were to receive the reservation wage $R_{C B}$, that wage would be so low relative to the insider wage, that the entrant would be more profitable than the insider. But then of course, the firm would have no incentive to bond with the insider. The worker, anticipating this, would no longer be willing to accept the (low) reservation wage $R_{C B}$, so that the firm would have to pay a higher entrant wage, $R_{C H}$, with a consequent loss of profit. The firm thus faces a credibility problem: it prefers bonding to churning, since bonding yields a lower entrant wage, but offering the bonding reservation wage is not credible, since this gives the firm the incentive to churn in the following period. To overcome this problem and restore credibility, the firm offers the entrant more than the bonding reservation wage $R_{C B}$ (but less than the churning reservation wage $R_{C H}$ ) - in fact just enough to keep the entrant from becoming more profitable then an insider. This scenario is called the Credible Wage Scenario $(C W)$ in Table 1. 
Figure 3 depicts the combination of the firing $\operatorname{cost} \varphi$ and the entrant productivity $\alpha$ which identify the $C H, C B$, and $C W$ scenarios. Combinations of the parameter values lying above the thick $a b c$ line imply blockaded entry, and those combinations lying below this line imply restricted entry.

[Figure 3 about here]

Observe how the relative magnitudes of the turnover costs determine the firm's decision to bond or churn: For any given positive level of the firing $\operatorname{cost} \varphi$, a sufficiently high level of entrant productivity $\alpha$ - corresponding to a sufficiently low insider-entrant productivity differential - puts the firm in the Churning Scenario, whereas a sufficiently low $\alpha$ (corresponding to a sufficiently high insider-entrant productivity differential) puts it in one of the bonding scenarios $(C W$ or $C B)$. Furthermore, observe how the combined magnitudes of the turnover costs determine the degree of competition between insiders and entrants: Moving in a northwesterly direction in Figure 3, we find that entry is restricted when the labor turnover $\operatorname{costs} \varphi$ and $1-\alpha$ are sufficiently low, and entry is blockaded when these costs are sufficiently high.

It is worth noting that the worker's ability to renegotiate the wage upon turning into an insider implies that the bargaining equilibrium need not be Pareto efficient. Specifically, in the Churning Scenario the firm keeps producing its output with low-productivity entrants. If the firm were able to enter into a long-term contract with an entrant, the entrant would receive the reservation wage $R_{C H},{ }^{12}$ but would be retained by the firm forever. After the initiation period, the worker's productivity would rise from $\alpha$ to 1 . Thus the entrant would receive the same as in the Churning Scenario, but the firm would earn more profit than in that scenario; thus the long-term contract would lead to a Pareto improvement. The inability of firms to prevent wage renegotiation is a common feature of labor markets, and it is this non-contractibility that leads to inefficiency.

We now proceed to derive the results outlined above. The workers' objective is to maximize the present discounted value of their wages over time, and the firm's objective is to maximize the present discounted value of its profits. We focus attention solely on stationary strategies (as is common when the environment of the game is deterministic and stationary). Further, we assume that the workers' strategies are symmetric, in the sense that all workers belonging to a specific group adopt the same strategy.

The following three propositions fully characterize the solution to this game.

\footnotetext{
${ }^{12}$ Alternatively, the worker could receive any other intertemporal stream of wages with the same present value.
} 


\section{3.c The Churning Scenario (CH)}

As noted, this bargaining outcome arises when the entrant productivity is "high" relative to the firing cost.

Proposition 1 There is a unique stationary subgame perfect equilibrium in which the entrant is hired at the churning reservation wage and the firm does not retain the entrant. Specifically, if either $\alpha>\frac{1}{1+\delta}$ and $\varphi \geq \frac{\alpha}{1-\delta}-\frac{\delta}{1-\delta^{2}}$, or $\alpha>1-\delta \varphi$ and $\varphi<\frac{\alpha}{1-\delta}-\frac{\delta}{1-\delta^{2}}$, the firm and the outsider agree immediately on sharing the revenue $\alpha$ such that he entrant's wage and the firm's profit are $(0 ; \alpha)$.

\section{Proof: See Appendix 1.}

In the Churning Scenario, the entrant is more profitable than the insider, even though the entrants receive the high reservation wage $R_{C H}$. It is on this account that the firm favors churning, hiring only entrants, who each generate the revenue $\alpha{ }^{13}$

\section{3.d The Credible Wage Scenario (CW)}

When the entrant productivity lies in an "intermediate" range relative to the firing cost, the bargaining outcome is characterized by the Credible Wage scenario.

Proposition 2 There is a unique stationary subgame perfect equilibrium such that:

1. If $1-\frac{\delta}{1-\delta^{2}} \leq \alpha \leq \frac{1}{1+\delta}$ and $\varphi \geq \frac{1}{1+\delta}$, entry is blockaded and (a) the firm and the outsider immediately agree to share the revenue $\alpha$ such that the entrant's wage and the firm's profit are $\left(\frac{\delta}{1+\delta}-(1-\alpha) ; \frac{1}{1+\delta}\right)$ respectively; and (b) after one period the firm retains the entrant, who thus turns into an insider and immediately agrees to share the revenue 1 such that the insider's wage and the firm's profit are $\left(\frac{\delta}{1+\delta} ; \frac{1}{1+\delta}\right)$ respectively.

\footnotetext{
${ }^{13}$ The firm has an incentive to churn when insiders are less profitable than entrants: $\Pi^{I}<\Pi^{E}$, where $\Pi^{I}$ and $\Pi^{E}$ denote firm's profits when employing an insider and an entrant, respectively. The parameter values which generate this scenario are derived by substitution into this condition. Entry is blockaded when the discounted stream of profits from an insider exceeds that from replacing an insider by an entrant:

$$
\varphi \geq \frac{\Pi^{E}-\delta \Pi^{I}}{1-\delta}
$$

This condition is derived by noting that the discounted stream of profits from an insider is $\frac{\delta \Pi^{I}}{1-\delta}$, while the discounted stream of profits from replacing an insider by an entrant is $\Pi^{E}-\varphi+\frac{\delta \Pi^{E}}{1-\delta}=\frac{\Pi^{E}}{1-\delta}-\varphi$. Thus there is blockaded entry when $\frac{\delta \Pi^{I}}{1-\delta} \geq \frac{\Pi^{E}}{1-\delta}-\varphi$, which can be rearranged as condition C1.
} 
2. If $1-\frac{\delta}{1-\delta} \varphi \leq \alpha \leq 1-\delta \varphi$ and $\varphi<\frac{1}{1+\delta}$, entry is restricted and

(a) the firm and the outsider agree immediately to share the revenue $\alpha$ such that the entrant's wage and the firm's profit are $(\delta \varphi-(1-\alpha) ; 1-\delta \varphi)$ respectively; and

(b) after one period the firm retains the entrant, who thus turns into an insider and immediately agrees to share the revenue 1 such that the insider's wage and the firm's profit are $(\delta \varphi ; 1-\delta \varphi)$ respectively.

In both cases above, the entrant wage exceeds the reservation wage.

\section{Proof: See Appendix 1.}

In this scenario, the equilibrium entrant wage lies above the reservation wage, so that in equilibrium outsiders prefer to gain employment as entrants rather than remain unemployed. To see why, note that in the $C W$ Scenario, the entrant productivity differential is so high that if the entrant were to receive the reservation wage $R_{C B}$, he would become more profitable than the insider. But in that case the firm would have an incentive to churn. Thus the firm cannot credibly offer an entrant $R_{C B}$ and promise to pay the insider wage in the future. For once the entrant's initiation period is over, it will be profitable for the firm to fire the entrant and replace him by another entrant.

In the Credible Wage Scenario, however, churning does not maximize the firm's profit, because under churning the entrant demands the reservation wage $R_{C H}$, which is greater than the bonding reservation wage, $R_{C B}$. The way for the firm to reduce its wage payment is to offer the entrant the minimum wage at which the entrant is not more profitable than the insider, which is greater than the reservation wage $R_{C B}$. At this wage, the entrant and the insider are equally profitable, and the firm can credibly promise the entrant to bond and pay the insider wage in the future.

An interesting feature of the Credible Wage Scenario is that the entrant takes the entire insider-entrant productivity differential, $1-\alpha$, as a wage reduction vis-a-vis the insider wage. This is the only way for the entrant to ensure that he is just as profitable as an insider, and thus be assured of bonding in the following period. ${ }^{14}$ Under blockaded entry - where the insider wage is given by the bilateral monopoly outcome, $\frac{\delta}{1+\delta}$ - the only way for an entrant to ensure retention is for him to bear the entire insider-entrant productivity differential, accepting a wage equal to $\frac{\delta}{1+\delta}-(1-\alpha)$. Under restricted entry, on the other hand, the insider can only achieve a wage that exceeds the reservation wage by the amount of the firing cost $\varphi$, which is the fee the firm must pay to access its outside option to hire another entrant. Consequently, the insider will be prepared to accept a wage of just $\delta \varphi$, which is the present discounted value of the firing cost that the firm

\footnotetext{
${ }^{14} \Pi^{I}=\Pi^{E}$ is equivalent to $1-W^{I}=\alpha-W^{E}$, so that $W^{I}-W^{E}=1-\alpha$.
} 
would have to pay in the next round if firing the incumbent insider. Thus the entrant will have to accept $\delta \varphi-(1-\alpha)$, which is lower than under blockaded entry. ${ }^{15}$

\section{3.e The Competitive Bonding Scenario (CB)}

When the entrant productivity is "low" relative to the firing cost, the bargaining outcome is characterized by the competitive bonding scenario.

Proposition 3 There is a unique stationary subgame perfect equilibrium such that:

1. If $\alpha<1-\frac{\delta}{1-\delta^{2}}$ and $\varphi \geq \alpha+\frac{\delta^{2}}{1-\delta^{2}}$, entry is blockaded and

(a) the firm and the outsider immediately agree to share the revenue $\alpha$ such that the entrant's wage and the firm's profit are $\left(-\frac{\delta^{2}}{1-\delta^{2}} ; \alpha+\frac{\delta^{2}}{1-\delta^{2}}\right)$ respectively; and

(b) after one period the firm retains the entrant, who thus turns into an insider and immediately agrees to share the revenue 1 such that the insider's wage and the firm's profit are $\left(\frac{\delta}{1+\delta} ; \frac{1}{1+\delta}\right)$ respectively.

2. If $\alpha<1-\frac{\delta}{1-\delta} \varphi$ and $\varphi<\alpha+\frac{\delta^{2}}{1-\delta^{2}}$, entry is restricted and

(a) the firm and the outsider immediately agree to share the revenue $\alpha$ such that the entrant's wage and the firm's profit are $\left(-\delta^{2}(\varphi+1-\alpha), \alpha\left(1-\delta^{2}\right)+\delta^{2}(1+\varphi)\right)$ respectively; and

(b) after one period the firm retains the entrant, who thus turns into an insider and immediately agrees to share the revenue 1 such that the insider's wage and the firm's profit are $(\delta(1-\delta)(\varphi+1-\alpha) ; 1-\delta(1-\delta)(\varphi+1-\alpha))$ respectively.

In both cases above, the entrant receives the bonding reservation wage.

Proof: See Appendix 1.

This proposition is a straightforward counterpart of Proposition 1. Whereas in the Churning Scenario the entrant is more profitable than the insider even though the entrant

\footnotetext{
${ }^{15}$ In order to derive the parameter values $\alpha, \delta$ and $\varphi$ which define the $\mathrm{CW}$ scenario, the following two optimality conditions are necessary. First, it must be optimal for the entrant to seek employment. This requires that the present discounted value of the entrant wage plus the insider wage from the following period onwards be at least as great as the payoff from being unemployed (i.e. zero): $W^{E}+\delta \frac{W^{I}}{1-\delta} \geq 0$.

Second, the entrant wage must be lower than $R_{C H}$, i.e. non-positive, because if it were positive, the firm would have an unexploited profit opportunity, namely to offer a slightly lower positive wage, which an outsider would still be prepared to accept: $W^{E} \leq 0$. (In the next section we extend our model to include a positive unemployment benefit - or equivalently, a positive utility of leisure - and consequently the entrant's wage may be positive as well.) Substitution of the relevant equilibrium values from Table 1 yields the desired bounds on parameters.
} 
receives the (high) churning reservation wage $R_{C H}$, in the Competitive Bonding Scenario the insider is more profitable than the entrant even though the entrant receives the (low) bonding reservation wage $R_{C B}$.

If the firing cost $(\varphi)$ is sufficiently high relative to the entrant productivity $(\alpha)$, there is blockaded entry to insider jobs. The insider fully exploits his bargaining power, obtaining the bilateral monopoly wage $\left(\frac{\delta}{1+\delta}\right)$, but labor turnover costs are high enough so that the insider is still more profitable to the firm than an entrant. Since the entrant is assured of gaining insider status after the initiation period is over, the entrant receives his bonding reservation wage $\left(-\frac{\delta^{2}}{1-\delta^{2}}\right) \cdot{ }^{16}$.

When the firing cost is sufficiently low relative to the entrant productivity, there is restricted entry to insiders' jobs: an insider who claimed the bilateral monopoly wage would be less profitable than an entrant, and the firm would have an incentive to replace him. The insider, knowing this, will claim a wage beneath the bilateral monopoly wage, but just high enough to make the firm indifferent between retaining and replacing him. This wage is $\delta(1-\delta)(\varphi+1-\alpha)$. As above, the entrant receives his reservation wage. But since the insider receives less than the bilateral monopoly wage, this reservation wage $\left(-\delta^{2}(\varphi+1-\alpha)\right)$ will be higher than in the case of blockaded entry. ${ }^{17}$

\footnotetext{
${ }^{16}$ It is easy to show that if the firm had to pay a hiring cost each time it switched from one outsider to another, then any outsider negotiating with the firm would have some bargaining power, and consequently receive more than his reservation wage.

${ }^{17}$ The parameter values which define this scenario (for blockaded and restricted entry) may be derived from the following conditions. First, for the firm to choose bonding, the profits from an insider $\left(\Pi^{I}\right)$ must be greater as the profits from an entrant $\left(\Pi^{E}\right)$ :

$$
\Pi^{I}>\Pi^{E}
$$

Entry to insiders jobs is blockaded when the stream of profits from an insider is not less than the stream of profits from replacing the insider by an entrant. This condition reduces to:

$$
\Pi^{E} \leq \varphi
$$

(In fact, consider a node off the equilibrium path, in which the firm has just rejected an offer by its insider: is it optimal for the firm to hire an outsider? By not replacing its insider, the firm receives a stream of payoffs of $\frac{\delta \Pi^{I}}{1-\delta}$ in present discounted value. If instead the firm were to deviate from its equilibrium strategy and hire an outsider, the future stream of the firm's payoff would be $\Pi^{E}-\varphi+\frac{\delta \Pi^{I}}{1-\delta}$. Thus, hiring an outsider will not be profitable if $\frac{\delta \Pi^{I}}{1-\delta} \geq \Pi^{E}-\varphi+\frac{\delta \Pi^{I}}{1-\delta}$, which can be rearranged as condition C3.) By contrast, entry is restricted when

$$
\Pi^{E}>\varphi
$$

The values of the parameters $\alpha, \delta$ and $\varphi$ which define the boundaries of the $C B$ scenario, for blockaded and restricted entry, may be derived by substituting the equilibrium values of $\Pi^{E}$ and $\Pi^{I}$ from Proposition 3 into conditions $\mathrm{C} 2-\mathrm{C} 4$.
} 


\section{Comparative Statics}

In the context of the model above, we now investigate the influence of firing costs and entrant productivity on wages.

\section{4.a The Influence of Firing Costs on Wages}

The analysis above sheds light on how firing costs affect wage determination. In particular, our analysis exposes four commonly held myths:

Myth 1: The effect of firing costs on wages can be assessed independently of other labor turnover costs. This presumption is implicit in much of the literature on the wage effects of firing costs. The effects of different labor turnover costs on wages are commonly modeled as additively separable, so that each effect may be analyzed in isolation. For example, the maximum insider wage (achievable through individualistic bargaining) is commonly expressed as $W^{I}=W^{E}+\omega+\varphi+(1-\alpha)$, where $\omega$ and $\varphi$ be the constant hiring and firing costs per worker, and $(1-\alpha)$ be the insider-entrant productivity differential. Under Nash wage bargaining, the negotiated wage is commonly expressed as a weighted average of this maximum wage and the insider's fall-back position. ${ }^{18}$ In this context, the effect of an increase in the firing $\operatorname{cost} \varphi$ on the wage is independent of the other labor turnover costs ( $\omega$ and $1-\alpha)$.

Myth 2: If entrants have no market power, then firing costs have no effect on the present value of a firm's wage payments to a worker. The conventional intuition is that if entrants have no market power, then they receive the reservation wage. So, when firing costs raise insider wages, entrant wages fall by an equal amount (in present value terms). Thus the present value of the firm's wage payments to the worker (over the worker's tenure at the firm) remains unchanged. This argument has played an important role in the literature on job security legislation, where it is commonly argued that such legislation may have a direct influence on employment (by discouraging both hiring and firing), but cannot have any employment effect via insider wages. ${ }^{19}$

Myth 3: If entrants have no market power, then an increase in firing costs (for insiders, but not outsiders) generally makes entrants worse off, and never makes them better off. The intuition is that an increase in firing costs raises the insider wage and this

\footnotetext{
${ }^{18}$ See, for example, Lindbeck \& Snower (1990).

${ }^{19}$ See, for example, Bertola (1990).
} 
goes at the expense of the entrants: the more the firm pays its insiders, the less it is prepared to pay its entrants.

Myth 4: Under perfect information, an increase in firing costs generally makes the current insiders better off, and never makes them worse off. The alleged reason is that a rise in firing costs increases insider wages up to the point at which these costs become prohibitively high (i.e. until firms have no incentive to fire their insiders under any circumstances). At that point, wage determination becomes a bilateral monopoly problem and any further increases in firing costs have no influence on insider wages. Thus, an increase in firing costs are never contrary to the interests of the insiders.

To expose these myths, we need to examine not only how firing costs affect $W^{I}$ and $W^{E}$ within each scenario, but also how these costs determine which scenario applies. Since firing costs have no effect on the insider wage when entry is blockaded (for then entrants are unable to complete with the insider), our analysis will center on the scenarios under restricted entry.

Figure 3 depicts the scenario boundaries and Figures 4 show the effect of firing costs on wages in and across these scenarios. Figure 3 shows that the role of firing costs in determining the relevant scenario, and consequently equilibrium wages, depends on the size of the insider-entrant productivity differential $(1-\alpha)$, thereby exposing Myth 1 .

Observe that when $\alpha$ is low $\left(0 \leq \alpha<1-\frac{\delta}{1-\delta^{2}}\right)$, then the productivity differential $(1-\alpha)$ is so high, that an insider is always more profitable than an entrant, and thus there is Competitive Bonding, regardless of the value of the firing cost $\varphi$. In this scenario, as Figure 4a shows, the firing cost varies positively with the insider wage and negatively with the entrant wage - until the firing cost is prohibitively high (i.e. $\varphi>\alpha+\frac{\delta^{2}}{1-\delta^{2}}$ ), so that the insider receives the bilateral monopoly wage.

When $\alpha$ is in an intermediate range $\left(1-\frac{\delta}{1-\delta^{2}} \leq \alpha<\frac{1}{1+\delta}\right)$, the productivity differential is not so high as to ensure that an insider is always more profitable than an entrant, but not so low that an entrant is always more profitable than an insider. Here the insider is however always able to claim a wage above his reservation wage that makes him at least as profitable as the entrant. Thus bonding obtains. If the firing costs is sufficiently low, the $C B$ scenario obtains, and if the firing cost is raised sufficiently the bargaining parties enter the $C W$ scenario. As Figure $4 \mathrm{~b}$ shows, the firing cost always varies positively with the insider wage (until the firing cost is prohibitive, that is when $\varphi>\frac{\delta}{1+\delta}$ ); moreover, it varies negatively with the entrant wage in the $C B$ scenario and then positively with the entrant wage in the $C W$ scenario.

Finally, when $\alpha$ is high ( $\alpha>\frac{1}{1+\delta}$, so that the productivity differential is low), the bargaining scenario again depends on the relative size of the firing cost and the productivity 
differential. If the firing cost is relatively low, the $C B$ scenario occurs; as the firing cost rises relative to the productivity differential, the bargaining partners enter the $C W$ scenario; and if the firing cost is relatively high, the $\mathrm{CH}$ scenario holds, and the firm churns. Thus, in Figure 4c there is no upper bound on the level of the firing costs (measured on the horizontal axis), since in this scenario workers never gain insider status. Under these circumstances, the firing cost varies positively with the insider wage until there is a sudden drop in the wage as the firm switches from bonding to churning. Moreover, a rise in the firing cost, starting from zero, first reduces the entrant wage, then increases it, and finally leaves the entrant wage unaffected. Under these circumstances, the effect of firing costs on wages is particularly sensitive to the insider-entrant productivity differential.

Myths 2 and 3 are exposed in the Credible Wage scenario. Here, as Figures 4 show, an increase in the firing cost leads to an increase in both the insider and the entrant wages. Thus the present value of the firm's wage payments to a worker (over the worker's job tenure) rise unambiguously. Furthermore, a rise in the firing cost can make an entrant better off.

Myth 4 is exposed when $\alpha$ is in the high range (illustrated in Figure 4c). Here, as we have seen, an increase in firing costs can make insiders worse off. Specifically, once firing costs exceed the critical value $(1-\alpha) / \delta$, the firm gains the incentive to fire all its insiders and churn instead.

At first sight this may sound counterintuitive. Why can't the insider prevent the firm from churning by keeping the insider wage sufficiently low, viz., below $\alpha$ in Figure 4c? (After all, the insider wage $\alpha$ still exceeds the worker's reservation wage.) The reason is that once the firm has decided to retain an entrant, who thereby turns into an insider, that insider has no way of credibly promising to exercise sufficient wage restraint. If the firm decided to bond, the insider's job would become associated with the (high) firing cost, and then the insider would have an incentive to push the wage above the critical value $\alpha$. The firm, anticipating this, churns.

Thus increases in firing costs are not invariably in the insiders' interests. Provided firing costs are not so high as to blockade entry, they raise insider wages only up to a limit, and beyond that, firms dispense with insiders altogether.

In short, just as the firm's inability to "tie its hands" (its inability to make a credible promise to bond) leads it to pay entrants more than the reservation wage in the $\mathrm{CW}$ scenario, so the insider's inability to "tie his hands" (his inability to make a credible promise to exercise sufficient wage restraint) leads the firm to churn when the firing cost is sufficiently high.

Proposition 4 The effect of firing costs on wages depends on the magnitude of the insider-entrant productivity differential. 
1. If the productivity differential is high $\left(\frac{\delta}{1-\delta^{2}}<1-\alpha \leq 1\right)$, the Competitive Bonding scenario obtains regardless of the value of the firing cost $\varphi$. Then, as firing costs increase, the insider wage rises and the entrant wage falls (up to the point at which firing costs are prohibitive). Firing costs have no effect on the present value of the firm's wage payments over the worker's job tenure.

2. If the productivity differential is intermediate $\left(\frac{\delta}{1+\delta}<1-\alpha \leq \frac{\delta}{1-\delta^{2}}\right)$, bonding obtains regardless of the value of the firing cost $\varphi$. Then an increase in firing costs (relative to the productivity differential) leads to an increase in the insider wage (up to the point at which firing costs become prohibitive), while the entrant wage first decreases (in the $\mathrm{CB}$ scenario) and then increases (in the $\mathrm{CW}$ scenario). Thus an increase in firing costs that moves the bargainers into the $\mathrm{CW}$ scenario, will increase the present value of the firm's wage payments over the worker's job tenure.

3. If the productivity differential is low $\left(1-\alpha \leq \frac{\delta}{1+\delta}\right)$, the magnitude of the firing cost relative to the productivity differential has the following implications. If the firing cost is relatively low, the $\mathrm{CB}$ scenario obtains, so that firing costs raise the insider wage and reduce the entrant wage. As firing costs rise, the $\mathrm{CW}$ scenario appears, so that firing costs raise both the insider and entrant wages. Finally, when the firing cost is sufficiently large relative to the productivity differential, the firm churns, so that the entrant receives the churning reservation wage. Thus, an increase in firing costs that moves the firm from the $\mathrm{CW}$ to the $\mathrm{CH}$ scenario makes the insider worse off.

\section{4.b The Influence of Entrant Productivity on Wages}

There is an asymmetry between the effects of the firing cost and the productivity differential on the firm's bonding-versus-churning decision. As we have seen, a high firing cost does not guarantee bonding and a low firing cost does not guarantee churning. But a high insider-entrant productivity differential does ensure bonding and a low productivity differential does ensure churning. ${ }^{20}$

Note that low insider-entrant productivity differentials are common in low-skill, deadend jobs. Our analysis indicates that these jobs will tend to feature churning. By contrast, jobs that significantly raise workers' productivity over their job tenure (so that the insiderentrant productivity differentials are high) will, according to our analysis, be characterized

\footnotetext{
${ }^{20}$ In Figure 3, increasing $\varphi$ from zero, for any given $\alpha$, does not lead the firm from churning to bonding. Quite on the contrary, it leads from bonding to churning when $\alpha$ is high; and there is no change of scenario when $\alpha$ is low. However, increasing $\alpha$ from zero, for any given, positive $\varphi$, invariably leads the firm from bonding to churning.
} 
by bonding.

Figures 5 describe the influence of entrant productivity $\alpha$ on wages, given the firing $\operatorname{cost} \varphi$. When $\alpha$ is low (i.e. the insider-entrant productivity differential $1-\alpha$ is high), the competitive bonding scenario $(C B)$ obtains; as $\alpha$ rises into an intermediate range, the bargaining outcome comes to be characterized by the credible wage scenario $(C W)$; and when $\alpha$ is high, the bargainers are in the churning scenario $(\mathrm{CH})$.

The figures show that an increase in entrant productivity may raise the entrant wage (and never reduces it) and it may reduce the insider wage (and never raises it).

In Figure 5a, entry is restricted, and thus a rise in entrant productivity $\alpha$ means that the entrant becomes more effective in competing with the insider. Then, under $C B$, an increase in entrant productivity reduces the insider wage $W^{I}$. The fall in the insider wage, in turn, is associated with a rise in the entrant wage $W^{E}$ (since it is equal to the bonding reservation wage). Under $C W$, the insider's wage claim is equal to the firm's cost of accessing its outside option: $W^{I}=\delta \varphi$. Thus a rise in entrant productivity leaves the insider wage unchanged. However, the increase in entrant productivity raises the entrant wage, for thereby the entrant remains just as profitable as the insider. Finally, under $\mathrm{CH}$, the entrant once again receives the churning reservation wage $\left(R_{C H}=0\right)$.

In Figure 5b entry is blockaded, so that the insider faces no competition from entrants. Here the insider wage is the bilateral monopoly outcome: $W^{I}=\frac{\delta}{1+\delta}$, independent of entrant productivity. Under $C B$, where the entrant receives the reservation wage, the entrant wage is also independent of entrant productivity. Under $C W$, by contrast, the entrant wage rises with entrant productivity, since the firm needs to pay an entrant wage that makes the entrant just as profitable as the insider. Finally, under $\mathrm{CH}$, the entrant again receives the churning reservation wage.

Observe that unless there is churning or competitive bonding with blockaded entry, the entrant is able to capture at least some of any increase in entrant productivity $\alpha$ through a higher entrant wage. Under $C B$ and restricted entry, the entrant captures a part of the productivity increase, whereas under $C W$ the entrant captures the entire productivity increase.

These considerations can be summarized as follows:

\section{Proposition 5 1. If the insider-entrant productivity differential is sufficiently high, ${ }^{21}$} there is Competitive Bonding. If the productivity differential lies in an intermediate range, ${ }^{22}$ the Credible Wage scenario occurs. If the productivity differential is low, ${ }^{23}$ the firm churns.

\footnotetext{
${ }^{21} \alpha<1-\frac{\delta}{1-\delta} \varphi$ under restricted entry, and $\alpha<\frac{1-\delta-\delta^{2}}{1-\delta^{2}}$ under blockaded entry.

$221-\frac{\delta}{1-\delta} \varphi<\alpha<1-\delta \varphi$ under restricted entry, and $\frac{1-\delta-\delta^{2}}{1-\delta^{2}}<\alpha<\frac{1}{1+\delta}$ under blockaded entry.

${ }^{23} 1-\delta \varphi<\alpha \leq 1$ under restricted entry, and $\frac{1}{1+\delta}<\alpha \leq 1$ under blockaded entry.
} 
2. Competitive Bonding scenario: Under restricted entry, a rise in entrant productivity reduces the insider wage and raises the entrant wage (but by less than the productivity rise). Under blockaded entry, the entrant and insider wages are independent of entrant productivity.

3. The Credible Wage scenario: A rise in entrant productivity is captured entirely by the entrant through an equal rise in the entrant wage. The insider wage is independent of entrant productivity.

\section{Extensions}

We now extend our simple model of wage determination to cover some other significant features of labor markets. We start by investigating the effects of on the job training. Second, we extend the model to derive a more plausible set of wage equations by showing how wages depend on productivity and unemployment benefits. Finally, we introduce quits and examine their influence on wage determination. ${ }^{24}$

\section{5.a The Influence of On-the-Job Training on wages}

To consider how on-the-job training affects wages, we need to reparameterize our model. While the entrant's productivity is still $\alpha$, the insider's productivity is now specified as $\alpha+A$, where $A$ is a positive constant. Then a change in $A$ may be interpreted as a change in the amount of on-the-job training. In this model, on-the-job training stimulates the productivity of the insider, but not the entrant.

The resulting equilibrium wages are reported in Table $2 .^{25}$

[Table 2 here.]

The influence of on-the-job training on wages is depicted in Figures 6.

[Figure 6 here.]

As we can see, when on-the-job training is sufficiently low, ${ }^{26}$ there is churning, so that variations in $A$ are irrelevant to wage determination. Then, if an entrant were to

\footnotetext{
${ }^{24}$ In the appendix we demonstrate the robustness of our central conclusions with respect to a variety of other extensions: entrant contracts of arbitrary length, and the relationship between equilibrium wages and the length of the negotiations rounds.

${ }^{25} \mathrm{We}$ omit the derivation of the results, which can be obtained by straightforward extension of the material in Appendix 1. Full details are available upon request.

${ }^{26} A \leq \delta \varphi$ under restricted entry and $A \leq \delta \alpha$ under blockaded entry.
} 
turn into an insider, productivity would rise too little to compensate for the firm's loss in bargaining power (due to firing costs). Thus the firm churns and the entrant is hired at the reservation wage.

When on-the-job training $A$ lies in an intermediate range, ${ }^{27}$ the bargainers are in the Credible Wage Scenario. Then, under restricted entry, the insider wage is independent of the amount of on-the-job training, since the insider's only protection from dismissal lies in the firing costs. Under blockaded entry, by contrast, the insider captures some of his higher productivity from on-the-job training through higher wages. Under both restricted and blockaded entry, the entrant wage falls with on-the-job training, since the entrant wage is set so that the insider and entrant are equally profitable.

Finally, when on-the-job training $A$ is high, ${ }^{28}$ there is competitive bonding. Then the insider wage rises with on-the-job training, either because the firm is locked in (under blockaded entry) or because the entrant finds it more difficult to compete with the insider (under restricted entry). In either case, on-the-job training is not wholly captured by the insider wage. The entrant receives the reservation wage, which depends inversely on the insider wage. Thus, once again, the entrant wage falls with on-the-job training.

Thus:

Proposition 6 1. When the amount of on-the-job training is low, the firm churns and the entrant wage is independent of on-the-job training.

2. When there is bonding, on-the-job training always reduces the entrant wage.

3. On-the-job training is never fully captured by the insider wage. Increases in on-thejob training do not necessarily raise the insider wage; specifically, under $C W$ and restricted entry, they leave the insider wage unchanged.

\section{5.b An Extended Model}

We now extend the model to allow for changes in overall productivity (of both insiders and entrants) and unemployment benefits. Accordingly, let the insider's productivity be a positive constant $\gamma$ (rather than unity) and each entrant's productivity be $\alpha \gamma$ (where again $\alpha \in[0,1]) .{ }^{29}$ Observe that now $\alpha$ can be interpreted as ratio between the productivity of an entrant and that of an insider. Each unemployed worker is now assumed to receive an unemployment benefit $\beta$ per period when out of work, ${ }^{30} \beta \in\left[0, \frac{\delta}{1+\delta} \gamma\right]$.

The equilibrium wages in these scenarios ${ }^{31}$ are summarized in Table 3.

\footnotetext{
${ }^{27} \delta \varphi<A<\frac{\delta \varphi}{1-\delta}$ under restricted entry and $\delta \alpha<A<\frac{\delta}{1-\delta-\delta^{2}} \alpha$ under blockaded entry.

${ }^{28} A>\frac{\delta \varphi}{1-\delta}$ under restricted entry and $A>\frac{\delta}{1-\delta-\delta^{2}} \alpha$ under blockaded entry.

${ }^{29}$ Thus the insider-entrant productivity differential is now expressed as $\gamma(1-\alpha)$.

${ }^{30}$ The restriction on $\beta$ ensures that the insider wage is not less than the unemployment benefit, otherwise the insider would prefer to be unemployed.

${ }^{31}$ In this context, the three scenarios may be redefined as follows:
} 
[Table 3 here]

We are now equipped to study the effects of unemployment benefits and productivity growth on equilibrium wages, to which we turn next.

\section{5.b.i The Influence of Unemployment Benefits on Wages}

When the unemployment benefit $\beta$ is sufficiently low, ${ }^{32}$ the reservation wage is so low that entrants are more profitable than insiders, and thus there is churning, as shown in Figures 7. In the Churning Scenario, an increase in the unemployment benefit naturally leads to a one-for-one increase in the entrant wage (i.e. the $W^{E}$ curve has a slope of unity in the $\mathrm{CH}$ scenario of Figures 7).

\section{[Figures 7 here]}

Once the unemployment benefit rises sufficiently so that entrant and insiders are equally profitable at the churning reservation wage $R_{C H}$, the bargainers pass into the

- $C H^{\prime}$ (Churning Scenario): If the entrant productivity is sufficiently high $\left(\alpha \gamma>\frac{1}{1+\delta} \gamma+\beta\right.$ or $\alpha \gamma>\gamma-(\delta \varphi-\beta))$, it is optimal for the firm to keep replacing entrants with new recruits, since an entrant is more profitable than an insider. The entrant receives the reservation wage, which is equal to the unemployment benefit $\beta$.

- $C W^{\prime}$ (Credible Wage Scenario): If the entrant productivity lies in an intermediate range $\left(\frac{1-\delta-\delta^{2}}{1-\delta^{2}} \gamma+\frac{\beta}{(1-\delta)} \leq \alpha \gamma \leq \frac{1}{1+\delta} \gamma+\beta\right.$ under blockaded entry and $\frac{\gamma(1-\delta)-(\delta \varphi-\beta)}{(1-\delta)} \leq \alpha \gamma \leq \gamma-(\delta \varphi-\beta)$ under restricted entry) entrants are retained, and their wage, is set in excess of their reservation wage, so that they are just as profitable as insiders. (If $\varphi \geq \frac{\gamma}{1+\delta}$, entry is blockaded. Then the insider receives the bilateral monopoly wage $W^{I}=\frac{\delta}{1+\delta} \gamma$ and the entrant wage is $W^{E}=\frac{\delta}{1+\delta} \gamma-\gamma(1-\alpha)$. If $\varphi<\frac{\gamma}{1+\delta}$, entry is restricted. Then insider wage is $W^{I}=\delta \varphi$ and the entrant wage is $W^{E}=\delta \varphi-\gamma(1-\alpha)$. In both cases, the entrant wage exceeds the bonding reservation wage.)

- $C B^{\prime}$ (Competitive Bonding Scenario): If the entrant productivity is sufficiently low $(\alpha \gamma<$ $\frac{1-\delta-\delta^{2}}{1-\delta^{2}} \gamma+\frac{\beta}{(1-\delta)}$ under blockaded entry and $\alpha \gamma<\frac{\gamma(1-\delta)-(\delta \varphi-\beta)}{(1-\delta)}$ under restricted entry) incumbent workers are at least as profitable as new recruits. Entrants are retained, but now receive their reservation wage. (In this scenario, if $\varphi \geq \alpha \gamma+\frac{\delta^{2} \gamma}{1-\delta^{2}}-\frac{\beta}{1-\delta}$, entry is blockaded. Then the insider receives $W^{I}=\frac{\delta}{1+\delta} \gamma$, whereas the entrant receives the reservation wage $W^{E}=-\frac{\delta^{2}}{1-\delta^{2}} \gamma+\frac{\beta}{1-\delta}$. Thus, when $\beta$ is sufficiently high and $\gamma$ is sufficiently low, the reservation wages becomes positive. If $\varphi<\alpha \gamma+\frac{\delta^{2} \gamma}{1-\delta^{2}}-\frac{\beta}{1-\delta}$, entry is restricted. Then the insider wage is $W^{I}=\delta \beta+\delta(1-\delta)[\gamma(1-\alpha)+\varphi]$. and the entrant wage is $W^{E}(1+\delta) \beta-\delta^{2}[\gamma(1-\alpha)+\varphi]$.)

It is straightforward to extend the proof of Propositions 1-3 and to redefine the corresponding subgame perfect equilibrium partitions.

${ }^{32} \beta<\delta \varphi-\gamma(1-\alpha)$ under restricted entry and $\beta<\left(\alpha-\frac{1}{1+\delta}\right) \gamma$ under blockaded entry. 
Credible Wage Scenario, where there is bonding. In this scenario, occurring in an intermediate range of unemployment benefits, ${ }^{33}$ the insider wage is independent of the unemployment benefit (under both restricted and blockaded entry), and the entrant wage is set so that the entrant is just as profitable as the insider. Thus the entrant wage is also independent of the unemployment benefit (viz., the $W^{E}$ curve is horizontal in the $C W$ scenario of Figures 7). Throughout this scenario, the entrant wage is below the churning reservation wage $R_{C H}$ but above the bonding reservation wage $R_{C B}$.

As the unemployment benefit keeps increasing, so does the bonding reservation wage. Thus there comes a point at which the entrant wage becomes equal to the bonding reservation wage. If the unemployment benefit is raised further, we then pass into the Competitive Bonding Scenario. In the $C B$ scenario, occurring in the high range for unemployment benefits ${ }^{34}$ increases in the unemployment benefit lead to increases in the entrant (reservation) wage. Under restricted entry, increases in the unemployment benefit also lead to rises in the insider wage, since the entrant becomes less of a threat to the insider. ${ }^{35}$ Under blockaded entry, by contrast, the entrant is no threat to the insider, and thus the insider wage is independent of the unemployment benefit.

Proposition 7 1. Increases in the unemployment benefit raise the entrant wage under Churning (when the unemployment benefit is sufficiently low) and Competitive Bonding (when the benefit is sufficiently high).

2. Changes in the unemployment benefit leave the insider and entrant wages unchanged in the Credible Wage scenario (occurring when the unemployment benefit falls into an intermediate range).

3. The insider wage rises with the unemployment benefit only under Competitive Bonding and restricted entry.

\section{5.b.ii The Influence of Productivity Growth on Wages}

To address the effect of productivity growth on wages, consider an economy on a steadystate growth path, in which productivity grows at a constant rate, and the firing cost and the unemployment benefit rise proportionately: ${ }^{36}$

$$
\varphi^{\prime}=a_{\varphi} \gamma \text { and } \beta^{\prime}=a_{\beta} \gamma
$$

\footnotetext{
${ }^{33} \delta \varphi-\gamma(1-\alpha) \leq \beta \leq \delta \varphi-\gamma(1-\alpha)(1-\delta)$ under restricted entry and $\left(\alpha-\frac{1}{1+\delta}\right) \gamma \leq \beta \leq \alpha \gamma(1-\delta)-$ $\frac{1-\delta-\delta^{2}}{1+\delta}$ under blockaded entry.

${ }_{34}^{14} \beta>\delta \varphi-\gamma(1-\alpha)$ under restricted entry and $\beta>\alpha \gamma(1-\delta)-\frac{1-\delta-\delta^{2}}{1+\delta}$ under blockaded entry.

${ }^{35}$ Recall that there is an upper bound to the level of $\beta$, which is to ensure that the insider always obtains a wage at least equal to the reservation wage.

${ }^{36}$ If the firing cost and the unemployment benefit were constant, they would become negligible, relative to the revenue, with the passage of time.
} 
where $a_{\varphi}$ and $a_{\beta}$ are positive constants, with $a_{\beta} \in\left[0, \frac{\delta}{1+\delta}\right]$.

The corresponding equilibrium wages ${ }^{37}$ are given in Table 4 .

[Table 4 here]

Note that productivity growth in this context does not shift the bargainers from one scenario to another, but only leads to continuous wage change within a particular scenario. Specifically, insider wages always rise proportionately with productivity $\gamma$, but the movement of entrant wages depends on the entrant-insider productivity ratio $\alpha$, the firing cost parameter $a_{\varphi}$ and the unemployment benefit parameter $a_{\beta}$.

If the insider-entrant productivity ratio $\alpha$ is sufficiently large relative to the firing parameter $a_{\varphi}$ (for a given unemployment benefit parameter $a_{\beta}$ ), ${ }^{38}$ the firm has an incentive to churn. Then the entrant wage grows proportionately with productivity.

Furthermore, in the $C W$ scenario under blockaded entry, the entrant wage will always rise with productivity growth, as Table 4 shows ${ }^{39}$ for the following reason. Although the entrant wage is still less than the insider wage, entrants benefit from increases in their own productivity, as they pose no threats to insiders.

Under all other circumstances, however, the entrant wage may rise or fall with productivity $\gamma$.

In particular, under restricted entry in the $C W$ scenario, by contrast, entrants are in a position to challenge the insiders. Then, if $1-\alpha$ is large relative to the firing cost parameter $a_{\varphi}$ (for given $\delta$ ), then what the firm gains from bonding (the insider-entrant productivity differential) is large relative to what it loses through the loss of bargaining power to the insider, and thus the insider becomes more profitable relative to the entrant.

${ }^{37}$ Then the three wage determination scenarios may now be characterized as follows:

- The $C B$ scenario obtains if the entrant-insider productivity ratio $\alpha$ is sufficiently low (i.e. $\alpha<$ $\frac{1-\delta-\delta^{2}}{1-\delta^{2}}+\frac{a_{\beta}}{(1-\delta)}$ under blockaded entry and $\alpha<1-\frac{\left(\delta a_{\varphi}-a_{\beta}\right)}{1-\delta}$ under restricted entry).

- The $C W$ scenario obtains if the entrant-insider productivity ration $\alpha$ lies in an intermediate range $\left(\frac{1-\delta-\delta^{2}}{1-\delta^{2}}+\frac{a_{\beta}}{(1-\delta)} \leq \alpha \leq \frac{1}{1+\delta}+a_{\beta}\right.$ under blockaded entry and $1-\frac{\delta a_{\varphi}-a_{\beta}}{1-\delta} \leq \alpha \leq 1-\left(\delta a_{\varphi}-a_{\beta}\right)$ under restricted entry).

- The $C H$ scenario obtains if the entrant-insider productivity ratio $\alpha$ is sufficiently high $\left(\alpha>\frac{1}{1+\delta}+a_{\beta}\right.$ or $\left.\alpha>1-\left(\delta a_{\varphi}-a_{\beta}\right)\right)$.

${ }^{38}$ See footnote 37 .

${ }^{39}$ Note that the parameter values defining the $C W$ scenario under blockaded entry as form footnote 37 can be rearranged to yield

$$
a_{\beta} \gamma \geq W^{E}=\left(\frac{\delta}{1+\delta}-(1-\alpha)\right) \gamma \geq\left(\frac{\delta^{2}}{1-\delta^{2}}+\frac{a_{\beta}}{1-\delta}\right) \gamma>0 .
$$

from which the claim in the text follows. 
But, as noted, the insider and entrant need to be equally profitable in $C W$ scenario. Consequently wage will need to fall to ensure this outcomes.

In the $C B$ scenario, the entrant wage will fall if $\alpha$ is sufficiently small (under restricted entry), $a_{\varphi}$ is sufficiently large (under restricted entry), and the unemployment benefit parameter $a_{\beta}$ is sufficiently small (under both restricted and blockaded entry). Under these circumstances, productivity growth is also "immizerizing" for the entrant.

Proposition 8 Suppose that productivity (of the insider and entrant) grows and that the firing cost and unemployment benefit grow in proportion.

1. The insider wage grows in proportion to productivity.

2. The entrant wage may decline steadily.

\section{5.d Quits}

Now consider the possibility of a random event (e.g. a shock to workers' preferences), causing the insider to quit the firm with probability $(1-p) \in(0,1)$. Thereupon the firm can, without delay, hire an entrant. Since the firm does not pay the firing cost to an insider who quits voluntarily, the only labor turnover cost that the firm incurs is the productivity differential. The modified extensive form is depicted in Figure 8.

[Figure 8 here]

Thus when making an offer in subgames $G^{I}$, the firm expects that negotiations with the insider will continue with probability $p$, whereas with probability $(1-p)$ the firm will have to employ an outsider.

The results are summarized in Table 5. (The derivation is given in Appendix 2.)

[Table 5 here]

Observe that the quit probability $(1-p)$ affects the equilibrium wage only in the Competitive Bonding Scenario $(C B)$, but not in the Credible Wage Scenario $(C W)$. The reason is that in the $C W$ Scenario the firm obtains the same profits from employing an insider and a new entrant, $\Pi^{I}=\Pi^{E}$, so that the firm's profits are not affected by a quit.

In the $C B$ scenario, by contrast, the quit probability is related positively to the insider wage. The reason is straightforward. If an insider were to quit, he would have to be replaced by a less productive entrant, since $\Pi^{I}>\Pi^{E}$ in the $C B^{\prime}$ scenario. Consequently, as the probability of a quit increases, firm's expected profits fall. In effect, a rise in the quit probability reduces the firm's bargaining power and increases that of the insider, and thus the insider wage is positively related to the quit probability. Since the entrant in the $C B$ scenario receives the reservation wage, and this reservation wage varies inversely with the insider wage, an increase in the quit probability reduces the entrant wage. 
Proposition 9 1. In the Credible Wage scenario, the insider's quit probability does not affect insider and entrant wages.

2. In the Competitive Bargaining scenario, a rise in the insider's quit probability raises the insider wage and reduces the entrant wage.

\section{Concluding Remarks}

Our conclusions differ markedly from some central results of the conventional wage bargaining theories. First, in contrast to the conventional theories, labor turnover costs in our analysis do not just affect the outside options or the fall-back positions of the negotiators, but influence the nature of the bargaining process itself. We have shown that different labor turnover costs play different roles in the bargaining process. Specifically:

- The firm's decision to bond or churn depends on the relative magnitude of labor turnover costs. More precisely, when the insider-entrant productivity differential is sufficiently high relative to the firing cost, there is bonding (the Competitive Bonding scenario, $C B$ ), since the insider is always more profitable than the entrant. When the insider-entrant productivity differential is sufficiently low relative to the firing cost, there is churning (the Churning scenario, $\mathrm{CH}$ ), since the entrant is always more profitable than the insider. Finally, when the insider-entrant productivity differential lies in an intermediate range relative to the firing cost, insiders are just as profitable as entrants (the Credible Wage scenario, $C W$ ). Although there is bonding, the entrant receives more than the relevant reservation wage.

- When the joint magnitude of the firing cost and the insider-entrant productivity differential is sufficiently high, then entry is blockaded and the insider wage is the outcome of a bilateral monopoly problem; whereas when these turnover costs are sufficiently low, entry is restricted and thus the insider wage depends on the entrant wage and vice versa.

Second, our results differ from the standard Nash bargaining solution to the wage determination problem. The reason is that in our analysis labor turnover costs determine the relationship between the firm's bargain with its insider and that with outsiders, whereas the standard Nash bargaining problems involve a single bargain between the firm and the insider, and the outsiders' influence flows only through outside options and fall-back positions of the negotiating parties. ${ }^{40}$

Third, our theory provides a new game-theoretic view of the role of labor turnover costs in wage bargaining. Our theory covers the rather general case in which labor turnover

\footnotetext{
${ }^{40} \mathrm{An}$ explicit comparison of our results with those of Nash bargaining is given in Appendix 4.
} 
costs are explicit costs of replacing incumbent employees by new recruits. Unlike other strategic theories of wage bargaining, our theory reflects the common observation that workers often have little if any bargaining power when they enter the firm, but may accumulate substantial power after a period of job tenure. Many models of wage bargaining ignore this observation by assuming that insiders and entrants face identical bargaining conditions and receive identical wages. In our analysis, entrants may receive more than their reservation wage even though they have no bargaining power in wage negotiations.

In examining the fundamental role of labor turnover costs in structuring the wage bargaining process, our analysis delivers a new theory of wage determination. Our contention is that most wage bargaining theories thus far have been incomplete, in that they provide no account of employees' bargaining power in terms of the firm's labor turnover costs. We have argued that labor turnover costs are a fundamental source of this bargaining power and our analysis shows how these costs determine the degree of competition between insiders and outsiders.

Our analysis also has striking implications for the influence of firing costs on wage determination. We have shown that:

- Under $C B$, firing costs raise the insider wage and reduce the entrant wage, so that the present value of wage payments over the worker's job tenure at the firm remain unchanged;

- whereas under $C W$, firing costs raise both the insider and entrant wages, so that firing costs raise the present value of the firm's wage payments.

- The bargaining scenario depends on the magnitude of the insider-entrant productivity differential. When this differential is sufficiently small, a rise in firing costs beyond a critical level may induce the firm to fire the insider and start churning. Thus a rise in firing costs can make insiders worse off.

We have seen that increases in entrant productivity

- are wholly captured through the entrant wage in the $C W$ scenario,

- are partially captured through the entrant wage under $C B$ and restricted entry,

- leave the entrant wage unchanged under $C B$ and blockaded entry, and

- leave the insider wage unchanged, except under $C B$ and restricted entry, where the insider wage is reduced.

Regarding on-the-job training, our analysis indicates that: 
- When on-the-job training is sufficiently low, there is churning; otherwise there is bonding.

- On-the-job training always reduces the entrant wage and is never fully captured by the insider wage. In fact, under $C W$ and restricted entry, on-the-job training leaves the insider wage unchanged.

Regarding unemployment benefits, we have shown that:

- Changes in unemployment benefits leave insider and entrant wages unchanged in the $C W$ scenario.

- Otherwise, increases in unemployment benefits always raise the entrant wage.

- Increases in unemployment benefits raise the insider wage only under $C B$ and restricted entry.

In our model of steady-state growth (where firing costs and unemployment benefits grew proportionately with productivity), we found that insider wages grow in line with productivity growth, but entrant wages may fall steadily.

Finally, our analysis showed that the wage effect of insiders' quit probability depends on the bargaining scenario. In the $C W$ scenario, it leaves insider and entrant wages unchanged; whereas in the $C B$ scenario, it raises the insider wage and reduces the entrant wage.

\section{References}

Bertola, G. (1990), "'Job Security, Employment and Wages"', European Economic Review 34, 851-856.

Binmore, K., Rubinstein, A. \& Wolinsky, A. (1986), "'The Nash Bargaining Solution in Economic Modelling"', Rand Journal of Economics 17, 176-188.

Binmore, K., Shaked, A. \& Sutton, J. (1989), '“An Outside Option Experiment"', Quarterly Journal of Economics 104, 753-770.

Burguet, R., Caminal, R. \& Matutes, C. (2002), “"Golden Cages for Showy Birds; Optimal Switching Cost in Labor Contracts"', European Economic Review forthcoming.

de Fontanay, C. \& Gans, J. S. (2000), "Involuntary Unemployment and Intrafirm Bargaining with Replacement Workers". Melbourne Business School Working Paper No. 2000-07. 
Fella, G. (1999), "When do Firing Costs Matter?". W.P. 400, Department of Economics, Queen Mary and Westfield College.

Fernandez, R. \& Glazer, J. (1991), “"Striking for a Bargain Between Two Completely Informed Agents"', American Economic Review 81, 240-252.

Haller, H. \& Holden, S. (1991), “"A Letter to the Editor on Wage Bargaining"', Journal of Economic Theory 52, 232-236.

Holden, S. (1994), "'Bargaining and Commitment in a Permanet Relationship"', Games and Economic Behaviour 7, 169-176.

Layard, R., Nickell, S. \& Jackman, R. (1991), Unemployment: Macroeconomic Performance and the Labour Market, Oxford University Press, Oxford.

Lindbeck, A. \& Snower, D. J. (1989), The Insider-Outsider Theory of Employment and Unemployment, MIT Press, Cambridge, Massachusetts.

Lindbeck, A. \& Snower, D. J. (1990), “"Demand- and Supply-Side Policies and Unemployment: Policy Implications of the Insider-Outsider Approach"', Scandinavian Journal of Economics 92(2), 279-305.

Malcomson, J. (1997), '“Contracts, Hold-Up, and Labor Markets"', Journal-of-EconomicLiterature 35(4), 1916-57.

Muthoo, A. (1999), Bargaining Theory with Applications, Cambridge University Press, Cambridge.

Nash, J. F. (1953), “"Two-Person Cooperative Games"', Econometrica 21, 128-140.

Osborne, M. (1988), “'Capitalist-Worker Conflict and Involuntary Unemployment"', Review of Economic Studies 51, 111-127.

Osborne, M. \& Rubinstein, A. (1990), Bargaining and Markets, Academic Press, San Diego.

Rubinstein, A. (1982), "'Perfect Equilibrium in a Bargaining Model"', Econometrica 50, 97-109.

Sabourian, H. (1988), '"Wage Norms and Involuntary Unemployment"', Economic Journal 90, 177-188.

Shaked, A. \& Sutton, J. (1984), " Involuntary Unemployment as a Perfect Equilibrium in a Bargaining Model"', Econometrica 52, 1351-1364. 
Stole, L. \& Zwiebel, J. (1996a), "Intra-firm Bargaining under Non-binding Contracts"', Review of Economic Studies 63, 375-410.

Stole, L. \& Zwiebel, J. (1996b), “"Organizational Design and Technology Choice under Intrafirm Bargaining"', American Economic Review 86, 195-222. 


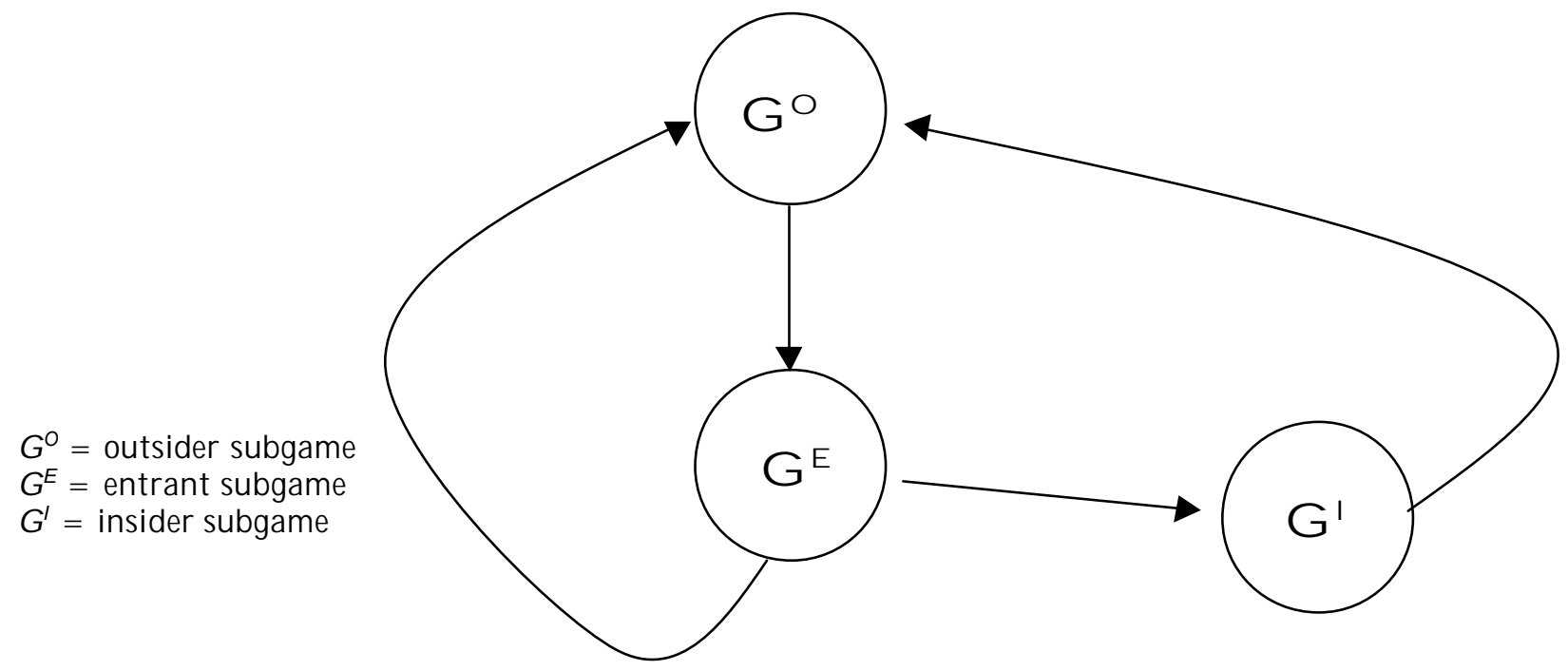

Fig. 1a: The Game

Subgame $\mathbf{G}^{\circ}$

$\mathrm{t}$

$t+1$

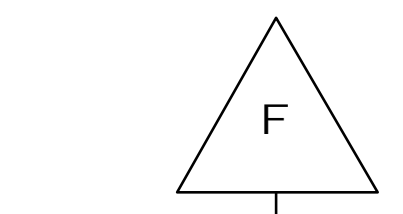

$t+2$

F ig. 1b: T he Subgames
Subgame G ${ }^{\mathrm{E}}$

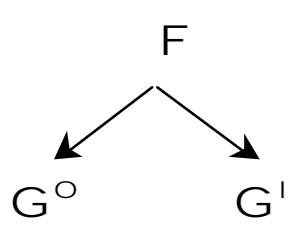

Subgame G '

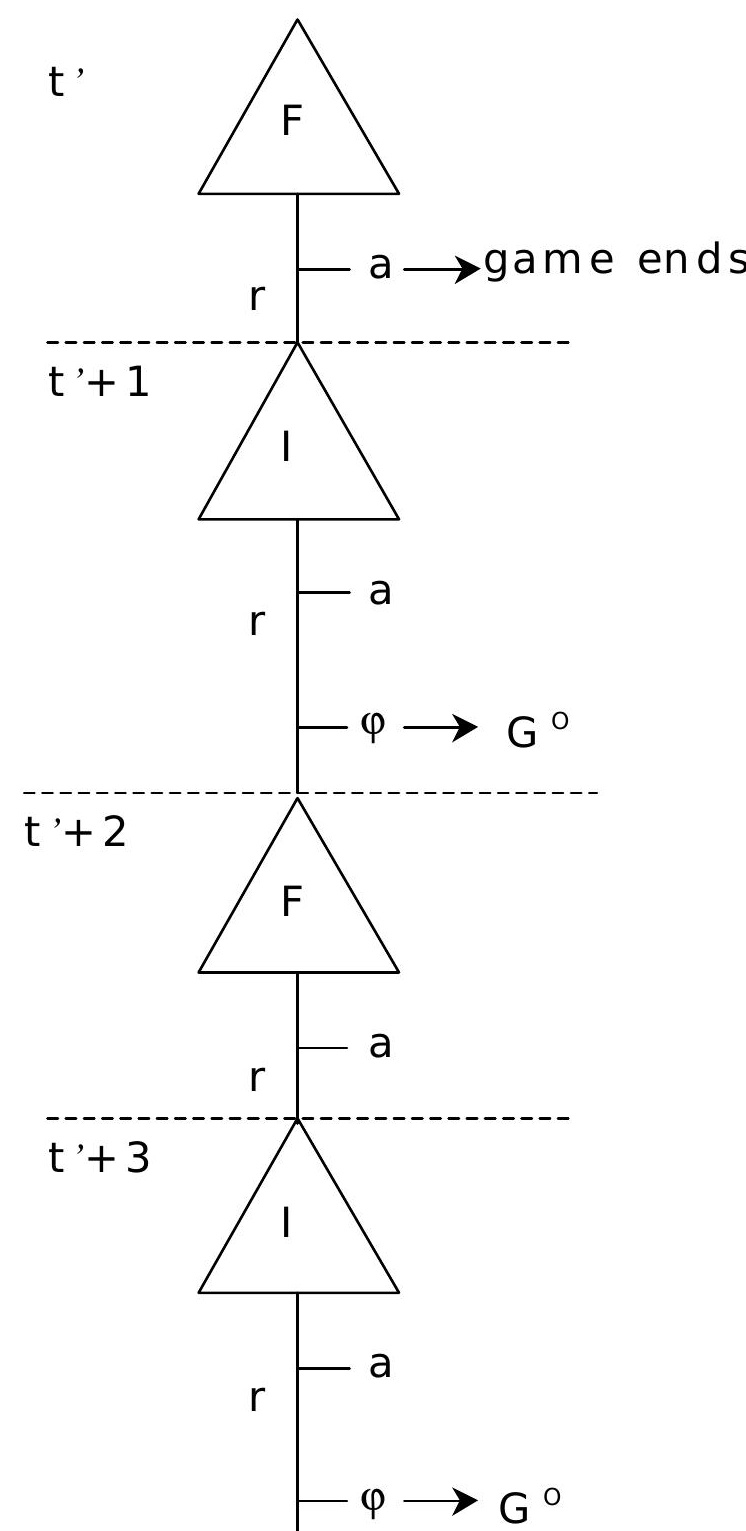



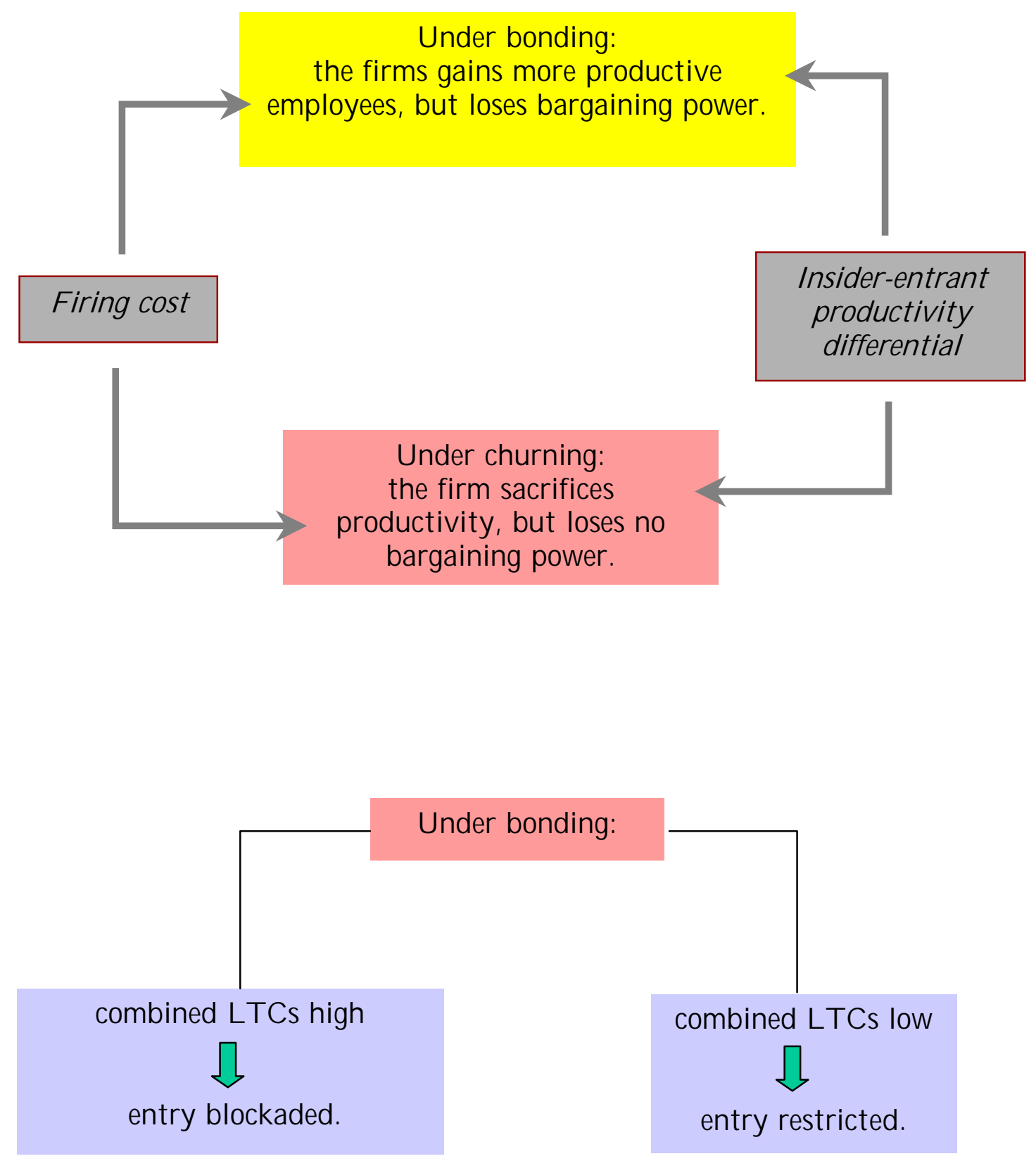

Figure 2: T wo F undamental Trade-offs 


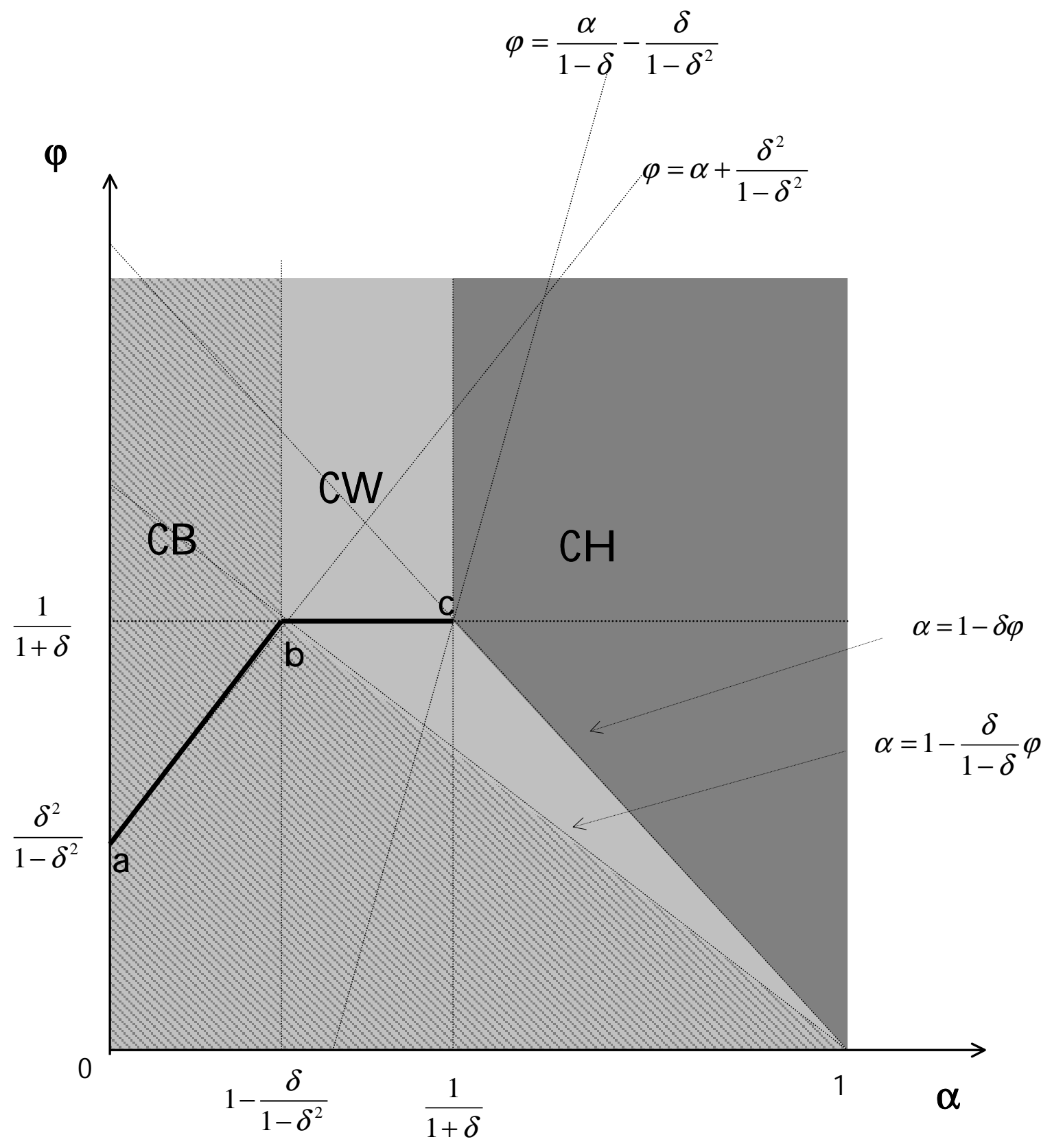

$\mathbb{N} \quad$ Competitive B onding Scenario (CB)

$\square$ Credible W age Scenario (CW)

$\square \quad$ Churning Scenario (aH)

F igure 3: The Three Scenarios 

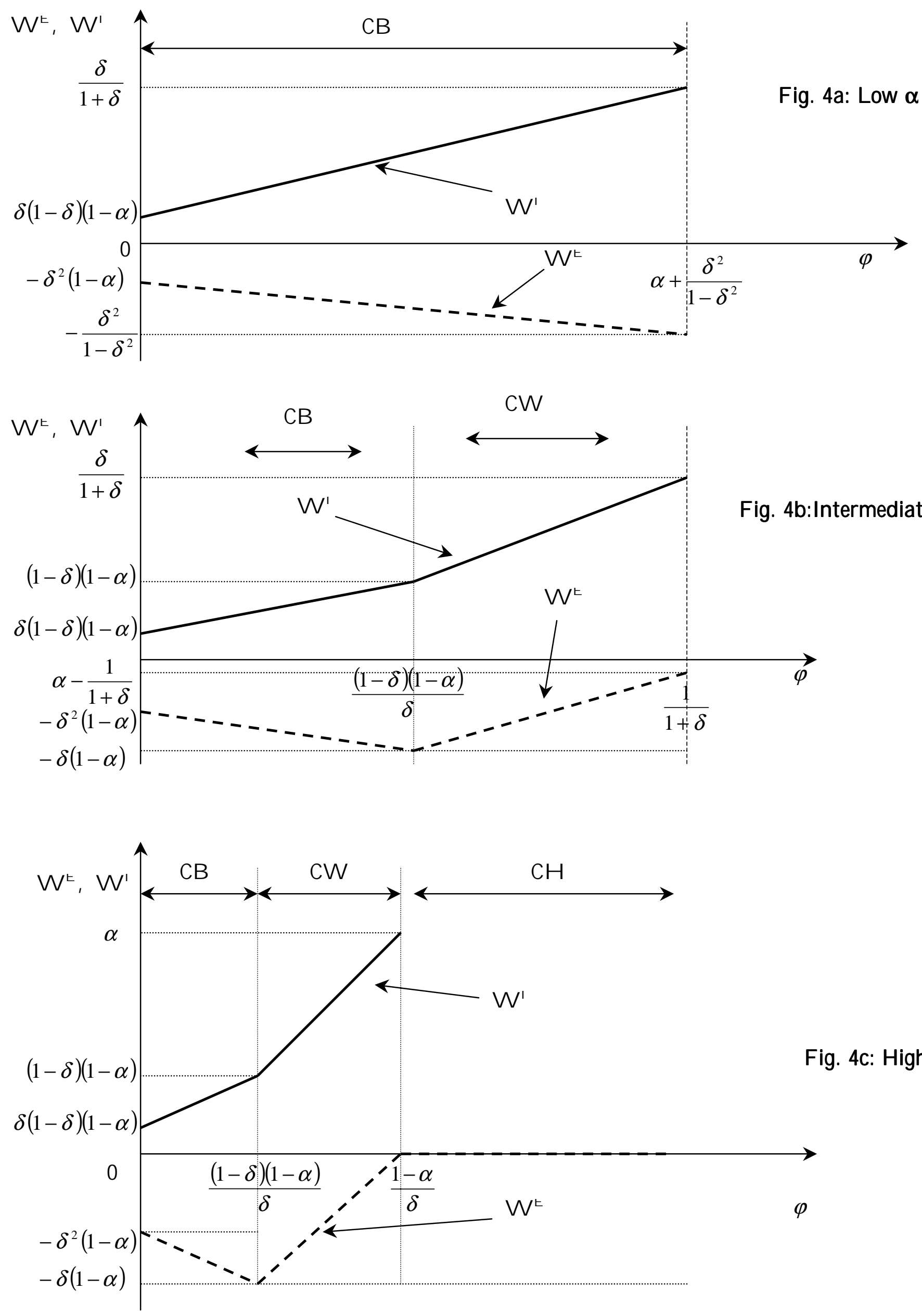

Fig. 4c: High $\alpha$

Figures 4: The Effect of the Firing Cost on Wages 

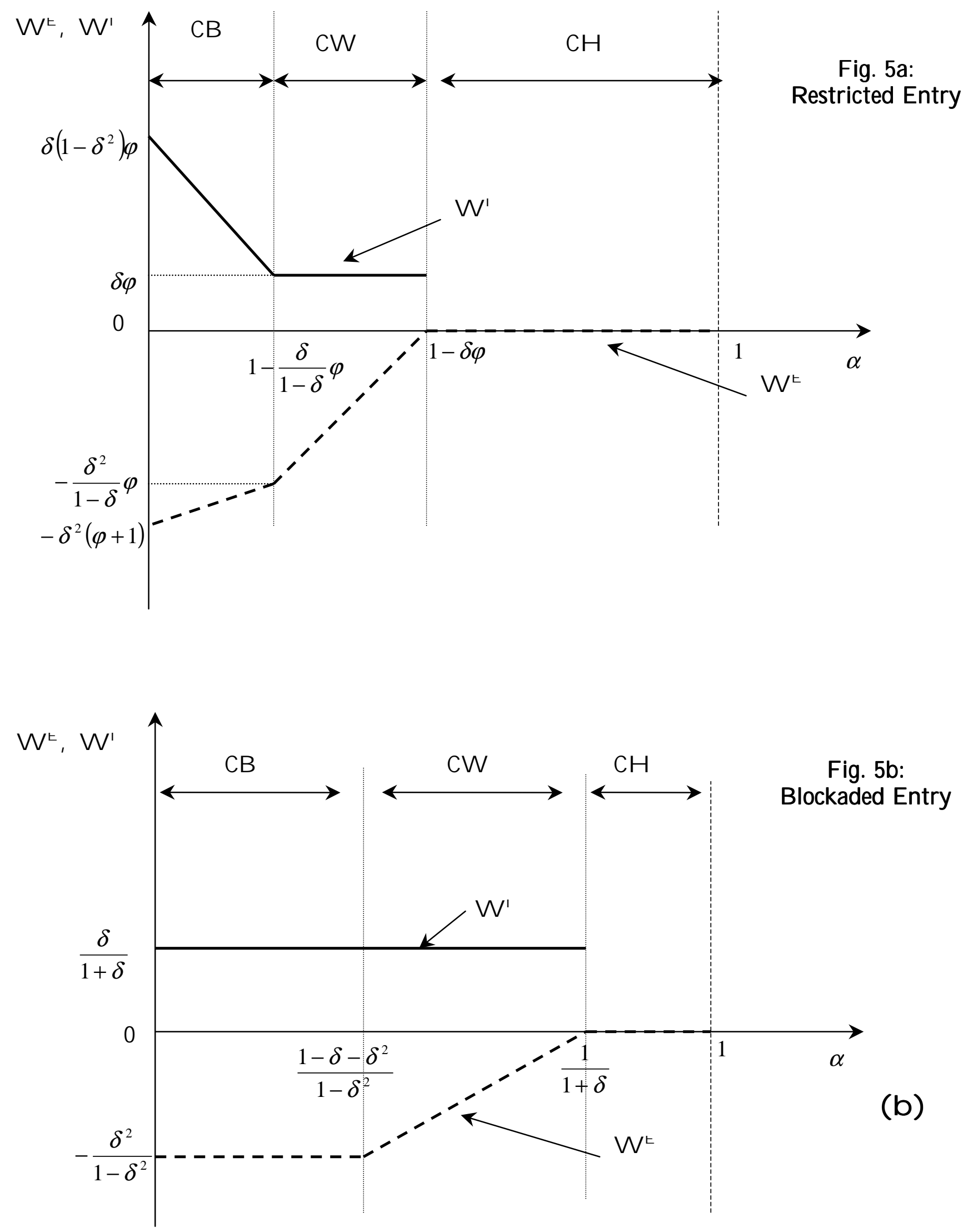

(b)

Figure 5: The Effect of Entrant Productivity on Wages 

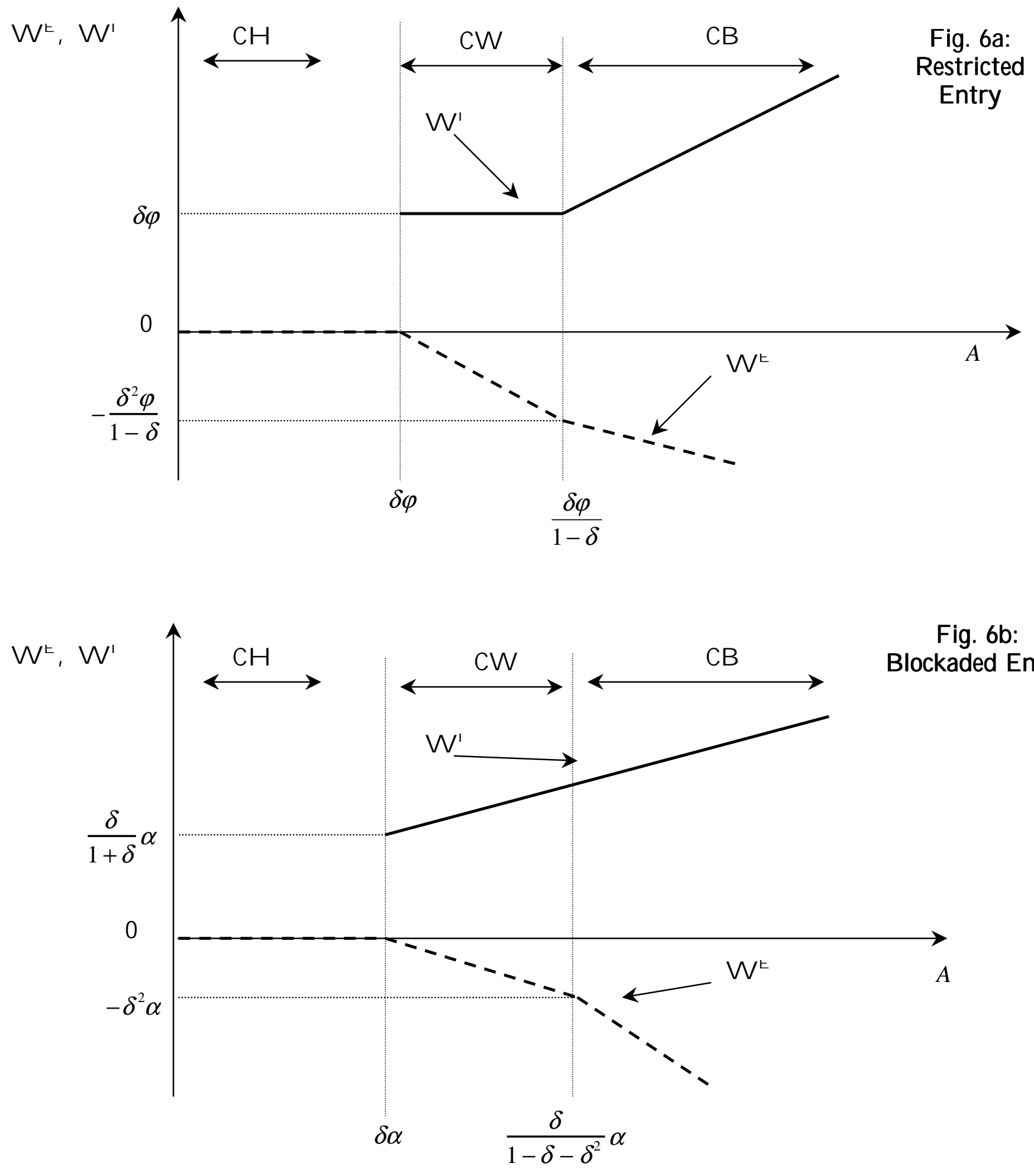

Figure 6: Effect of on the job training on wages 

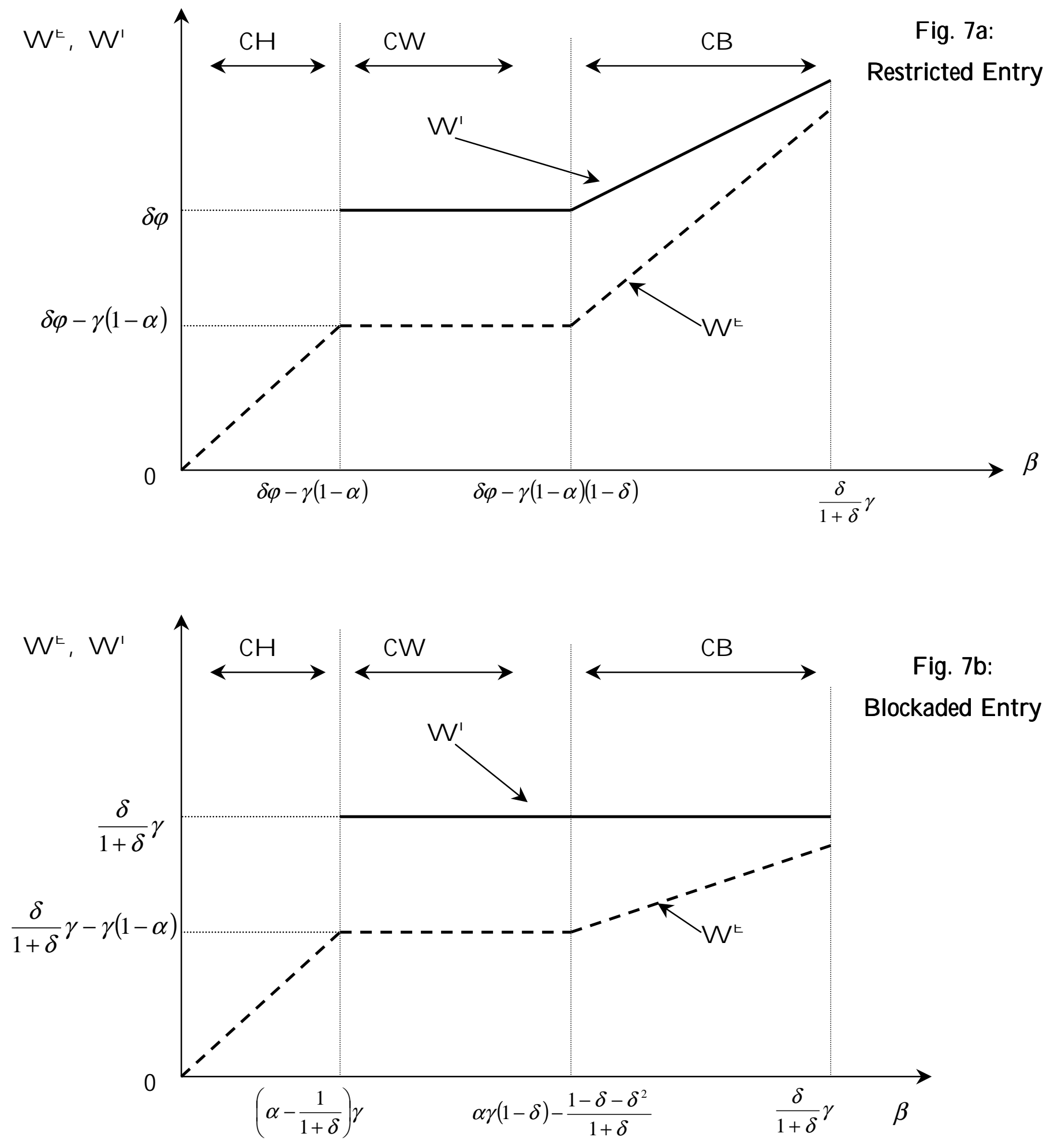

Figures 7: The Effect of Unemployment Benefits on Wages 
Subgame $\mathbf{G}^{\circ}$

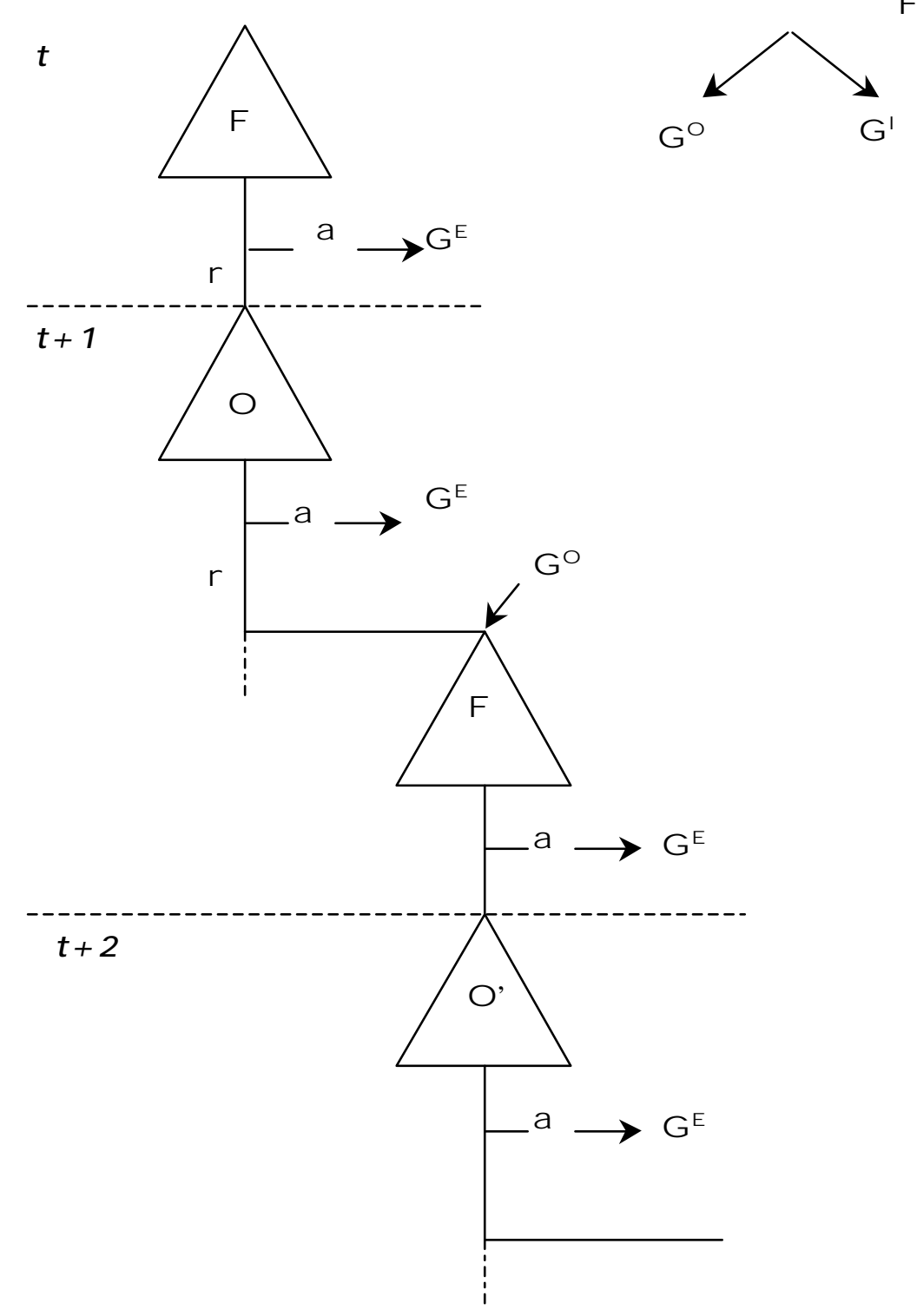

Subgame G $\mathbf{E}$
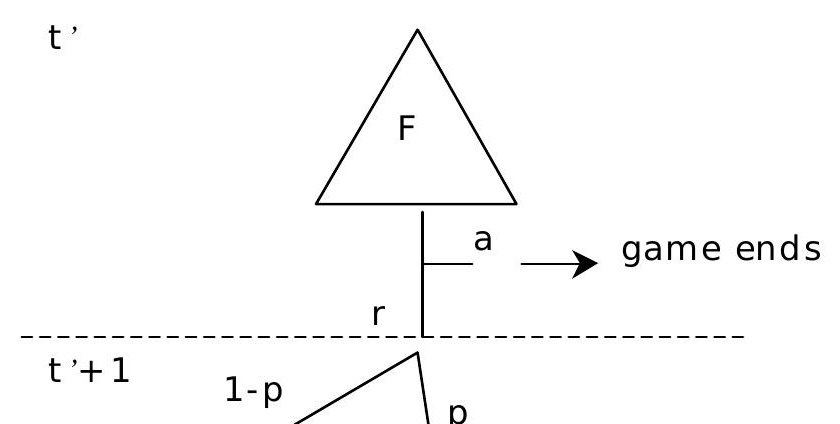

F igure 8: Structure of the Subgames in the M odel with Q uits 


\begin{tabular}{|c|c|c|c|}
\hline \multicolumn{2}{|c|}{ Scenarios } & Entrant Wage & Insider Wage \\
\hline $\begin{array}{l}\text { Churning } \\
\text { Scenario }(\mathrm{CH})\end{array}$ & & $W^{E}=R_{C H}=0$ & \\
\hline $\begin{array}{l}\text { Credible Wage } \\
\text { Scenario ( CW) }\end{array}$ & $\begin{array}{l}\text { restricted } \\
\text { entry } \\
\text { blockaded } \\
\text { entry }\end{array}$ & $\begin{aligned} W^{E} & =\delta \varphi-(1-\alpha) \\
W^{E} & =\frac{\delta}{1+\delta}-(1-\alpha)\end{aligned}$ & $\begin{array}{c}W^{I}=\delta \varphi \\
W^{I}=\frac{\delta}{1+\delta}\end{array}$ \\
\hline $\begin{array}{l}\text { Competitive } \\
\text { Bonding } \\
\text { Scenario ( } C B)\end{array}$ & $\begin{array}{l}\text { restricted } \\
\text { entry } \\
\text { blockaded } \\
\text { entry }\end{array}$ & $\begin{array}{c}W^{E}=-\delta^{2}(\varphi+1-\alpha) \\
W^{E}=-\frac{\delta^{2}}{1-\delta^{2}}\end{array}$ & $\begin{array}{c}W^{I}=\delta(1-\delta)(\varphi+1-\alpha) \\
W^{I}=\frac{\delta}{1+\delta}\end{array}$ \\
\hline
\end{tabular}

Table 1: Equilibrium Wages in the Basic Model 


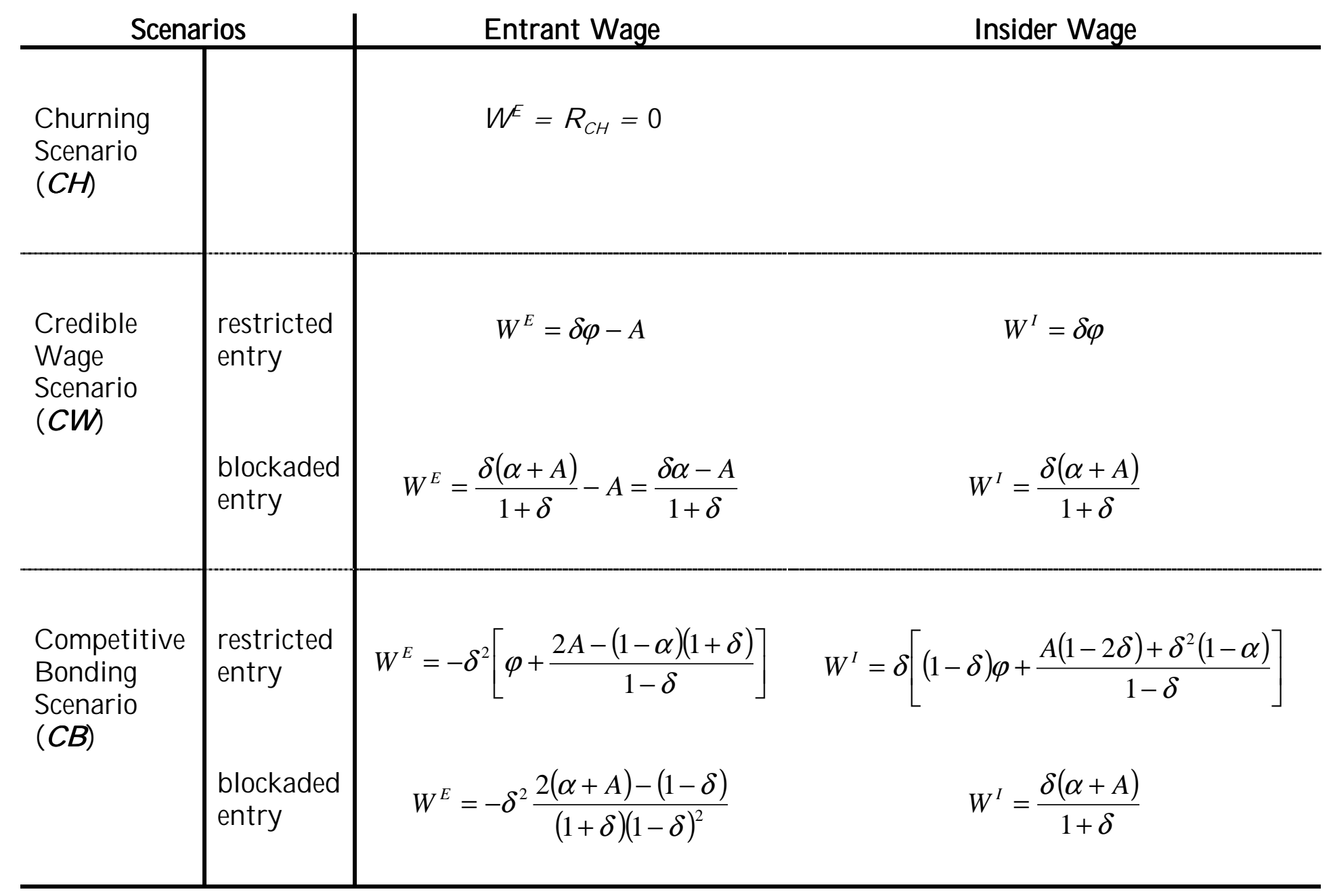

Table 2: Equilibrium Wages in the Model with On-the-J ob Training 


\begin{tabular}{|c|c|c|c|}
\hline \multicolumn{2}{|c|}{ Scenarios } & Entrant Wage & Insider Wage \\
\hline $\begin{array}{l}\text { Churning } \\
\text { Scenario } \\
(\mathrm{CH})\end{array}$ & & \multicolumn{2}{|l|}{$W^{E}=R_{C H}=\beta$} \\
\hline \multirow{2}{*}{$\begin{array}{l}\text { Credible } \\
\text { Wage } \\
\text { Scenario } \\
\text { (CW) }\end{array}$} & restricted entry & $W^{E}=\delta \varphi-\gamma(1-\alpha)$ & $W^{I}=\delta \varphi$ \\
\hline & $\begin{array}{l}\text { blockaded } \\
\text { entry }\end{array}$ & $W^{E}=\frac{\delta}{1+\delta} \gamma-\gamma(1-\alpha)$ & $W^{I}=\frac{\delta}{1+\delta} \gamma$ \\
\hline \multirow{2}{*}{$\begin{array}{l}\text { Competitive } \\
\text { Bonding } \\
\text { Scenario } \\
(C B)\end{array}$} & restricted entry & $W^{E}=(1+\delta) \beta-\delta^{2}[\gamma(1-\alpha)+\varphi]$ & $W^{I}=\delta \beta+\delta(1-\delta)[\gamma(1-\alpha)+\varphi]$ \\
\hline & $\begin{array}{l}\text { blockaded } \\
\text { entry }\end{array}$ & $W^{E}=-\frac{\delta^{2}}{1-\delta^{2}} \gamma+\frac{\beta}{1-\delta}$ & $W^{I}=\frac{\delta}{1+\delta} \gamma$ \\
\hline
\end{tabular}

Table 3: Equilibrium Wages in the Extended Mode 


\begin{tabular}{|c|c|c|c|}
\hline \multicolumn{2}{|c|}{ Scenarios } & Entrant Wage & Insider Wage \\
\hline $\begin{array}{l}\text { Churning } \\
\text { Scenario } \\
(\mathrm{CH})\end{array}$ & & $W^{E}=R_{C H}=\beta=a_{\beta} \gamma$ & \\
\hline $\begin{array}{l}\text { Credible } \\
\text { Wage }\end{array}$ & $\begin{array}{l}\text { restricted } \\
\text { entry }\end{array}$ & $W^{E}=\left[\delta a_{\varphi}-(1-\alpha)\right] \gamma$ & $W^{I}=\delta a_{\varphi} \gamma$ \\
\hline & $\begin{array}{l}\text { blockaded } \\
\text { entry }\end{array}$ & $W^{E}=\left[\frac{\delta}{1+\delta}-(1-\alpha)\right] \gamma$ & $W^{I}=\frac{\delta}{1+\delta} \gamma$ \\
\hline $\begin{array}{l}\text { Competiti } \\
\text { ve }\end{array}$ & $\begin{array}{l}\text { restricted } \\
\text { entry }\end{array}$ & $W^{E}=\left[(1+\delta) a_{\beta}-\delta^{2}\left(1-\alpha+a_{\varphi}\right)\right] y$ & $W^{I}=\delta\left[a_{\beta}+(1-\delta)\left(1-\alpha+a_{\varphi}\right)\right] \gamma$ \\
\hline & $\begin{array}{l}\text { blockaded } \\
\text { entry }\end{array}$ & $W^{E}=\left(-\frac{\delta^{2}}{1-\delta^{2}}+\frac{a_{\beta}}{1-\delta}\right) \gamma$ & $W^{I}=\frac{\delta}{1+\delta} \gamma$ \\
\hline
\end{tabular}

Table 4: Equilibrium Wages in the Model of Productivity Growth 


\begin{tabular}{|c|c|c|c|}
\hline \multicolumn{2}{|c|}{ Scenarios } & Entrant Wage & Insider Wage \\
\hline $\begin{array}{l}\text { Churning } \\
\text { Scenario } \\
(\mathrm{CH})\end{array}$ & & $W^{E}=R_{C H}=0$ & \\
\hline \multirow{2}{*}{$\begin{array}{l}\text { Credible } \\
\text { Wage } \\
\text { Scenario } \\
\text { (CW) }\end{array}$} & $\begin{array}{l}\text { restricted } \\
\text { entry }\end{array}$ & $W^{E}=\delta \varphi-(1-\alpha)$ & $W^{I}=\delta \varphi$ \\
\hline & $\begin{array}{l}\text { blockaded } \\
\text { entry }\end{array}$ & $W^{E}=\frac{\delta}{1+\delta}-(1-\alpha)$ & $W^{I}=\frac{\delta}{1+\delta}$ \\
\hline \multirow{2}{*}{$\begin{array}{l}\text { Competitive } \\
\text { Bonding } \\
\text { Scenario } \\
(C B)\end{array}$} & $\begin{array}{l}\text { restricted } \\
\text { entry }\end{array}$ & $W^{E}=-\delta[p \delta \varphi-(1-p(1-\delta))(1-\alpha)]$ & $W^{I}=(1-\delta)[p \delta \varphi+(1-p(1-\delta))(1-\alpha)]$ \\
\hline & $\begin{array}{l}\text { blockaded } \\
\text { entry }\end{array}$ & $W^{E}=-\delta \frac{\delta p+(1-p)(1-\alpha)}{1-p \delta^{2}}$ & $W^{I}=\frac{(1-\delta)[p \delta-(1-p)(1-\alpha)]}{1-p \delta^{2}}$ \\
\hline
\end{tabular}

Table 5: Equilibrium Wages in the Model with Quits 


\begin{tabular}{|c|c|c|c|}
\hline Scenarios & & Entrant Wage & Insider Wage \\
\hline $\begin{array}{l}\text { Churning Scenario } \\
(\mathrm{CH})\end{array}$ & & $W^{E}=R_{C H}=0$ & \\
\hline $\begin{array}{l}\text { Credible Wage } \\
\text { Scenario ( CW }\end{array}$ & $\begin{array}{l}\text { restricted } \\
\text { entry } \\
\text { blockaded } \\
\text { entry }\end{array}$ & $\begin{aligned} W^{E} & =\delta \varphi-\frac{(1-\delta)(1-\alpha)}{1-\delta^{T}} \\
W^{E} & =\frac{\delta}{1+\delta}-\frac{(1-\delta)(1-\alpha)}{1-\delta^{T}}\end{aligned}$ & $\begin{array}{c}W^{I}=\delta \varphi \\
W^{I}=\frac{\delta}{1+\delta}\end{array}$ \\
\hline $\begin{array}{l}\text { Competitive Bonding } \\
\text { Scenario }(C B)\end{array}$ & $\begin{array}{l}\text { restricted } \\
\text { entry } \\
\text { blockaded } \\
\text { entry }\end{array}$ & $\begin{array}{c}W^{E}=-\frac{\delta^{T+1}(1-\delta)(\varphi+1-\alpha)}{1-\delta^{T}} \\
W^{E}=-\frac{\delta^{T+1}}{\left(1-\delta^{T}\right)(1+\delta)}\end{array}$ & $\begin{array}{c}W^{I}=\delta(1-\delta)(\varphi+1-\alpha) \\
W^{I}=\frac{\delta}{1+\delta}\end{array}$ \\
\hline
\end{tabular}

Table A.1: Equilibrium wages with an initiation contract of length T 


\begin{tabular}{|c|c|c|c|}
\hline Scenarios & & Entrant Wage & Insider Wage \\
\hline $\begin{array}{l}\text { Churning Scenario } \\
(\mathrm{CH})\end{array}$ & & $W^{E}=R_{C H}=0$ & \\
\hline $\begin{array}{l}\text { Credible Wage } \\
\text { Scenario ( CW }\end{array}$ & $\begin{array}{l}\text { restricted } \\
\text { entry } \\
\text { blockaded } \\
\text { entry }\end{array}$ & $\begin{array}{c}W^{E}=\frac{\delta^{\Delta}(1-\delta) \varphi}{1-\delta^{\Delta}}-\frac{(1-\delta)(1-\alpha)}{1-\delta^{T}} \\
W^{E}=\frac{\delta^{\Delta}}{1+\delta^{\Delta}}-\frac{(1-\delta)(1-\alpha)}{1-\delta^{T}}\end{array}$ & $\begin{array}{c}W^{I}=\frac{\delta^{\Delta}(1-\delta) \varphi}{1-\delta^{\Delta}} \\
W^{I}=\frac{\delta^{\Delta}}{1+\delta^{\Delta}}\end{array}$ \\
\hline $\begin{array}{l}\text { Competitive Bonding } \\
\text { Scenario }(C B)\end{array}$ & $\begin{array}{l}\text { restricted } \\
\text { entry } \\
\text { blockaded } \\
\text { entry }\end{array}$ & $\begin{array}{c}W^{E}=-\frac{\delta^{T+\Delta}(1-\delta)(\varphi+1-\alpha)}{1-\delta^{T}} \\
W^{E}=-\frac{\delta^{\Delta+T}}{\left(1-\delta^{T}\right)\left(1+\delta^{\Delta}\right)}\end{array}$ & $\begin{array}{c}W^{I}=\delta^{\Delta}(1-\delta)(\varphi+1-\alpha) \\
W^{I}=\frac{\delta^{\Delta}}{1+\delta^{\Delta}}\end{array}$ \\
\hline
\end{tabular}

Table A.2: Equilibrium wages with an initiation contract of length $T$ and arbitrary length of initiation round 


\begin{tabular}{|c|c|c|c|}
\hline \multicolumn{2}{|l|}{ Scenarios } & Entrant Wage & Insider Wage \\
\hline $\begin{array}{l}\text { Churning Scenario } \\
(\mathrm{CH})\end{array}$ & & $W^{E}=R_{C H}=0$ & \\
\hline $\begin{array}{l}\text { Credible Wage } \\
\text { Scenario ( CW }\end{array}$ & $\begin{array}{l}\text { restricted } \\
\text { entry } \\
\text { blockaded } \\
\text { entry }\end{array}$ & $W^{E}=\frac{1}{2}-\frac{(1-\delta)(1-\alpha)}{1-\delta^{T}}$ & $W^{I}=\frac{1}{2}$ \\
\hline $\begin{array}{l}\text { Competitive Bonding } \\
\text { Scenario }(C B)\end{array}$ & $\begin{array}{l}\text { restricted } \\
\text { entry } \\
\text { blockaded } \\
\text { entry }\end{array}$ & $\begin{array}{r}\text { Not } \\
W^{E}=-\frac{\delta^{T}}{2\left(1-\delta^{T}\right)}\end{array}$ & $W^{I}=\frac{1}{2}$ \\
\hline
\end{tabular}

Table A.3: Limiting equilibrium wages 


\section{Appendix 1: Proof of Propositions 1, 2, and 3}

Supporting strategies are detailed in Boxes 1-3 below. ${ }^{41}$

\begin{tabular}{|c|c|c|}
\hline & $\begin{array}{l}\alpha>\frac{1}{1+\delta} ; \varphi \geq \frac{\alpha}{1-\delta}-\frac{\delta}{1-\delta^{2}} \\
\text { (blockaded entry) }\end{array}$ & $\begin{array}{l}\alpha>1-\delta \varphi ; \varphi<\frac{\alpha}{1-\delta}-\frac{\delta}{1-\delta^{2}} \\
\text { (restricted entry) }\end{array}$ \\
\hline \multicolumn{3}{|l|}{$\begin{array}{l}\text { In firm-outsider bargains: } \\
\text { (subgames } \mathrm{G}^{O} \text { ) } \\
\text { The firm: }\end{array}$} \\
\hline$\overline{\text { proposes* }} *$ & $(\alpha ; 0)$ & $(\alpha ; 0)$ \\
\hline accepts & $x \geq \alpha$ & $x \geq \alpha$ \\
\hline rejects & $x<\alpha$ & $x<\alpha$ \\
\hline turns to another outsider & always & always \\
\hline \multicolumn{3}{|l|}{ The outsider: } \\
\hline proposes* & $(\alpha ; 0)$ & $(\alpha ; 0)$ \\
\hline accepts & $x \geq 0$ & $x \geq 0$ \\
\hline rejects & $x<0$ & $x<0$ \\
\hline \multicolumn{3}{|l|}{ In subgames $\mathrm{G}^{E}$} \\
\hline The firm retains its entrant & never & never \\
\hline \multicolumn{3}{|l|}{$\begin{array}{l}\text { In firm-insider bargains: } \\
\text { (subgames } \mathrm{G}^{I} \text { ) } \\
\text { The firm: }\end{array}$} \\
\hline proposes* & $\left(\frac{1}{1+\delta} ; \frac{\delta}{1+\delta}\right)$ & $(1-\delta[1-\alpha+(1-\delta) \varphi] ; \delta[1-\alpha+(1-\delta) \varphi])$ \\
\hline accepts & $x \geq \frac{\delta}{1+\delta}$ & $x \geq \alpha-(1-\delta) \varphi$ \\
\hline rejects & $x<\frac{\delta}{1+\delta}$ & $x<\alpha-(1-\delta) \varphi$ \\
\hline fires the insider & never & always \\
\hline \multicolumn{3}{|l|}{ The insider: } \\
\hline proposes* & $\left(\frac{\delta}{1+\delta} ; \frac{1}{1+\delta}\right)$ & $(\alpha-(1-\delta) \varphi ; 1-\alpha+(1-\delta) \varphi)$ \\
\hline accepts & $x \geq \frac{\delta}{1+\delta}$ & $x \geq \delta[1-\alpha+(1-\delta) \varphi]$ \\
\hline rejects & $x<\frac{\delta}{1+\delta}$ & $x<\delta[1-\alpha+(1-\delta) \varphi]$ \\
\hline
\end{tabular}

\section{Box 1: Equilibrium strategies for Proposition 1.}

* The first and the second entry refer to the firm's and the worker's payoffs, respectively.

\footnotetext{
${ }^{41}$ Although the agreement that is struck with the outsider in the churning equilibrium is independent on whether entry to insider's jobs is blockaded or restricted, the strategies that support such equilibrium have to specify the outcomes off the equilibrium path, and therefore depend on the size of $\varphi$ relative to $\alpha$. If in fact the firm ever were to retain an entrant and allow him to recontract his wage, the firing cost would influence the outcome of negotiations between the firm and an insider.
} 
In firm-outsider bargains:

$$
\begin{array}{ll}
\frac{1-\delta-\delta^{2}}{1-\delta^{2}} \leq \alpha \leq \frac{1}{1+\delta} ; \varphi \geq \frac{1}{1+\delta} & \begin{array}{l}
1-\frac{\delta}{1-\delta} \varphi \leq \alpha \leq 1-\delta \varphi ; \varphi<\frac{1}{1+\delta} \\
\text { (blockaded entry) }
\end{array} \\
\text { (restricted entry) }
\end{array}
$$

(subgames $\mathrm{G}^{O}$ )

The firm:

proposes*

accepts

rejects

turns to another outsider

The outsider:

proposes* $^{*}$

accepts

rejects $\left(\frac{1}{1+\delta} ; \frac{\delta}{1+\delta}-(1-\alpha)\right)$

$x \geq \frac{1}{1+\delta}$

$x<\frac{1}{1+\delta}$

always

$\left(\frac{1}{1+\delta} ; \frac{\delta}{1+\delta}-(1-\alpha)\right)$

$x \geq \frac{\delta}{1+\delta}-(1-\alpha)$

$x<\frac{\delta}{1+\delta}-(1-\alpha)$

$(1-\delta \varphi ; \delta \varphi-(1-\alpha))$

$x \geq 1-\delta \varphi$

$x<1-\delta \varphi$

always

$(1-\delta \varphi ; \delta \varphi-(1-\alpha))$

$x \geq \delta \varphi-(1-\alpha)$

$x<\delta \varphi-(1-\alpha)$

\section{In subgames $\mathrm{G}^{E}$}

The firm retains its entrant always

always

\section{In firm-insider bargains:}

(subgames $\mathrm{G}^{I}$ )

The firm:

$\begin{array}{ll}\text { proposes* } & \left(\frac{1}{1+\delta} ; \frac{\delta}{1+\delta}\right) \\ \text { accepts } & x \geq \frac{\delta}{1+\delta} \\ \text { rejects } & x<\frac{\delta}{1+\delta} \\ \text { fires the insider } & \text { never }\end{array}$

$(1-\delta \varphi ; \delta \varphi)$

$x \geq 1-\varphi$

$x<1-\varphi$

always

The insider:

proposes*

accepts

rejects

$$
\begin{aligned}
& \left(\frac{\delta}{1+\delta} ; \frac{1}{1+\delta}\right) \\
& x \geq \frac{\delta}{1+\delta} \\
& x<\frac{\delta}{1+\delta}
\end{aligned}
$$

rejects

\section{Box 2: Equilibrium strategies for Proposition 2.}

* The first and the second entry refer to the firm's and the worker's payoffs, respectively. 


\section{In firm-outsider bargains} (subgames $G^{O}$ )

The firm:

proposes* $^{*}$

accepts

rejects

turns to another outsider

The outsider:

proposes* $^{*}$

accepts

rejects $\alpha<\frac{1-\delta-\delta^{2}}{1-\delta^{2}} ; \varphi \geq \alpha+\frac{\delta^{2}}{1-\delta^{2}}$

(blockaded entry) $\alpha<1-\frac{\delta}{1-\delta} \varphi ; \varphi<\alpha+\frac{\delta^{2}}{1-\delta^{2}}$

(restricted entry)

$$
\begin{array}{ll}
\left(\alpha+\frac{\delta^{2}}{1-\delta^{2}} ;-\frac{\delta^{2}}{1-\delta^{2}}\right) & \left(\alpha\left(1-\delta^{2}\right)+\delta^{2}(1+\varphi),-\delta^{2}(\varphi+1-\alpha)\right) \\
x \geq \alpha+\frac{\delta^{2}}{1-\delta^{2}} & x \geq \alpha\left(1-\delta^{2}\right)+\delta^{2}(1+\varphi) \\
x<\alpha+\frac{\delta^{2}}{1-\delta^{2}} & x<\alpha\left(1-\delta^{2}\right)+\delta^{2}(1+\varphi) \\
\text { always } & \text { always }
\end{array}
$$

$$
\begin{array}{ll}
\left(\alpha+\frac{\delta^{2}}{1-\delta^{2}} ;-\frac{\delta^{2}}{1-\delta^{2}}\right) & \left(\alpha\left(1-\delta^{2}\right)+\delta^{2}(1+\varphi) ;-\delta^{2}(\varphi+1-\alpha)\right) \\
x \geq-\frac{\delta^{2}}{1-\delta^{2}} & x \geq-\delta^{2}(\varphi+1-\alpha) \\
x<-\frac{\delta^{2}}{1-\delta^{2}} & x<-\delta^{2}(\varphi+1-\alpha)
\end{array}
$$

\section{In subgames $G^{E}$}

The firm retains its entrant always

always

\section{In firm-insider bargains:} (subgames $G^{I}$ )

The firm:

proposes*

accepts

rejects

fires the insider

$$
\begin{aligned}
& \left(\frac{1}{1+\delta} ; \frac{\delta}{1+\delta}\right) \\
& x \geq \frac{\delta}{1+\delta} \\
& x<\frac{\delta}{1+\delta} \\
& \text { never }
\end{aligned}
$$

$(1-\delta(1-\delta)(\varphi+1-\alpha) ; \delta(1-\delta)(\varphi+1-\alpha))$

$x \geq \delta+(1-\delta)(\alpha-\varphi)$

$x<\delta+(1-\delta)(\alpha-\varphi)$

always

The insider:

proposes*

accepts

rejects

$$
\begin{aligned}
& \left(\frac{\delta}{1+\delta} ; \frac{1}{1+\delta}\right) \\
& x \geq \frac{\delta}{1+\delta} \\
& x<\frac{\delta}{1+\delta}
\end{aligned}
$$

\section{Box 3: Equilibrium strategies for Proposition 3.}

* The first and the second entry refer to the firm's and the worker's payoffs, respectively.

Checking for subgame perfection by the one step deviation property is straightforward though tedious, thus it is omitted.

\section{Uniqueness}

Since we are looking at stationary subgame perfect equilibria, there can be no equilibrium with delayed agreement: delayed agreement can obtain only if at least one agent rejects one offer, and because of the stationarity requirement this implies that no agreement would ever be struck. But perpetual disagreement cannot be an equilibrium, as at 
least one agent would have a profitable deviation. Thus we need to show that there is a unique stationary equilibrium with immediate agreement.

All subgames of the same kind starting with an offer by the firm are homeomorphic, as all subgames starting with an offer by the worker; however the identity of the workers called in the bargaining may change depending on the branch of the game tree, which of course will matter in terms of payoff to the specific worker involved in any particular subgame. Bearing this in mind, and recalling that we assumed symmetric strategies (that is, all workers of a specific type adopt the same strategy), let $M_{i}^{j}$ be the stationary subgame perfect equilibrium (henceforth s.s.p.e.) payoff for player $i$ (with $i=W, F)^{42}$ in any subgame $G_{i}^{j}(j=I, O)$ where player $i$ is the first mover. Moreover, let $A$ be the s.s.p.e. payoff which accrues to the firm in subgames ${ }^{43} G^{E}$. Note that by stationarity, if a firm decides to retain (fire, respectively) an entrant at a subgame $G^{E}$, it will do so at all other subgames $G^{E}$. Consequently, the total surplus generated by an agreement is:

$$
\left\{\begin{array}{l}
\frac{1}{1-\delta} \text { if agreement is struck with an insider } \\
\alpha+\frac{\delta}{1-\delta} \text { if agreement is struck with an entrant who is subsequently retained } \\
\frac{\alpha}{1-\delta} \text { if agreement is struck with an entrant who is not subsequently retained }
\end{array}\right.
$$

In order to characterize the equilibrium partition, observe that at an equilibrium all payoff divisions will be efficient, in the sense of exhausting completely the available surplus (otherwise at least one agent could profitably deviate and claim a bit more). Thus, it is enough to specify requirements for the equilibrium payoffs of one agent only in each type of subgames. Then equilibrium payoffs must solve the following set of equations ${ }^{44}$ :

$$
\begin{aligned}
& \mathbf{A}=\max \left\{\frac{\mathbf{M}_{\mathbf{F}}^{\mathrm{I}}}{\mathbf{1}-\delta}, \frac{\mathbf{M}_{\mathbf{F}}^{\mathrm{O}}}{\mathbf{1}-\delta}\right\} \\
& \frac{\mathbf{M}_{\mathbf{F}}^{\mathrm{I}}}{\mathbf{1}-\delta}=\frac{\mathbf{1}}{\mathbf{1}-\delta}-\frac{\delta \mathbf{M}_{\mathbf{W}}^{\mathrm{I}}}{\mathbf{1}-\delta} \\
& \frac{\mathbf{M}_{\mathbf{W}}^{\mathrm{I}}}{\mathbf{1}-\delta}=\frac{\mathbf{1}}{\mathbf{1}-\delta}-\max \left\{\frac{\delta \mathbf{M}_{\mathbf{F}}^{\mathrm{I}}}{\mathbf{1}-\delta}, \mathbf{M}_{\mathbf{F}}^{\mathbf{O}}-\varphi+\delta \mathbf{A}\right\} \\
& \mathbf{M}_{\mathbf{F}}^{\mathbf{O}}+\delta \mathbf{A}=\mathbf{k}\left(\alpha+\frac{\delta}{\mathbf{1}-\delta}-\delta\left(\mathbf{M}_{\mathbf{W}}^{\mathbf{O}}+\frac{\delta\left(\mathbf{1}-\mathbf{M}_{\mathbf{F}}^{\mathrm{I}}\right)}{\mathbf{1}-\delta}\right)\right)+(\mathbf{1}-\mathbf{k})\left(\frac{\alpha}{1-\delta}-\frac{\delta \mathbf{M}_{\mathbf{W}}^{\mathbf{O}}}{\mathbf{1}-\delta}\right) \\
& \mathbf{M}_{\mathbf{W}}^{\mathbf{O}}=\alpha-\mathbf{M}_{\mathbf{F}}^{\mathbf{O}}
\end{aligned}
$$

Equation 1 refers to subgames of type $G^{E}$, where the firm has to choose whether or not to fire its entrant. If it decides to keep him and to allow him to turn into an insider, then the firm obtains $\frac{M_{F}^{I}}{1-\delta}$, whereas if the firm decides to replace him with a new recruit,

\footnotetext{
${ }^{42}$ In what follows we keep the same index $W$ for all types of workers for notational simplicity.

${ }^{43}$ Here no subscript index is needed, since a subgame of type $G^{E}$ starts with the decision problem of the firm alone.

${ }^{44}$ Each of the conditions on equilibrium payoffs has to hold with equality. If not, then at least one agent could profitably deviate by asking for a slightly higher payoff, leaving the opponent's payoff unchanged.
} 
its payoff is $M_{F}^{O}$ for that period (out of a cake of size just $\alpha$ ), and then, if and after reaching an agreement with the outsider, it would enter again a subgame like $G^{E}$. Hence, $A=\max \left\{\frac{M_{F}^{I}}{1-\delta}, M_{F}^{O}+\delta A\right\}$. Recall that by stationarity an action (keeping the current employment or switching bargaining partner) chosen once is always chosen in all other subgames of that type. Thus $\frac{M_{F}^{I}}{1-\delta} \geq M_{F}^{O}+\delta A$ implies that $A=\frac{M_{F}^{I}}{1-\delta}$, so that substitution of this value in the last inequality yields $M_{F}^{I} \geq M_{F}^{O}$. Similarly, $\frac{M_{F}^{I}}{1-\delta}<M_{F}^{O}+\delta A$ implies that $A=\frac{M_{F}^{o}}{1-\delta}$, which substituted back in the condition yields $\frac{M_{F}^{I}}{1-\delta}<\frac{M_{F}^{O}}{1-\delta}$.

Equation 2 refers to subgames of type $G_{F}^{I}$. Here the firm can obtain what is left of the available surplus, $\frac{1}{1-\delta}$ after deducting the s.s.p.e. payoff to the worker, $M_{W}^{I}$, from the time of agreement onwards.

Similarly, equation 3 refers to subgames of type $G_{W}^{I}$, in which the worker is the first mover. Suppose first that the firm's outside option (fire the incumbent worker and hire an outsider) is binding (i.e. the corresponding continuation payoff is greater than the payoff from staying in the current bargain). Then for his proposal to be accepted, the insider has to offer the firm at least the value of its outside option, i.e. $M_{F}^{O}-\varphi+\delta A$. On the other hand, if the firm's outside option is not binding, the insider will have to give the firm at least the present discounted value of the payoff the firm could attain in the following subgame, in which the firm is first mover, $\frac{\delta M_{F}^{I}}{1-\delta}$. Since the firm's decision whether or not to opt out depends on what is greater between $\frac{\delta M_{F}^{I}}{1-\delta}$ and $M_{F}^{O}-\varphi+\delta A$, equation 3 follows.

Equation 4 refers to subgames of type $G_{F}^{O}$ and is derived as follows. Immediate agreement would yield the firm an overall payoff given by $M_{F}^{O}$ plus the present discounted value of the stream of future payoffs it can obtain in the ensuing subgame $G^{E}$, which explains the left hand side of 4 . In order for the firm's proposal to be accepted by the worker, such payoff will has to be equal to what is left of the discounted sum of all profits that can be generated over time net of what the worker can claim in the following round. Depending on the firm's equilibrium strategy we can have two alternative cases:

- It is optimal for the firm to bond: Consequently, in subgames of type $G_{W}^{O}$ the outsider anticipates that once hired the firm will be prepared to keep him in the following round, turning him into an insider. Consequently in subgames in which he is a proposer the outsider obtains the outsider wage plus the continuation payoff in a subgame $G^{E}$, that is, $M_{W}^{O}+\frac{\delta\left(1-M_{F}^{I}\right)}{1-\delta}$.

- It is optimal for the firm to churn: In this case the outsider anticipates that if hired, he will be laid off in the subsequent period (the firm is churning), so that he will be prepared to bargain only over one period surplus; however from the point of view of the firm, it will have to forego $M_{W}^{O}$ in each of the following (infinite) rounds, 
that is $\frac{M_{W}^{O}}{1-\delta}$.

Letting $k$ be a variable which takes value 1 in case of bonding between the worker and the firm and value 0 in case of short term agreement, equation 4 follows.

Finally, equation 5 refers to subgames of type $G_{W}^{O}$. To determine the worker's payoff in this subgame, one has to take into account the behavior of the firm. In fact, after any proposal from the worker, the firm can choose between moving to the following round, in which it is its turn to make a proposal, and opting out and start another bargain with another outsider (being again the first mover). In both cases the firm acquires the right to make an offer, finding itself at the beginning of two identical subgames; however by opting out it does not need wait until the following period, so that opting out is always optimal (hence the above comes as a reduction of $M_{W}^{O} \leq \alpha-\max \left\{M_{F}^{O}, \delta M_{F}^{O}\right\}$ ). As above, we distinguish two cases, depending on whether or not the firm bonds with its current employee:

- It is optimal for the firm to bond: Then an entrant's continuation payoff is given by the sum of the agreed wage and of what the firm will concede in the subsequent subgames $G_{F}^{I}$ and from then onwards, that is $M_{W}^{O}+\frac{\delta\left(1-M_{F}^{I}\right)}{1-\delta}$. Such payoff must satisfy $M_{W}^{O}+\frac{\delta\left(1-M_{F}^{I}\right)}{1-\delta}+\left(M_{F}^{O}+\frac{\delta M_{F}^{I}}{1-\delta}\right)=\alpha+\frac{\delta}{1-\delta}$, that is, the sum of the continuation payoff to the worker and the firm (in present discounted value) has to be equal to the discounted sum of all future "pies" generated. The last expression can be rearranged to yield equation 5 .

- It is optimal for the firm to churn: Now for his proposal to be accepted, an outsider has to offer the firm what it could get if it were do disagree and opt out, that is $\alpha-M_{F}^{O}$ (since his bargaining objective is how to share just one period profits), which once again yields equation 5 .

The solution to the above system depends on the value of two expressions,

$$
\begin{aligned}
& \max \left\{\frac{\mathbf{M}_{\mathbf{F}}^{\mathrm{I}}}{\mathbf{1}-\delta}, \frac{\mathbf{M}_{\mathbf{F}}^{\mathbf{O}}}{\mathbf{1}-\delta}\right\} \\
& \max \left\{\frac{\delta \mathbf{M}_{\mathbf{F}}^{\mathrm{I}}}{\mathbf{1}-\delta}, \mathbf{M}_{\mathbf{F}}^{\mathbf{O}}-\varphi+\delta \mathbf{A}\right\}
\end{aligned}
$$

where expression 6 determines also the value of $k$ in equation 4 . It is important to stress that for condition 6 , one has to be careful in the case where $M_{F}^{I}=M_{F}^{O}$, this substitutes equation 5 (now redundant). Optimality now requires that the present discounted value of the worker's payoff be non-negative (otherwise he would have an incentive to refuse employment, and remain unemployed). Thus, in case of churning this requires $\alpha-M_{F}^{O} \geq 0$.

In case of bonding, instead, the present discounted value of the stream of payoffs to the worker along the equilibrium path is $\alpha-M_{F}^{O}+\frac{\delta}{1-\delta}\left(1-M_{F}^{O}\right) \geq 0$. In addition, 
as explained in the text, if in equilibrium the firm bonds with its employee, then the equilibrium entrant wage must be non-positive, i.e. $\alpha-M_{F}^{O}<0$.

The above does not apply to condition 7 , as this has the effect of imposing restrictions on the exogenous parameter values (for $\varphi$ and/or $\alpha$ ), rather than on the endogenous variables. Consequently six possible cases can arise, corresponding to the three scenarios (under blockaded and restricted entry) of propositions 1-3:

$$
\begin{aligned}
& \text { case 1: } \frac{\mathbf{M}_{\mathbf{F}}^{\mathrm{I}}}{\mathbf{1}-\delta}>\frac{\mathbf{M}_{\mathbf{F}}^{\mathbf{O}}}{\mathbf{1}-\delta} \text { and }\left\langle\begin{array}{l}
\text { blockaded entry: } \frac{\delta \mathbf{M}_{\mathbf{F}}^{\mathrm{I}}}{\mathbf{1}-\delta} \geq \mathbf{M}_{\mathbf{F}}^{\mathbf{O}}-\varphi+\delta \mathbf{A}(\mathbf{B}) \\
\text { restricted entry: } \frac{\delta \mathbf{M}_{\mathbf{F}}^{\mathrm{I}}}{\mathbf{1}-\delta}<\mathbf{M}_{\mathbf{F}}^{\mathbf{O}}-\varphi+\delta \mathbf{A}(\mathbf{R})
\end{array}\right. \\
& \text { case 2: } \frac{\mathbf{M}_{\mathbf{F}}^{\mathrm{I}}}{\mathbf{1}-\delta}<\frac{\mathbf{M}_{\mathbf{F}}^{\mathbf{O}}}{\mathbf{1}-\delta} \text { and }\left\langle\begin{array}{l}
\text { blockaded entry: } \frac{\delta \mathbf{M}_{\mathbf{F}}^{\mathrm{I}}}{\mathbf{1}-\delta} \geq \mathbf{M}_{\mathbf{F}}^{\mathbf{O}}-\varphi+\delta \mathbf{A}(\mathbf{B}) \\
\text { restricted entry: } \frac{\delta \mathbf{M}_{\mathbf{F}}^{\mathrm{I}}}{\mathbf{1} \delta}<\mathbf{M}_{\mathbf{F}}^{\mathbf{O}}-\varphi+\delta \mathbf{A}(\mathbf{R})
\end{array}\right. \\
& \text { case 3: } \frac{\mathbf{M}_{\mathbf{F}}^{\mathrm{I}}}{\mathbf{1 - \delta}}=\frac{\mathbf{M}_{\mathbf{F}}^{\mathbf{O}}}{\mathbf{1}-\delta} \text { and }\left\langle\begin{array}{l}
\text { blockaded entry: } \frac{\delta \mathbf{M}_{\mathbf{F}}^{\mathrm{I}}}{\mathbf{1}-\delta} \geq \mathbf{M}_{\mathbf{F}}^{\mathbf{O}}-\varphi+\delta \mathbf{A}(\mathbf{B}) \\
\text { restricted entry: } \frac{\delta \mathbf{M}_{\mathbf{F}}^{\mathrm{I}}}{\mathbf{1}-\delta}<\mathbf{M}_{\mathbf{F}}^{\mathbf{O}}-\varphi+\delta \mathbf{A}(\mathbf{R})
\end{array}\right.
\end{aligned}
$$

1. Competitive Bonding: $\quad \frac{\mathbf{M}_{\mathbf{F}}^{\mathrm{I}}}{\mathbf{1}-\delta}>\frac{\mathbf{M}_{\mathbf{F}}^{\mathrm{O}}}{\mathbf{1 - \delta}}$

case 1. Then it is optimal for the firm to bond with the current incumbent in subgames of type $G^{E}$, i.e. $k=1$.

(a) Blockaded entry. Because of (B), in subgames of type $G^{I}$ it is optimal for the firm to keep negotiating with the current insider rather than firing him and replacing him with an outsider. The system now simplifies to

which is solved by

$$
\left\{\begin{array}{l}
\mathbf{A}=\frac{\mathbf{M}_{\mathbf{F}}^{\mathrm{I}}}{\mathbf{1 - \delta}} \\
\frac{\mathbf{M}_{\mathbf{F}}^{\mathrm{I}}}{\mathbf{1}-\delta} \frac{\mathbf{1}}{\mathbf{1 - \delta}}-\frac{\delta \mathbf{M}_{\mathbf{W}}^{\mathrm{I}}}{\mathbf{1}-\delta} \\
\frac{\mathbf{M}_{\mathrm{W}}^{\mathrm{I}}}{\mathbf{1}-\delta}=\frac{\mathbf{1}}{\mathbf{1 - \delta}}-\frac{\delta \mathbf{M}_{\mathbf{F}}^{\mathrm{I}}}{\mathbf{1 - \delta}} \\
\mathbf{M}_{\mathbf{F}}^{\mathbf{O}}+\delta \mathbf{A}=\alpha+\frac{\delta}{\mathbf{1}-\delta}-\delta\left(\mathbf{M}_{\mathbf{W}}^{\mathbf{O}}+\frac{\delta\left(\mathbf{1}-\mathbf{M}_{\mathbf{F}}^{\mathrm{I}}\right)}{\mathbf{1}-\delta}\right) \\
\mathbf{M}_{\mathbf{W}}^{\mathbf{O}}=\alpha-\mathbf{M}_{\mathbf{F}}^{\mathbf{O}}
\end{array}\right.
$$

$$
A=\frac{1}{1-\delta^{2}} ; M_{W}^{I}=\frac{1}{1+\delta}=M_{F}^{I} ; M_{W}^{O}=-\frac{\delta^{2}}{1-\delta^{2}} ; M_{F}^{O}=\alpha+\frac{\delta^{2}}{1-\delta^{2}}
$$

Substituting these equilibrium values into the condition defining case 1 and condition (B) yields: $\alpha<\frac{1-\delta-\delta^{2}}{1-\delta^{2}}$ and $\varphi \geq \alpha+\frac{\delta^{2}}{1-\delta^{2}}$.

(b) Restricted entry: Because of (R), when responding in subgames of type $G_{W}^{I}$ it is optimal for the firm to fire the current insider and replace him with an outsider. The system now simplifies to 


$$
\left\{\begin{array}{l}
\mathbf{A}=\frac{\mathbf{M}_{\mathbf{F}}^{\mathrm{I}}}{\mathbf{1 - \delta}} \\
\frac{\mathbf{M}_{\mathbf{F}}^{\mathrm{I}}}{\mathbf{1}-\delta}=\frac{\mathbf{1}}{\mathbf{1 - \delta}}-\frac{\delta \mathbf{M}_{\mathbf{W}}^{\mathrm{I}}}{\mathbf{1 - \delta}} \\
\frac{\mathbf{M}_{\mathbf{W}}^{\mathrm{I}}}{\mathbf{1}-\delta}=\frac{\mathbf{1}}{\mathbf{1 - \delta}}-\left(\mathbf{M}_{\mathbf{F}}^{\mathrm{O}}-\varphi+\delta \mathbf{A}\right) \\
\mathbf{M}_{\mathbf{F}}^{\mathrm{O}}+\delta \mathbf{A}=\alpha+\frac{\delta}{\mathbf{1 - \delta}}-\delta\left(\mathbf{M}_{\mathbf{W}}^{\mathrm{O}}+\frac{\delta\left(\mathbf{1}-\mathbf{M}_{\mathbf{F}}^{\mathrm{I}}\right)}{\mathbf{1}-\delta}\right) \\
\mathbf{M}_{\mathbf{W}}^{\mathrm{O}}=\alpha-\mathbf{M}_{\mathbf{F}}^{\mathrm{O}}
\end{array}\right.
$$

This admits the unique solution

$$
\begin{gathered}
A=\frac{1-\delta(1-\delta)(\varphi+1-\alpha)}{1-\delta} ; M_{F}^{I}=1-\delta(1-\delta)(\varphi+1-\alpha) ; M_{W}^{I}=(\varphi+1-\alpha)(1-\delta) ; \\
M_{F}^{O}=\alpha\left(1-\delta^{2}\right)+\delta^{2}(1+\varphi) ; M_{W}^{O}=-\delta^{2}(\varphi+1-\alpha)
\end{gathered}
$$

and substitution into condition defining case 1 and condition $(\mathbf{R})$ yields: $\alpha<$ $1-\frac{\delta}{1-\delta} \varphi$ and $\varphi<\alpha+\frac{\delta^{2}}{1-\delta^{2}}$.

2. Churning:

$$
\frac{\mathbf{M}_{\mathbf{F}}^{\mathrm{I}}}{\mathbf{1}-\delta}<\frac{\mathbf{M}_{\mathbf{F}}^{\mathbf{O}}}{\mathbf{1}-\delta}
$$

case 2.

Thus it is optimal for the firm to replace the current incumbent in subgames of type $G^{E}$, i.e. $k=0$.

(a) Blockaded entry. Because of (B), in subgames of type $G^{I}$ in equilibrium the firm does not fire the incumbent insider. The system is then

$$
\left\{\begin{array}{l}
\mathbf{A}=\frac{\mathbf{M}_{\mathbf{F}}^{\mathrm{O}}}{\mathbf{1 - \delta}} \\
\frac{\mathbf{M}_{\mathbf{F}}^{\mathrm{I}}}{1-\delta}=\frac{\mathbf{1}}{\mathbf{1 - \delta}}-\frac{\delta \mathbf{M}_{\mathbf{W}}^{\mathrm{I}}}{\mathbf{1}-\delta} \\
\frac{\mathbf{M}_{\mathrm{W}}^{\mathrm{I}}}{\mathbf{1 - \delta}}=\frac{\mathbf{1}}{\mathbf{1 - \delta}}-\frac{\delta \mathbf{M}_{\mathbf{F}}^{\mathrm{I}}}{\mathbf{1 - \delta}} \\
\mathbf{M}_{\mathbf{F}}^{\mathbf{O}}+\delta \mathbf{A}=\frac{\alpha}{\mathbf{1 - \delta}}-\frac{\delta \mathbf{M}_{\mathrm{W}}^{\mathrm{O}}}{\mathbf{1 - \delta}} \\
\mathbf{M}_{\mathbf{W}}^{\mathrm{O}}=\alpha-\mathbf{M}_{\mathbf{F}}^{\mathrm{O}}
\end{array}\right.
$$

This admit the unique solution

$$
A=\frac{\alpha}{1-\delta} ; M_{W}^{I}=\frac{1}{1+\delta}=M_{F}^{I} ; M_{W}^{O}=0 ; M_{F}^{O}=\alpha
$$

Substituting these equilibrium values into the condition defining case 2 and condition (B) yields $\alpha>\frac{1}{1+\delta}$ and $\varphi \geq \frac{\alpha}{1-\delta}-\frac{\delta}{1-\delta^{2}}$.

(b) Restricted entry: Because of (R), in subgames of type $G^{I}$ it is optimal for the firm to fire the current insider and replace him with an outsider. Then

with unique solution

$$
\left\{\begin{array}{l}
\mathbf{A}=\frac{\mathbf{M}_{\mathbf{F}}^{\mathrm{O}}}{\mathbf{1 - \delta}} \\
\frac{\mathbf{M}_{\mathbf{F}}^{\mathrm{I}}}{1-\delta}=\frac{\mathbf{1}}{\mathbf{1 - \delta}}-\frac{\delta \mathbf{M}_{\mathrm{W}}^{\mathrm{I}}}{\mathbf{1}-\delta} \\
\frac{\mathbf{M}_{\mathbf{W}}^{\mathrm{I}}}{\mathbf{1}-\delta}=\frac{\mathbf{1}}{\mathbf{1 - \delta}}-\left(\mathbf{M}_{\mathbf{F}}^{\mathrm{O}}-\varphi+\delta \mathbf{A}\right) \\
\mathbf{M}_{\mathbf{F}}^{\mathrm{O}}+\delta \mathbf{A}=\frac{\alpha}{1-\delta}-\frac{\delta \mathbf{M}_{\mathrm{W}}^{\mathrm{O}}}{\mathbf{1 - \delta}} \\
\mathbf{M}_{\mathbf{W}}^{\mathrm{O}}=\alpha-\mathbf{M}_{\mathbf{F}}^{\mathrm{O}}
\end{array}\right.
$$

$$
A=\frac{\alpha}{1-\delta} ; M_{F}^{I}=1-\delta(1-\alpha+(1-\delta) \varphi) ; M_{W}^{I}=1-\alpha+(1-\delta) \varphi ; M_{F}^{O}=\alpha ; M_{W}^{O}=0
$$


and substitution into the condition defining case 2 and condition $(\mathbf{R})$ yields $\alpha>1-\delta \varphi$ and $\varphi<\frac{\alpha}{1-\delta}-\frac{\delta}{1-\delta^{2}}$.

\section{Indifference: \\ $\frac{\mathbf{M}_{\mathbf{F}}^{\mathrm{I}}}{1-\delta}=\frac{\mathbf{M}_{\mathbf{F}}^{\mathrm{O}}}{1-\delta}$ \\ case 3 .}

Then the firm is indifferent between bonding and churning. This makes equation 4 redundant.

(a) Blockaded entry. Because of (B), in subgames of type $G^{I}$ it is optimal for the not to replace the incumbent. Regardless of bonding or churning, the original system simplifies to

$$
\left\{\begin{array}{l}
\mathbf{A}=\frac{\mathbf{M}_{\mathbf{F}}^{\mathrm{I}}}{1-\delta} \\
\frac{\mathbf{M}_{\mathbf{F}}^{\mathrm{I}}}{1-\delta}=\frac{1}{1-\delta}-\frac{\delta \mathbf{M}_{\mathbf{W}}^{\mathrm{I}}}{1-\delta} \\
\frac{\mathbf{M}_{\mathrm{W}}^{\mathrm{W}}}{\mathbf{1}-\delta}=\frac{\mathbf{1}}{1-\delta}-\frac{\delta \mathbf{M}_{\mathbf{F}}^{\mathrm{I}}}{\mathbf{1 - \delta}} \\
\mathbf{M}_{\mathbf{F}}^{\mathrm{O}}=\mathbf{M}_{\mathbf{F}}^{\mathrm{I}} \\
\mathbf{M}_{\mathbf{W}}^{\mathrm{O}}=\alpha-\mathbf{M}_{\mathbf{F}}^{\mathrm{O}}
\end{array}\right.
$$

which admits the unique solution

$$
A=\frac{1}{1-\delta^{2}} ; M_{F}^{I}=\frac{1}{1+\delta}=M_{F}^{O}=M_{W}^{I} ; M_{W}^{O}=\alpha-\frac{1}{1+\delta}
$$

requiring $\varphi \geq \frac{1}{1+\delta}$ (from condition 7 ). Furthermore, the long term equilibrium payoff of an entrant must be non-negative (otherwise he could gain by remaining unemployed). Long term equilibrium payoff are non negative as long as $\alpha-M_{F}^{O}+\delta \frac{1-M_{F}^{I}}{1-\delta}=\alpha-\frac{1-\delta-\delta^{2}}{1-\delta^{2}} \geq 0$, or $\alpha \geq \frac{1-\delta-\delta^{2}}{1-\delta^{2}}$. Moreover, as explained in the text, under bonding the entrant wage must be non-positive (see condition C5 in the last footnote in section 3), that is $\alpha \leq \frac{1}{1+\delta}$.

(b) Restricted entry: Because of (R), in subgames of type $G^{I}$ it is optimal for the firm to fire the incumbent insider, so that the system is now

$$
\left\{\begin{array}{l}
\mathbf{A}=\frac{\mathbf{M}_{\mathbf{F}}^{\mathrm{I}}}{\mathbf{1 - \delta}} \\
\frac{\mathbf{M}_{\mathbf{F}}^{\mathrm{I}}}{\mathbf{1}-\delta}=\frac{1}{1-\delta}-\frac{\delta \mathbf{M}_{\mathbf{W}}^{\mathrm{I}}}{\mathbf{1}-\delta} \\
\frac{\mathbf{M}_{\mathrm{W}}^{\mathrm{I}}}{\mathbf{1}-\delta}=\frac{\mathbf{1}}{1-\delta}-\left(\mathbf{M}_{\mathbf{F}}^{\mathrm{O}}-\varphi+\delta \mathbf{A}\right) \\
\mathbf{M}_{\mathbf{F}}^{\mathrm{O}}=\mathbf{M}_{\mathbf{F}}^{\mathrm{I}} \\
\mathbf{M}_{\mathbf{W}}^{\mathrm{O}}=\alpha-\mathbf{M}_{\mathbf{F}}^{\mathrm{O}}
\end{array}\right.
$$

which admits the unique solution

$$
A=\frac{1-\delta \varphi}{1-\delta} ; M_{F}^{I}=1-\delta \varphi=M_{F}^{O} ; M_{W}^{I}=\varphi ; M_{W}^{O}=\delta \varphi-(1-\alpha)
$$

requiring $\varphi<\frac{1}{1+\delta}$ (from condition 7 ). Furthermore, the requirements on long term equilibrium payoff of an entrant become $\alpha-M_{F}^{O}+\delta \frac{1-M_{F}^{I}}{1-\delta}=\alpha+\frac{\delta \varphi}{1-\delta}-1 \geq 0$, or $\alpha \geq 1-\frac{\delta}{1-\delta} \varphi$. Moreover, as above, the requirement for the entrant wage to be non-positive implies $\alpha \leq 1-\delta \varphi$ (see condition C5 in section 3).

This concludes the proof. 


\section{Appendix 2: Derivation of the Equilibrium Partitions under Quits}

Whenever it is the firm's turn to make an offer in negotiations with an insider, with probability $1-p \in(0,1)$ a random event occurs so that the entrant quits, in which case the firm can (without delay) hire at no cost an outsider. This means that the stationary subgame perfect equilibrium (s.s.p.e.) payoff to the firm in subgames $G_{f}^{I}, M_{F}^{I}$, satisfy:

$$
\frac{M_{F}^{I}}{1-\delta}=p\left(\frac{1}{1-\delta}-\frac{\delta M_{W}^{I}}{1-\delta}\right)+(1-p)\left(M_{F}^{O}+\delta A\right)
$$

where notation is as in Appendix 1.

The other equations describing agents equilibrium payoffs in all other subgames are unaffected. Thus, we can solve for the equilibrium values in a similar manner to Appendix 1 , so here we omit the details. Results are as follows:.

1. Competitive Bonding:

$$
\frac{\mathrm{M}_{\mathrm{F}}^{\mathrm{I}}}{1-\delta}>\frac{\mathrm{M}_{\mathrm{F}}^{\mathrm{O}}}{1-\delta}
$$

case 1.

Then it is optimal for the firm to bond with the current incumbent in subgames of type $G^{E}$, i.e. $k=1$.

(a) Blockaded entry. Because of (B), in subgames of type $G^{I}$ it is optimal for the firm to keep negotiating with the current insider rather than firing him and replacing him with an outsider. The system is solved uniquely by

$$
\begin{gathered}
M_{F}^{I}=\frac{1-p \delta-(1-p)(1-\delta)(1-\alpha)}{1-p \delta^{2}} ; M_{F}^{O}=\frac{1-(1-\alpha)(1-\delta)(1+\delta p)}{1-p \delta^{2}} \\
M_{W}^{O}=-\delta \frac{p \delta+(1-p)(1-\alpha)}{1-p \delta^{2}} ; M_{W}^{I}=\frac{1-\delta+(1-p) \delta(1-\delta)(1-\alpha)}{1-p \delta^{2}} \\
A=\frac{1-p \delta-(1-p)(1-\delta)(1-\alpha)}{\left(1-p \delta^{2}\right)(1-\delta)}
\end{gathered}
$$

Note that

$$
\frac{\partial\left(M_{F}^{I}\right)}{\partial p}=\frac{(1-\delta)\left(\left(1-\delta^{2}\right)(1-\alpha)-\delta\right)}{\left(1-p \delta^{2}\right)^{2}}>0
$$

if $\alpha<\frac{1-\delta-\delta^{2}}{1-\delta^{2}}$, which is the value of $\alpha$ that defines this scenario, as can be derived after making the usual substitutions. Thus, the firm's equilibrium payoff increases with the probability of continuation, and conversely decreases with the quit probability.

(b) Restricted entry: Because of (R), when responding in subgames of type $G_{W}^{I}$ it is optimal for the firm to fire the current insider and replace him with an 
outsider. The system admits the unique solution

$$
\begin{gathered}
M_{F}^{I}=1-(1-\delta)(p \delta \varphi+(1-p(1-\delta))(1-\alpha)) ; \\
M_{F}^{O}=1+p \delta^{2} \varphi-(1+p \delta)(1-\alpha)(1-\delta) \\
M_{W}^{O}=-\delta(p \delta \varphi+(1-\alpha)(1-p(1-\delta))) ; M_{W}^{I}=(1-\delta)((1-\alpha)+\varphi) \\
A=\frac{1-(1-\delta)(p \delta \varphi+(1-p(1-\delta))(1-\alpha))}{1-\delta}
\end{gathered}
$$

Note that

$$
\frac{\partial\left(M_{F}^{I}\right)}{\partial p}=(1-\delta)((1-\delta)(1-\alpha)-\delta \varphi)>0
$$

if $\alpha<1-\frac{\delta}{1-\delta} \varphi$, which is the value of $\alpha$ that defines this scenario.

2. Churning:

$$
\frac{\mathbf{M}_{\mathbf{F}}^{\mathrm{I}}}{1-\delta}<\frac{\mathbf{M}_{\mathbf{F}}^{\mathrm{O}}}{1-\delta}
$$

case 2.

Thus it is optimal for the firm to replace the current incumbent in subgames of type $G^{E}$, i.e. $k=0$.

(a) Blockaded entry. Because of (B), in subgames of type $G^{I}$ in equilibrium the firm does not fire the incumbent insider. The system's unique solution is

$$
\begin{gathered}
M_{F}^{I}=\frac{1-(1-p)(1-\alpha)}{1+p \delta} ; M_{F}^{O}=1+p \delta^{2} \varphi-(1+p \delta)(1-\alpha)(1-\delta) \\
M_{W}^{I}=\frac{1-\delta(1-p)+\delta(1-p)(1-\alpha)}{1+p \delta} ; M_{W}^{O}=0 ; M_{F}^{O}=\alpha ; A=\frac{1-(1-p)(1-\alpha)}{(1+p \delta)(1-\delta)}
\end{gathered}
$$

Note that

$$
\frac{\partial\left(\frac{1-(1-p)(1-\alpha)}{1+p \delta}\right)}{\partial p}=\frac{(1-\alpha)(1+\delta)-\delta}{(1+p \delta)^{2}}<0
$$

if $\alpha>\frac{1}{1+\delta}$, which is the value of $\alpha$ that defines this scenario, as can be found by substitution. So now the firm's equilibrium payoff decreases with the probability of continuation, and conversely increases with the quit probability (the opposite as in the competitive bonding scenario).

(b) Restricted entry: Because of (R), in subgames of type $G^{I}$ it is optimal for the firm to fire the current insider and replace him with an outsider. Then the unique solution is

$$
\begin{gathered}
M_{F}^{I}=1-\frac{p \delta(1-\delta) \varphi+(1-\alpha)(1-\delta-p(1-2 \delta))}{1-\delta(1-p)} \\
M_{W}^{I}=(1-\alpha)+(1-\delta) \varphi ; M_{F}^{O}=\alpha ; M_{W}^{O}=0 ; A=\frac{\alpha}{1-\delta}
\end{gathered}
$$

Note that

$$
\frac{\partial\left(M_{F}^{I}\right)}{\partial p}=\frac{(1-\delta)^{2}(1-\alpha-\delta \varphi)}{(1-\delta(1-p))^{2}}<0
$$


if $\alpha>1-\delta \varphi$, which is the value of $\alpha$ that defines this scenario, as in the model without quits. Thus, as above, the firm's equilibrium payoff in bargains with an insider increases with the probability of continuation, and conversely decreases with the quit probability.

\section{Indifference: $\quad \frac{\mathrm{M}_{\mathrm{F}}^{\mathrm{I}}}{1-\delta}=\frac{\mathrm{M}_{\mathrm{F}}^{\mathrm{O}}}{1-\delta} \quad$ case 3.}

Then the firm is indifferent between bonding and churning. This makes equation 4 redundant.

(a) Blockaded entry. Because of (B), in subgames of type $G^{I}$ it is optimal for the not to replace the incumbent. The unique solution is

$$
A=\frac{1}{1-\delta^{2}} ; M_{F}^{I}=\frac{1}{1+\delta}=M_{F}^{O}=M_{W}^{I} ; M_{W}^{O}=\alpha-\frac{1}{1+\delta}
$$

In other words, this scenario is totally unaffected by the introduction of quits.

(b) Restricted entry: Because of (R), in subgames of type $G^{I}$ it is optimal for the firm to fire the incumbent insider, so that the unique solution is now

$$
A=\frac{1-\delta \varphi}{1-\delta} ; M_{F}^{I}=1-\delta \varphi=M_{F}^{O} ; M_{W}^{I}=\varphi ; M_{W}^{O}=\delta \varphi-(1-\alpha)
$$

This concludes the proof.

\section{Appendix 3: Further Extensions}

\subsection{Arbitrary length of the initial contract}

In the basic model we assumed that the length of the entrant's employment contract (the "initiation period") is just one period. In this section we relax this assumption, allowing the initiation period to be of arbitrary length $T \geq 1$.

The resulting equilibrium wages are given in Table A1. ${ }^{45}$ this analysis is of no consequence for the $\mathrm{CH}$ scenario, since in that case the entrant wage is always at the reservation level (zero); nor for the $C W$ scenario, as in that case the profitability of an entrant and an insider are the same from the point of view of the firm, regardless of the length of the initial contract.

To the contrary, in the $C B$ scenario the firm has an interest in setting the length of the initial contract as high as possible compatible with legislative requirements, as

\footnotetext{
${ }^{45}$ The derivation of these resutls follows the proof of proposition 10 below, setting $\Delta=1$.
} 
the entrant acquires a higher productivity after one period but is not protected by labor turnover $\operatorname{costs}^{46}$.

\subsection{The Length of the Negotiation Rounds}

We now examine how the length of the negotiation rounds (relative to the production period) affects the bargaining outcome. In particular, we focus on the limit behavior of subgame perfect equilibrium partitions as the time interval between two consecutive offers becomes vanishingly small, thereby removing the artificial first mover advantage of the firm in making a wage offer.

For this purpose, the model needs be reparametrized. Let production take place at times $0,1,2, \ldots, t, \ldots$ The production span is fixed and depends on technology, and we normalize its length to unity, so that production spans are indexed by natural numbers. The bargaining span (the time between successive bargaining offers) is $\Delta$ time units, shorter than the production span. Thus bargaining offers take place at discrete times 0 , $\Delta, 2 \Delta, \ldots$

Let the length of the initiation period $(T)$ be some multiple of the production span, and let the production span be $k \Delta=1$, where $k$ is an appropriately chosen real number. In order to see what happens to the bargaining outcomes when the bargaining span becomes infinitesimally small, we let $\Delta$ approach zero, while increasing $k$ so that $k \Delta$ remains equal to the production span $(k \Delta=1)$. Furthermore, let $\delta^{t}=e^{-r t}$ be the instantaneous time discount factor for the negotiating parties (where $r$ is the rate of time preference), so that at time $\Delta t$, the discount factor is $\delta^{\Delta t}=e^{-r \Delta t}$.

The resulting equilibrium wages are summarized in Table A.2. The following proposition summarizes the bargaining outcomes in the limit, as the time $\Delta$ between successive offers and counteroffers goes to zero.

\section{[Table A.2 here]}

Proposition 10 As $\Delta \rightarrow 0$, the stationary subgame perfect equilibrium payoffs which obtain along the equilibrium path are as described in Table A.3.

[Table A.3 here.]

\footnotetext{
${ }^{46}$ For instance, under blockaded entry:

$\frac{\partial\left(\Pi^{E}\right)}{\partial T}=\frac{\partial\left(\frac{1+\delta-\delta^{T}-(1-\alpha)\left(1-\delta^{2}\right)}{(1+\delta)\left(1-\delta^{T}\right)}\right)}{\partial T}=-(\ln \delta) \frac{\delta^{T}\left((1-\alpha)\left(1-\delta^{2}\right)-\delta\right)}{(1+\delta)\left(1-\delta^{T}\right)^{2}}>0 \Leftrightarrow \alpha<\frac{1-\delta-\delta^{2}}{1-\delta^{2}}$
} 
Proof. An entrant is retained for $T$ periods, so that the equilibrium payoff to the firm when hiring an entrant is $M_{F}^{O} \frac{1-\delta^{T}}{1-\delta}$. The system to be solved is now:

$$
\begin{gathered}
\mathbf{A}=\max \left\{\frac{\mathbf{M}_{\mathbf{F}}^{\mathbf{I}}}{\mathbf{1}-\delta}, \frac{\mathbf{M}_{\mathbf{F}}^{\mathbf{O}}}{\mathbf{1}-\delta}\right\} \\
\frac{M_{F}^{I}}{1-\delta}=\frac{1}{1-\delta}-\delta^{\Delta} \frac{M_{W}^{I}}{1-\delta} \\
\frac{M_{W}^{I}}{1-\delta}=\frac{1}{1-\delta}-\max \left\{\delta^{\Delta} \frac{M_{F}^{I}}{1-\delta},-\varphi+\frac{1-\delta^{T}}{1-\delta} M_{F}^{O}+\delta^{T} A\right\} \\
\mathbf{M}_{\mathbf{F}}^{\mathbf{O}} \frac{1-\delta^{T}}{1-\delta}+\delta^{T} A=\mathbf{k}\left(\alpha+\frac{\delta}{\mathbf{1}-\delta}-\delta^{\Delta}\left(M_{W}^{O} \frac{1-\delta^{T}}{1-\delta}+\delta^{T} \frac{\left(1-M_{F}^{I}\right)}{1-\delta}\right)\right)+ \\
+(\mathbf{1}-\mathbf{k})\left(\frac{1}{1-\delta}-\frac{1-\alpha}{1-\delta^{T}}-\frac{\delta^{\Delta}}{1-\delta} M_{W}^{O}\right) \\
\mathbf{M}_{\mathbf{W}}^{\mathbf{O}}=\mathbf{1}-(1-\alpha) \frac{(1-\delta)}{\left(1-\delta^{T}\right)}-\mathbf{M}_{\mathbf{F}}^{\mathbf{O}}
\end{gathered}
$$

Recall that the present discounted value of the stream of payoffs associated to hiring an entrant is $M_{F}^{O}$ for the first $T$ periods and $A$ from the $T$ th period onwards, that is $\frac{1-\delta^{T}}{1-\delta} M_{F}^{O}+\delta^{T} A$. Thus equation 8 comes from reducing $A=\max \left\{\frac{M_{F}^{I}}{1-\delta}, \frac{1-\delta^{T}}{1-\delta} M_{F}^{O}+\delta^{T} A\right\}$. Equation 9 is very similar to the corresponding one in the basic model, modified to take into account that the time interval between successive offers is $\Delta$. Similarly for equation 10. Equation 11 is obtained taking into account that now the present discounted value of surplus created bonding (i.e. $k=1$ ) it is obtained as the sum of surpluses produced by the entrants for the duration initial contract length, plus the unitary surpluses from period $T$ onwards, that is $\alpha+\frac{\delta}{1-\delta}$, since:

$$
\begin{gathered}
\left(\alpha+\delta+\delta^{2}+\ldots+\delta^{T-1}\right)+\delta^{T}\left(1+\delta+\delta^{2}+\ldots\right) \\
=\alpha+\sum_{j=1}^{T-1} \delta^{j}+\frac{\delta^{T}}{1-\delta}=\alpha+\frac{\delta}{1-\delta}
\end{gathered}
$$

Under churning (i.e. $k=0$ ) the surpluses created is equal to $\frac{1}{1-\delta}-\frac{\alpha}{1-\delta^{T}}$, derived as follows:

$$
\begin{gathered}
\left(\alpha+\delta+\delta^{2}+\ldots+\delta^{T-1}\right)+\delta^{T}\left(\alpha+\delta+\delta^{2}+\ldots+\delta^{T-1}\right)+\ldots \\
\quad=\sum_{i=0}^{\infty} \delta^{i T}\left(\alpha+\sum_{j=1}^{T-1} \delta^{j}\right)=\frac{(1-\delta) \alpha+\delta-\delta^{T}}{\left(1-\delta^{T}\right)(1-\delta)}=\frac{1}{1-\delta}-\frac{1-\alpha}{1-\delta^{T}}
\end{gathered}
$$

Finally, consider subgames of type $G_{W}^{O}$ (summarized in equation 12). First of all, the surplus available in any one temporary contract of length $T$ periods is $\left(\alpha+\sum_{j=1}^{T-1} \delta^{j}\right)=$ $\alpha+\frac{\delta-\delta^{T}}{1-\delta}$. Similarly to the basic model, we have to distinguish according to whether or not the firm bonds with the incumbent employee. Under bonding, the entrant's continuation payoff is given by the sum of the agreed wage and of what the firm will concede in the 
subsequent subgames $G_{F}^{I}$ and from then onwards, that is $M_{W}^{O} \frac{1-\delta^{T}}{1-\delta}+\frac{\delta\left(1-M_{F}^{I}\right)}{1-\delta}$. Such payoff must satisfy $M_{W}^{O} \frac{1-\delta^{T}}{1-\delta}+\frac{\delta^{T}\left(1-M_{F}^{I}\right)}{1-\delta}+\left(M_{F}^{O} \frac{1-\delta^{T}}{1-\delta}+\frac{\delta^{T} M_{F}^{I}}{1-\delta}\right)=\alpha+\frac{\delta}{1-\delta}$, that is, the sum of the continuation payoff to the worker and the firm (in present discounted value) has to be equal to the discounted sum of all future "pies" generated. The last expression can be rearranged to yield $M_{W}^{O}=1-(1-\alpha) \frac{(1-\delta)}{\left(1-\delta^{T}\right)}-M_{F}^{O}$ (equation 12). Under churning, instead, for his proposal to be accepted, an outsider has to offer the firm what it could get if it were do disagree and opt out, that is $\alpha+\frac{\delta-\delta^{T}}{1-\delta}-M_{F}^{O} \frac{1-\delta^{T}}{1-\delta}$ (since his bargaining objective is how to share just one period profits). This requires $M_{W}^{O} \frac{1-\delta^{T}}{1-\delta}=\alpha+\frac{\delta-\delta^{T}}{1-\delta}-M_{F}^{O} \frac{1-\delta^{T}}{1-\delta}$, which once again yields equation 12 .

The conditions defining whether entry is blockaded or restricted depend on the terms in equation 10.

Under churning $A=\frac{M_{F}^{O}}{1-\delta}$, so that entry is blockaded if the first term exceeds the second, or

$$
(1-\delta) \varphi \geq M_{F}^{O}-\delta^{\Delta} M_{F}^{I}
$$

and restricted otherwise. Under bonding, $A=\frac{M_{F}^{I}}{1-\delta}$, so that entry is blockaded if

$$
(1-\delta) \varphi \geq\left(1-\delta^{T}\right) M_{F}^{O}+\left(\delta^{T}-\delta^{\Delta}\right) M_{F}^{I}
$$

and restricted otherwise.

Entry to insiders' jobs is restricted if the opposite inequality holds. Below we solve for the equilibrium payoff vector.

1. Competitive Bonding:

$$
\frac{\mathrm{M}_{\mathrm{F}}^{\mathrm{I}}}{1-\delta}>\frac{\mathrm{M}_{\mathrm{F}}^{\mathrm{O}}}{1-\delta}
$$

(a) Blockaded entry. In this case the unique solution is

$$
\begin{gathered}
A=\frac{1}{\left(1+\delta^{\Delta}\right)(1-\delta)} ; M_{W}^{I}=\frac{1}{1+\delta^{\Delta}}=M_{F}^{I} \\
M_{F}^{O}=\frac{1+\delta^{\Delta}-\delta^{T}-(1-\alpha)\left(1+\delta^{\Delta}\right)(1-\delta)}{\left(1+\delta^{\Delta}\right)\left(1-\delta^{T}\right)} ; M_{W}^{O}=\frac{1-\delta^{T}+\delta^{\Delta}}{\left(1+\delta^{\Delta}\right)\left(1-\delta^{T}\right)}-\frac{(1-\alpha)(1-\delta)}{\left(1-\delta^{T}\right)}
\end{gathered}
$$

Substitution into the conditions defining this scenario yields:

$$
\alpha<\frac{1-\delta-\delta^{\Delta+1}}{\left(1+\delta^{\Delta}\right)(1-\delta)} \text { and } \varphi \geq \alpha-\frac{\delta^{\Delta}-\delta-\delta^{\Delta+1}}{\left(1+\delta^{\Delta}\right)(1-\delta)}
$$

(b) Restricted entry: The unique solution is now

$$
\begin{gathered}
M_{W}^{O}=-\delta^{\Delta} \delta^{T} \frac{(1-\delta)(\varphi+1-\alpha)}{1-\delta^{T}} \\
M_{F}^{O}=1+\frac{(1-\delta)\left(\delta^{\Delta} \delta^{T} \varphi-(1-\alpha)\left(1-\delta^{\Delta} \delta^{T}\right)\right)}{1-\delta^{T}} \\
M_{W}^{I}=(1-\delta)(\varphi+1-\alpha) \\
M_{F}^{I}=1-\delta^{\Delta}(\varphi+1-\alpha)(1-\delta) \\
A=\frac{1-\delta^{\Delta}(1-\delta)(\varphi+1-\alpha)}{1-\delta}
\end{gathered}
$$


Substitution into the conditions defining this scenario yields:

$$
\alpha<1-\frac{\delta^{\Delta}}{\left(1-\delta^{\Delta}\right)} \varphi \text { and } \varphi<\frac{1}{\left(1+\delta^{\Delta}\right)(1-\delta)}-(1-\alpha)
$$

2. Churning:

$$
\frac{\mathrm{M}_{\mathrm{F}}^{\mathrm{I}}}{1-\delta}<\frac{\mathrm{M}_{\mathrm{F}}^{\mathrm{O}}}{1-\delta}
$$

case 2.

(a) Blockaded entry. Because of (B), in subgames of type $G^{I}$ in equilibrium the firm does not fire the incumbent insider. The unique solution is

$$
A=\frac{1}{1-\delta}-\frac{1-\alpha}{1-\delta^{T}} ; M_{W}^{I}=\frac{1}{1+\delta^{\Delta}}=M_{F}^{I} ; M_{F}^{O}=1-\frac{(1-\delta)(1-\alpha)}{1-\delta^{T}} ; M_{W}^{O}=0
$$

Substitution into the conditions defining this scenario yields:

$$
\alpha>1-\frac{\delta^{\Delta}\left(1-\delta^{T}\right)}{(1-\delta)\left(1+\delta^{\Delta}\right)} \text { and } \varphi \geq \frac{1}{\left(1+\delta^{\Delta}\right)(1-\delta)}-\frac{1-\alpha}{1-\delta^{T}}
$$

(b) Restricted entry: Because of $(\mathbf{R})$, in subgames of type $G^{I}$ it is optimal for the firm to fire the current insider and replace him with an outsider. Then the unique solution is

$$
\begin{gathered}
A=\frac{1}{1-\delta}-\frac{1-\alpha}{1-\delta^{T}} ; M_{F}^{I}=1-\frac{\delta^{\Delta}\left(\varphi\left(1-\delta^{T}\right)+1-\alpha\right)(1-\delta)}{1-\delta^{T}} ; M_{F}^{O}=1-\frac{(1-\delta)(1-\alpha)}{1-\delta^{T}} ; \\
M_{W}^{I}=\frac{(1-\delta)\left(\varphi\left(1-\delta^{T}\right)+1-\alpha\right)}{1-\delta^{T}} ; M_{W}^{O}=0
\end{gathered}
$$

Substitution into the conditions defining this scenario yields:

$$
\alpha>1-\frac{\delta^{\Delta}\left(1-\delta^{T}\right) \varphi}{1-\delta^{\Delta}} \text { and } \varphi<\frac{1}{\left(1+\delta^{\Delta}\right)(1-\delta)}-\frac{1-\alpha}{1-\delta^{T}}
$$

3. Indifference:

$$
\frac{\mathrm{M}_{\mathrm{F}}^{\mathrm{I}}}{1-\delta}=\frac{\mathrm{M}_{\mathrm{F}}^{\mathrm{O}}}{1-\delta}
$$

case 3 .

(a) Blockaded entry. Because of (B), in subgames of type $G^{I}$ it is optimal for the not to replace the incumbent. Here the unique solution is

$$
A=\frac{1}{\left(1+\delta^{\Delta}\right)(1-\delta)} ; M_{F}^{I}=\frac{1}{1+\delta^{\Delta}}=M_{F}^{O}=M_{W}^{I} ; M_{W}^{O}=\frac{\delta^{\Delta}}{1+\delta^{\Delta}}-\frac{(1-\delta)(1-\alpha)}{\left(1-\delta^{T}\right)}
$$

Substitution into the conditions defining this scenario yields:

$$
\frac{1-\delta-\delta^{\Delta+1}}{\left(1+\delta^{\Delta}\right)(1-\delta)} \leq \alpha \leq 1-\frac{\delta^{\Delta}\left(1-\delta^{T}\right)}{(1-\delta)\left(1+\delta^{\Delta}\right)} \text { and } \varphi \geq \frac{1-\delta^{\Delta}}{(1-\delta)\left(1+\delta^{\Delta}\right)}
$$


(b) Restricted entry: Because of (R), in subgames of type $G^{I}$ it is optimal for the firm to fire the incumbent insider, so that the solution is now

$$
\begin{gathered}
A=\frac{1}{1-\delta}-\frac{\delta^{\Delta} \varphi}{1-\delta^{\Delta}} ; M_{F}^{I}=1-\frac{\delta^{\Delta}(1-\delta) \varphi}{1-\delta^{\Delta}}=M_{F}^{O} ; M_{W}^{I}=\frac{(1-\delta)}{1-\delta^{\Delta}} \varphi ; \\
M_{W}^{O}=\frac{\left(\delta^{\Delta} \varphi\left(1-\delta^{T}\right)-(1-\alpha)\left(1-\delta^{\Delta}\right)\right)(1-\delta)}{\left(1-\delta^{\Delta}\right)\left(1-\delta^{T}\right)}
\end{gathered}
$$

Substitution into the conditions defining this scenario yields:

$$
1-\frac{\delta^{\Delta}}{\left(1-\delta^{\Delta}\right)} \varphi \leq \alpha \leq 1-\frac{\delta^{\Delta}\left(1-\delta^{T}\right) \varphi}{1-\delta^{\Delta}} \text { and } \varphi<\frac{1-\delta^{\Delta}}{(1-\delta)\left(1+\delta^{\Delta}\right)}
$$

Taking limits as $\Delta \rightarrow 0^{+}$yields the results reported in Table A.3.

Note that the possibility of restricted entry disappears as $\Delta \rightarrow 0$. In particular, in the $C B$ and $C W$ scenarios, even a vanishingly small level of firing costs is enough to guarantee that entry to insiders' jobs is blockaded. Here the firm's threat to fire an insider is never credible.

To see why, recall that when the firm makes its decision to retain or fire an insider, it faces the following trade-off: either it pays the firing cost $\varphi$ and replaces the current incumbent with another entrant immediately; or it makes a counteroffer in the following bargaining round. Thus, entry is restricted if the profits from firing the incumbent worker $\left(-\varphi+\frac{1-\delta^{T}}{1-\delta} \Pi^{E}+\delta^{T} \frac{\Pi^{I}}{1-\delta}\right)$ exceed the present discounted value of retaining him, which is $\Pi^{I}$ from the following round onwards: $-\varphi+\frac{1-\delta^{T}}{1-\delta} \Pi^{E}+\delta^{T} \frac{\Pi^{I}}{1-\delta}>\delta^{\Delta} \frac{\Pi^{I}}{1-\delta}$.

In the Credible Wage Scenario, the insider and entrant are equally productive $\left(\Pi^{I}=\right.$ $\left.\Pi^{E}\right)$, so that the above inequality reduces to

$$
-\varphi+\frac{\Pi^{I}}{1-\delta}>\delta^{\Delta} \frac{\Pi^{I}}{1-\delta}
$$

However, as the time between successive offers shrinks to zero $(\Delta \rightarrow 0)$, the firm's cost of waiting another round in order to reach agreement becomes smaller and smaller, and eventually vanishes. Then the firm is faced with the decision to either fire the incumbent, pay $\varphi$ and get $\frac{\Pi^{I}}{1-\delta}$; or wait for a negligibly small span and still obtain $\frac{\Pi^{I}}{1-\delta}$, avoiding firing costs. Similar argument holds in the Competitive Bonding scenario. ${ }^{47}$

Notice that the limit equilibrium payoffs are defined for all admissible combinations of $\alpha$ and $\varphi$ (see Figure A1).

\footnotetext{
${ }^{47}$ In that scenario, $\Pi^{E}<\Pi^{I}$. For simplicity, let $T=1$ so that $-\varphi+\Pi^{E}+\delta \frac{\Pi^{I}}{1-\delta}>\delta^{\Delta} \frac{\Pi^{I}}{1-\delta}$ The trade-off for the firm is now between (i) paying the firing costs and obtain immediately a ("small") profit from a new entrant, and then bond with him from the next production span (of fixed length 1) onwards; and (ii) wait for the next bargaining period (after $\Delta$ units of time) and obtain the insider profits forever after. In this scenario firing is more "expensive" than in the Credible Wage Scenario, in that the immediate profitability of an entrant is now $\Pi^{E}<\Pi^{I}$ (whereas in the CW scenario $\Pi^{E}=\Pi^{I}$ ), so that the balance shifts towards making entry blockaded even sooner than in the Credible Wage Scenario. Similar reasoning applies when the initiation contract has arbitrary length $T$.
} 
[Figure A1 here]

\section{Appendix 4: Comparison with Nash Bargaining}

We now consider the Nash Bargaining counterpart of our model, and show that straightforward application of the Nash Bargaining Solution to wage negotiations of the type we analyzed above does not account for the full extent of our results.

As mentioned in section 2, the standard way to proceed is to maximize the Nash product of gains from agreement with respect to each bargainer's fallback position, subject to any available outside options. To replicate our framework in this setting we have to link the two sets of negotiations, those between the firm and a potential entrant, and those between the firm and an insider. By stationarity, if a firm bonds once with the current employee, then it always bonds; on the other hand, if a firm does not retain its entrant, it does so forever, thus becoming a churning firm. Thus, a firm bonds with its current employee if the present discounted value of doing so, $\frac{1-W^{I}}{1-\delta}$, is greater or equal to the present discounted payoff of churning, $\frac{\alpha-W^{E}}{1-\delta}$, where as usual $W^{I}$ and $W^{E}$ denote the insider and entrant wage, respectively. Thus, let bonding and churning refer to ${ }^{48}$

$$
\begin{aligned}
& \Pi^{I}=\left(1-W^{I}\right) \geq\left(1-\frac{(1-\delta)(1-\alpha)}{1-\delta^{T}}-W^{E}\right)=\Pi^{E} \\
& \Pi^{I}=\left(1-W^{I}\right)<\left(1-\frac{(1-\delta)(1-\alpha)}{1-\delta^{T}}-W^{E}\right)=\Pi^{E}
\end{aligned}
$$

respectively.

Consider the bargain between the firm and an insider first. In firm-insider bargains the total surplus available to the parties is simply $\frac{1}{1-\delta}$. The bargaining problem amounts to finding equilibrium values to:

$$
\begin{gathered}
\max _{W^{I}}\left(\frac{1}{1-\delta}-\frac{W^{I}}{1-\delta}\right)\left(\frac{W^{I}}{1-\delta}\right) \\
\text { s.t. } \frac{1-W^{I}}{1-\delta} \geq-\varphi+\left(1-\frac{(1-\delta)(1-\alpha)}{1-\delta^{T}}-W^{E}\right) \frac{\left(1-\delta^{T}\right)}{1-\delta}+\frac{\delta^{T}}{1-\delta} \max \left\{\left(1-W^{I}\right),\left(1-\frac{(1-\delta)(1-\alpha)}{1-\delta^{T}}-W^{E}\right)\right\}
\end{gathered}
$$

Turning to firm-outsider bargains, notice that here competition among outsiders guarantees that the constraints on wages hold with equality always ${ }^{49}$, so that the equilibrium value of $W^{E}$ results from either

$$
\begin{aligned}
& \frac{1-\delta^{T}}{1-\delta} W^{E}+\delta^{T} \frac{W^{I}}{1-\delta}=0 \Leftrightarrow \\
& W^{E}=-\frac{\delta^{T}}{1-\delta^{T}} W^{I}
\end{aligned}
$$

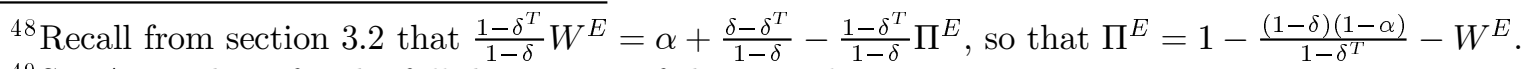

${ }^{49}$ See Appendix 5 for the full derivations of these results.
} 
(bonding behavior ${ }^{50}$ ) or

$$
W^{E}=0
$$

(churning behavior).

Simple calculations ${ }^{51}$ show that in firm outsider bargains only the interior solution can obtain, so that $W^{I}=\frac{1}{2}$. Consequently, in case of bonding substitution of the value of $W^{I}$ into equation 16 yields $W^{E}=-\frac{\delta^{T}}{2\left(1-\delta^{T}\right)}$. Finally, one can substitute the equilibrium wage pairs $\left(W^{E}=0, W^{I}=\frac{1}{2}\right)$ and $\left(W^{E}=-\frac{\delta^{T}}{2\left(1-\delta^{T}\right)}, W^{I}=\frac{1}{2}\right)$ into conditions 14 and 13 to retrieve $\alpha>1-\frac{1-\delta^{T}}{2(1-\delta)}$ and $\alpha \leq 1-\frac{1}{2(1-\delta)}=\frac{1-2 \delta}{2(1-\delta)}$, respectively. In other words, in the Nash Bargaining setup we find equilibrium wages which correspond to the limit ${ }^{52}$ equilibrium payoffs derived in section 3.2 for the $\mathrm{CH}$ and $\mathrm{CB}$ scenarios (see Table A.3). Not surprisingly, the intuitive explanation for these results is the same as in our model: By employing an entrant the firm enjoys profits of $\Pi^{E}=1-\frac{(1-\delta)(1-\alpha)}{1-\delta^{T}}+\frac{\delta^{T}}{2\left(1-\delta^{T}\right)}$, whereas by employing an insider profits are $\Pi^{I}=\frac{1}{2}$. Thus, $\Pi^{I} \geq \Pi^{E}$ as long as $\alpha \leq \frac{1-2 \delta}{2(1-\delta)}$. As soon as $\alpha$ increases above this threshold level, an entrant becomes more profitable than an insider, so that the firm switches to churning behavior: $W^{E}=0$ since the entrant, anticipating only one period of employment, no longer accepts a negative wage.

This is as far as a standard Nash bargaining analysis coherent with our strategic model would go. Although we have made an effort to link the two set of negotiations, in the derivation above equilibrium entrant wages are fixed, and independent of labor turnover costs. The problem is that in this framework one important way through which turnover costs influence strategically the behavior of the bargaining parties is concealed. Namely, turnover costs may create the opportunity for the firm to charge a negative wage while at the same time retaining its own incentive to employ the incumbent entrant in the future. This incentive can be retained only as long as the entrant bears himself the burden of his lower productivity, so that it is his own wage, rather than firm's profits, that is negatively related to turnover costs.

Consequently, the only way to retrieve the equilibrium wages corresponding to our Credible Wage scenario is to feed back our findings from the alternating bargaining paradigm into the Nash bargaining approach. This requires treating the comparisons between $\Pi^{E}$ and $\Pi^{I}$ (see conditions 13 and 14) not just as providing bounds on the labor

\footnotetext{
${ }^{50}$ We use the term "behavior" rather than "scenario" to distinguish this analysis from that in our strategic model.

${ }^{51}$ See Appendix 5.

${ }^{52}$ As it is well known (Binmore, Rubinstein \& Wolinsky (1986). See also Osborne \& Rubinstein (1990) and Muthoo (1999)), the equivalence between the equilibrium outcomes in the alternating offers and Nash bargaining models holds in the limit as the time between alternating proposals becomes vanishingly small.
} 
turnover costs that define which behavior (bonding or churning) maximizes firm's profits; but also as providing an additional constraint to the firm's employment strategy. In other words, to complete the analysis it is necessary to replace equation 16 with a condition that allows the firm to introduce a "credible wage" whenever the insider-entrant productivity differential is too low to ensure that an entrant is surely retained. This condition is ${ }^{53}$

$$
W^{E}=\max \left\{W^{I}-\frac{(1-\delta)}{\left(1-\delta^{T}\right)}(1-\alpha),-\frac{\delta^{T}}{1-\delta^{T}} W^{I}\right\}
$$

Thus, our modeling strategy gives an insight into the impact of labor turnover costs in wage negotiations which the standard treatment does not. The wage equations we have derived for the basic model and for all of its extensions take explicit account of how labor turnover costs affect the wage bargaining process, whereas the standard equations in the conventional labor economics literature merely include these costs in the negotiators' fall back positions and/or outside options. Since the standard analysis provides no account of the origin of employee's bargaining power, we argue that analysis obscures the way productivity, unemployment benefits, and quits influence wage bargaining. Our analysis, by contrast, gives a clear insight into the effect of labor turnover costs on wage negotiations, since it shows how employees' bargaining power is generated by labor turnover costs.

\section{Appendix 5: Derivation of wages under Nash bargain- ing}

The present discounted value of the total surplus bargained is different in the two types of negotiations (those between the firm and an insider and those between the firm and an outsider). Consider the bargain between the firm and an outsider first. The total surplus available for division is $\alpha+\frac{\delta}{1-\delta}$ in case of bonding and $\frac{1}{1-\delta}-\frac{1-\alpha}{1-\delta^{T}}$ if the firm keeps switching between entrants ${ }^{54}$. In case of disagreement, both parties get a null payoff. In firm-insider bargains the total surplus available to the parties is simply $\frac{1}{1-\delta}$.

Recall that in firm-insider bargains the insider wage, $W^{I}$, maximizes problem 15 above. Then, in firm-outsider bargains the equilibrium value of $W^{E}$ results from either ${ }^{55}$ :

$$
\begin{gathered}
\max _{W^{E}}\left(\frac{1-\delta^{T}}{1-\delta}\left(1-\frac{(1-\delta)(1-\alpha)}{1-\delta^{T}}-W^{E}\right)+\delta^{T} \frac{1-W^{I}}{1-\delta}\right)\left(\frac{1-\delta^{T}}{1-\delta} W^{E}+\delta^{T} \frac{W^{I}}{1-\delta}\right) \\
\text { s.t. } \frac{1-\delta^{T}}{1-\delta} W^{E}+\delta^{T} \frac{W^{I}}{1-\delta} \geq 0
\end{gathered}
$$

\footnotetext{
${ }^{53}$ Note that when $\max \left\{W^{I}-\frac{(1-\delta)}{\left(1-\delta^{T}\right)}(1-\alpha),-\frac{\delta^{T}}{1-\delta^{T}} W^{I}\right\}=W^{I}-\frac{(1-\delta)}{\left(1-\delta^{T}\right)}(1-\alpha)$, then $W^{E}=W^{I}-$ $\frac{(1-\delta)}{\left(1-\delta^{T}\right)}(1-\alpha)$ can be rearranged as $\Pi^{I}=\Pi^{E}$. See below for the full derivation of these results.
${ }^{54}$ See section 3.2.

${ }^{55}$ Recall from section 3.2 that $\frac{1-\delta^{T}}{1-\delta} W^{E}=\frac{1-\delta^{T}}{1-\delta}-\alpha-\frac{1-\delta^{T}}{1-\delta} \Pi^{E}$, so that $\Pi^{E}=1-\frac{(1-\delta) \alpha}{1-\delta^{T}}-W^{E}$.
} 
(under bonding behavior) or

$$
\max _{W^{E}}\left(\frac{1}{1-\delta}\left(1-\frac{(1-\delta)(1-\alpha)}{1-\delta^{T}}-W^{E}\right)\right)\left(W^{E}\right) \text { s.t. } W^{E} \geq 0
$$

(churning behavior). Let us analyze them in turn.

\section{Churning behavior:}

In this case problem 19 has a solution which is independent of the other set of negotiations, and which is simply $W^{E}=0$, since any strictly positive wage will be "beaten" by an unemployed outsider. Substitution of this value in problem 15 yields for the firm-insider bargain

$$
\begin{gathered}
\max _{W^{I}}\left(\frac{1}{1-\delta}-\frac{W^{I}}{1-\delta}\right)\left(\frac{W^{I}}{1-\delta}\right) \\
\text { s.t. } \frac{1-W^{I}}{1-\delta} \geq-\varphi+\frac{\left(1-\delta^{T}\right)}{1-\delta}-(1-\alpha)+\frac{\delta^{T}}{1-\delta}\left(1-\frac{(1-\delta)(1-\alpha)}{1-\delta^{T}}\right)
\end{gathered}
$$

which admits solution $W^{I}=\frac{1}{2}$ under blockaded entry and

$$
\begin{gathered}
\frac{1-W^{I}}{1-\delta}=-\varphi+\frac{\left(1-\delta^{T}\right)}{1-\delta}-(1-\alpha)+\frac{\delta^{T}}{1-\delta}\left(1-\frac{(1-\delta)(1-\alpha)}{1-\delta^{T}}\right) \Rightarrow \\
W^{I}=(1-\delta) \varphi+(1-\alpha) \frac{1-\delta}{1-\delta^{T}}
\end{gathered}
$$

under restricted entry, where the two scenarios are defined by $\alpha>1-\frac{1-\delta^{T}}{2(1-\delta)}$ and $\varphi \geq$ $\frac{1}{2(1-\delta)}-\frac{1-\alpha}{1-\delta^{T}}$, and $\varphi \geq 0$, respectively.

\section{Bonding behavior:}

In this case the firm-insider bargain simplifies to:

$$
\begin{gathered}
\max _{W^{I}}\left(\frac{1}{1-\delta}-\frac{W^{I}}{1-\delta}\right)\left(\frac{W^{I}}{1-\delta}\right) \\
\text { s.t. } \frac{1-W^{I}}{1-\delta} \geq-\varphi+\left(1-\frac{(1-\delta)(1-\alpha)}{1-\delta^{T}}-W^{E}\right) \frac{\left(1-\delta^{T}\right)}{1-\delta}+\frac{\delta^{T}}{1-\delta}\left(1-W^{I}\right)
\end{gathered}
$$

Suppose first that the constraint in the first problem does not bind (i.e. blockaded entry), so that we have the interior solution $W^{I}=\frac{1}{2}$. Substituting this into the firm-entrant bargain yields

$$
\begin{gathered}
\max _{W^{E}}\left(\frac{1-\delta^{T}}{1-\delta}\left(1-\frac{(1-\delta)(1-\alpha)}{1-\delta^{T}}-W^{E}\right)+\delta^{T} \frac{1}{2(1-\delta)}\right)\left(\frac{1-\delta^{T}}{1-\delta} W^{E}+\delta^{T} \frac{1}{2(1-\delta)}\right) \\
\text { s.t. } \frac{1-\delta^{T}}{1-\delta} W^{E}+\delta^{T} \frac{1}{2(1-\delta)} \geq 0
\end{gathered}
$$

or more simply

$$
\begin{gathered}
\max _{W^{E}}\left(\frac{2-\delta^{T}}{2(1-\delta)}-(1-\alpha)-\frac{1-\delta^{T}}{1-\delta} W^{E}\right)\left(\frac{1-\delta^{T}}{1-\delta} W^{E}+\delta^{T} \frac{1}{2(1-\delta)}\right) \\
\text { s.t. } \frac{1-\delta^{T}}{1-\delta} W^{E}+\delta^{T} \frac{1}{2(1-\delta)} \geq 0
\end{gathered}
$$

First order conditions become:

$$
\begin{aligned}
& \frac{\partial L\left(W^{E}, \lambda\right)}{\partial W^{E}}=0=-\frac{1-\delta^{T}}{1-\delta}\left(\frac{1-\delta^{T}}{1-\delta} W^{E}+\frac{\delta^{T}}{2-2 \delta}\right)+\left(\frac{2-\delta^{T}}{2(1-\delta)}-(1-\alpha)-\frac{1-\delta^{T}}{1-\delta} W^{E}\right) \frac{1-\delta^{T}}{1-\delta}-\lambda \frac{1-\delta^{T}}{1-\delta} \\
& \frac{1-\delta^{T}}{1-\delta} W^{E}+\delta^{T} \frac{1}{2(1-\delta)} \geq 0 \\
& \lambda\left(\frac{1-\delta^{T}}{1-\delta} W^{E}+\delta^{T} \frac{1}{2(1-\delta)}\right)=0
\end{aligned}
$$


where $L\left(W^{E}, \lambda\right)$ is the Lagrangian and $\lambda$ is the Lagrange multiplier. This system admits two solutions, $\left(\lambda=0, W^{E}=\frac{1}{2}\left(1-\frac{(1-\delta)(1-\alpha)}{1-\delta^{T}}\right)\right)$ and $\left(W^{E}=-\frac{1}{2} \frac{\delta^{T}}{1-\delta^{T}}, \lambda=\frac{1-\left(1-\delta^{T}\right)(1-\alpha)}{1-\delta}\right)$. However, we can discard the interior solution, since given that an insider earns a positive wage, an outsider will always be willing to undercut a firm's current partner in firmoutsider negotiations and be made better off. By substituting back the equilibrium values into the condition on the constraint in the firm-insider bargain yields the condition under which entry is blockaded:

$$
\alpha \leq \frac{1-2 \delta}{2(1-\delta)}
$$

The restricted entry scenario is not defined ${ }^{56}$.

To retrieve the wages corresponding to those for the Credible Wage Scenario from Table A.3 we have to look at the bargains:

$$
\begin{gathered}
\max _{W^{I}}\left(\frac{1}{1-\delta}-\frac{W^{I}}{1-\delta}\right)\left(\frac{W^{I}}{1-\delta}\right) \\
\text { s.t. } \frac{1-W^{I}}{1-\delta} \geq-\varphi+\left(1-\frac{(1-\delta)(1-\alpha)}{1-\delta^{T}}-W^{E}\right) \frac{\left(1-\delta^{T}\right)}{1-\delta}+\delta^{T} \frac{\left(1-W^{I}\right)}{1-\delta}
\end{gathered}
$$

under the additional restriction

$$
\left(1-\frac{(1-\delta)(1-\alpha)}{1-\delta^{T}}-W^{E}\right) \frac{\left(1-\delta^{T}\right)}{1-\delta}+\delta^{T} \frac{\left(1-W^{I}\right)}{1-\delta}=\frac{1}{1-\delta}-\frac{W^{I}}{1-\delta}
$$

to ensure that the firm is indifferent between an insider and an entrant. The last condition can be rearranged as

$$
\begin{gathered}
\left(1-\frac{(1-\delta)(1-\alpha)}{1-\delta^{T}}-W^{E}\right)\left(1-\delta^{T}\right)+\delta^{T}\left(1-W^{I}\right)=1-W^{I} \\
(1-\delta)(1-\alpha)+\left(1-\delta^{T}\right) W^{E}=\left(1-\delta^{T}\right) W^{I} \\
(1-\delta)(1-\alpha)+\left(1-\delta^{T}\right) W^{E}=\left(1-\delta^{T}\right) W^{I} \Rightarrow W^{E}=W^{I}-\frac{(1-\delta)}{\left(1-\delta^{T}\right)}(1-\alpha)
\end{gathered}
$$

In case of an interior solution ${ }^{57}$ of the firm-insider bargain we obtain

$$
W^{E}=\frac{1}{2}-\frac{(1-\delta)}{\left(1-\delta^{T}\right)}(1-\alpha) \text { and } W^{I}=\frac{1}{2}
$$

Note the condition defining blockaded entry simplifies to:

$$
\varphi \geq 0
$$

\footnotetext{
${ }^{56}$ This can be checked by explicitly finding the solutions in this case, which are not admissible since they imply $\Pi^{I}>\Pi^{E}$. Details are available from the authors upon request.

${ }^{57}$ Note that there is no other admissible solution.
} 
while the threshold on $\alpha$ defining this scenario becomes $\frac{1-2 \delta}{2(1-\delta)} \leq \alpha \leq 1-\frac{1-\delta^{T}}{2(1-\delta)}$.

Finally, it is easy to check that the equilibrium wages in the presence of bonding behavior correspond to solving

$$
\begin{gathered}
\max _{W^{I}}\left(\frac{1}{1-\delta}-\frac{W^{I}}{1-\delta}\right)\left(\frac{W^{I}}{1-\delta}\right) \\
\text { s.t. } W^{E}=\max \left\{W^{I}-\frac{(1-\delta)}{\left(1-\delta^{T}\right)}(1-\alpha),-\frac{\delta^{T}}{1-\delta^{T}} W^{I}\right\}
\end{gathered}
$$




\section{IZA Discussion Papers}

\begin{tabular}{|c|c|c|c|c|}
\hline No. & Author(s) & Title & Area & Date \\
\hline 518 & $\begin{array}{l}\text { P. Carneiro } \\
\text { J. J. Heckman }\end{array}$ & $\begin{array}{l}\text { The Evidence on Credit Constraints in } \\
\text { Post-Secondary Schooling }\end{array}$ & 5 & $06 / 02$ \\
\hline 519 & $\begin{array}{l}\text { S. Cohen } \\
\text { Z. Eckstein }\end{array}$ & $\begin{array}{l}\text { Labor Mobility of Immigrants: Training, } \\
\text { Experience, Language and Opportunities }\end{array}$ & 1 & $06 / 02$ \\
\hline 520 & U. Sunde & $\begin{array}{l}\text { Unobserved Bilateral Search on the Labor } \\
\text { Market: A Theory-Based Correction for a } \\
\text { Common Flaw in Empirical Matching Studies }\end{array}$ & 1 & $06 / 02$ \\
\hline 521 & $\begin{array}{l}\text { U. Sunde } \\
\text { R. Fahr }\end{array}$ & $\begin{array}{l}\text { Employment Status, Endogenous Regional } \\
\text { Mobility, and Spatial Dependencies in Labor } \\
\text { Markets }\end{array}$ & 1 & $06 / 02$ \\
\hline 522 & $\begin{array}{l}\text { S.-Å. Dahl } \\
\varnothing . \text { A. Nilsen } \\
\text { K. Vaage }\end{array}$ & $\begin{array}{l}\text { Gender Differences in Early Retirement } \\
\text { Behaviour }\end{array}$ & 3 & $06 / 02$ \\
\hline 523 & $\begin{array}{l}\text { J. Falkinger } \\
\text { V. Grossmann }\end{array}$ & $\begin{array}{l}\text { Workplaces in the Primary Economy and Wage } \\
\text { Pressure in the Secondary Labor Market }\end{array}$ & 3 & $07 / 02$ \\
\hline 524 & $\begin{array}{l}\text { J. J. Dolado } \\
\text { F. Felgueroso } \\
\text { J. F. Jimeno }\end{array}$ & $\begin{array}{l}\text { Recent Trends in Occupational Segregation by } \\
\text { Gender: A Look Across the Atlantic }\end{array}$ & 2 & $07 / 02$ \\
\hline 525 & $\begin{array}{l}\text { J. J. Heckman } \\
\text { C. Heinrich } \\
\text { J. Smith }\end{array}$ & The Performance of Performance Standards & 6 & $07 / 02$ \\
\hline 526 & $\begin{array}{l}\text { E. Leuven } \\
\text { H. Oosterbeek }\end{array}$ & $\begin{array}{l}\text { A New Approach to Estimate the Wage Returns } \\
\text { to Work-Related Training }\end{array}$ & 6 & $07 / 02$ \\
\hline 527 & J. C. van Ours & The Locking-in Effect of Subsidized Jobs & 4 & $07 / 02$ \\
\hline 528 & $\begin{array}{l}\text { P. Manzini } \\
\text { M. Mariotti }\end{array}$ & $\begin{array}{l}\text { Arbitration and Mediation: An Economic } \\
\text { Perspective }\end{array}$ & 3 & $07 / 02$ \\
\hline 529 & $\begin{array}{l}\text { J. M. Orszag } \\
\text { D. Snower }\end{array}$ & Incapacity Benefits and Employment Policy & 3 & $07 / 02$ \\
\hline 530 & $\begin{array}{l}\text { M. Karanassou } \\
\text { D. Snower }\end{array}$ & Unemployment Invariance & 3 & $07 / 02$ \\
\hline 531 & $\begin{array}{l}\text { M. Karanassou } \\
\text { H. Sala } \\
\text { D. Snower }\end{array}$ & $\begin{array}{l}\text { Unemployment in the European Union: A } \\
\text { Dynamic Reappraisal }\end{array}$ & 3 & $07 / 02$ \\
\hline 532 & $\begin{array}{l}\text { J. M. Orszag } \\
\text { D. Snower }\end{array}$ & $\begin{array}{l}\text { From Unemployment Benefits to Unemployment } \\
\text { Accounts }\end{array}$ & 3 & $07 / 02$ \\
\hline 533 & $\begin{array}{l}\text { S. Fölster } \\
\text { R. Gidehag } \\
\text { M. Orszag } \\
\text { D. Snower }\end{array}$ & Assessing Welfare Accounts & 3 & $07 / 02$ \\
\hline 534 & $\begin{array}{l}\text { A. Lindbeck } \\
\text { D. Snower }\end{array}$ & The Insider-Outsider Theory: A Survey & 3 & $07 / 02$ \\
\hline 535 & $\begin{array}{l}\text { P. Manzini } \\
\text { D. Snower }\end{array}$ & $\begin{array}{l}\text { Wage Determination and the Sources of } \\
\text { Bargaining Power }\end{array}$ & 3 & $07 / 02$ \\
\hline
\end{tabular}

